Universidade de São Paulo

Instituto de Astronomia, Geofísica e Ciências Atmosféricas

Departamento de Astronomia

André de Almeida Schutzer

\title{
Estudo das componentes superluminais do blazar TXS 0506+056
}

São Paulo 

André de Almeida Schutzer

\section{Estudo das componentes superluminais do blazar TXS 0506+056}

Dissertação apresentada ao Departamento de Astronomia do Instituto de Astronomia, Geofísica

e Ciências Atmosféricas da Universidade de São Paulo como requisito parcial para a obtenção do título de Mestre em Ciências.

Área de Concentração: Astronomia Orientador(a): Prof $^{\mathrm{a}}$. Dra ${ }^{\mathrm{a}}$. Zulema Abraham

São Paulo 

Aos meus pais,

Tina e Herbert 



\section{Agradecimentos}

À minha família, em especial aos meus pais Tina e Herbert por todo o suporte durante minha formação como cientista e ser humano. Gostaria de agradecer à minha irmã, Mariana, e ao meu irmão e melhor amigo, Luiz Eduardo;

À minha esposa, Taianny, por acompanhar e sempre apoiar meus sonhos, mesmo que o principal deles envolvesse fazer ciência no Brasil. Sem ela, essa trajetória seria ainda mais árdua, e agradeço-a por fazer minha vida cada vez mais leve;

À minha querida orientadora, Zulema Abraham, sem ela essa dissertação jamais teria sido escrita. Reconheço-me mais maduro academicamente por conta de diversas discussões que tivemos ao longo desses anos. Agradeço-a também por toda sua contribuição, não tão reconhecida pelos mais jovens, à ciência brasileira, se a astronomia se desenvolveu tão grandiosamente no Brasil, parte foi graças à ela;

Aos meus colegas de grupo, Pedro Beaklini, Juliana Motter e Tânia Dominici por toda ajuda concedida ao longo desses últimos anos;

Aos colegas Heitor Ernandes, Henrique Volpato, Pablo Araya-Araya e Marcelo Vicentin pela grandiosa amizade que construímos ao longo da pós-graduação. Em especial, ao Fábio Cafardo por compartilhar seu conhecimento acerca da análise em raios- $\gamma$. Aproveito para agradecer aos meus colegas de sala Natália, Nilo e Johnny;

Aos funcionários do departamento de Astronomia, em especial, ao Marco, ao Luís e ao Carlos. A Universidade de São Paulo não seria tão respeitada sem o trabalho de técnicos como vocês.

À CAPES, pelo apoio financeiro.

Esta tese/dissertação foi escrita em ATEX com a classe IAGTESE, para teses e dissertações do IAG. 

"Science cannot solve the ultimate mystery of nature. And that is because, in the last analysis, we ourselves are a part of the mystery that we are trying to solve."

Max Planck 



\section{Resumo}

O principal objetivo deste trabalho é estudar a estrutura e evolução de jatos do AGN TXS 0506+056. Esse objeto é um blazar de espectro plano que, em 2017, foi reconhecido como a primeira fonte de neutrinos extragaláctica (IceCube Collaboration, et al., 2018) e, na mesma época, intensos flares em raios- $\gamma$ foram detectados. Emissões de Núcleos Ativos de Galáxias (AGNs) em ondas de rádio foram analisadas utilizando dados de domínio público obtidos através Interferometria de Longa Linha de Base (VLBI). Observações deste e de outros AGNs mostram a existência de jatos originados em seus núcleos com intensas componentes movendo-se com velocidades superluminais. A direção de novas componentes ejetadas, ambas no plano do céu e na linha de visada, podem variar de uma componente para outra, o problema é como identificar a mesma componente utilizando mapas obtidos em diferentes épocas. O método tradicional ajusta um arbitrário número de gaussianas elípticas representada como componentes do jato e posicionadas em diferentes distâncias do núcleo, seus parâmetros são determinados através da função de visibilidade. Caproni et al. (2009) adaptaram o método Cross-Entropy (CE) e ajustaram os parâmetros das componentes do jato através de gaussianas bidimensionais no plano da imagem. A técnica do CE pode calcular os parâmetros das fontes com similar acurácia comparada aos obtidos através do método tradicional, que tem sido utilizado na literatura, e apresenta a vantagem de ser independente dos parâmetros iniciais do modelo, permitindo a determinação do número de componentes do jato. Neste trabalho, nós utilizamos o CE para modelar 17 imagens de domínio público do jato de TXS 0506+056 que tem sido monitorado pelo programa MOJAVE utilizando o VLBA em $15 \mathrm{GHz}$. Adicionalmente, desenvolvemos uma análise utilizando dados do Fermi-LAT entre $300 \mathrm{MeV}$ e $300 \mathrm{GeV}$ com o objetivo de gerar uma curva de luz raios- $\gamma$ e verificar uma possível correlação entre a ejeção de novas 
componentes com a ocorrência de flares em raios- $\gamma$. Nós identificamos 12 componentes distintas, através de suas densidades de fluxo e ângulos de posição no plano do céu, se afastando do núcleo em trajetória balística com velocidades superluminais que variam entre $10.1 \leq \beta_{a p p} \leq 18.6$. Nesta dissertação, nós propomos um cenário cinemático para essas componentes bem como uma análise de seus ângulos de posição com o objetivo de verificar uma precessão no jato do blazar em escala de parsec, seguindo o modelo desenvolvido por Abraham e Carrara (1998). Entretanto, não possível encontrar precessão e periodicidade em raios- $\gamma$ no TXS $0506+056$.

Palavras-chave: radioastronomia; jatos de AGNs; blazares. 


\section{Abstract}

The main goal of this work is to study the structure and evolution of jets in the blazar TXS 0506+056. The AGN is a flat spectrum blazar that, in 2017, was recognized as the first extragalactic neutrino source (IceCube Collaboration, et al., 2018) and, at the same epoch, intense flares in $\gamma$-rays were detected. Emissions from this Active Galactic Nucleus (AGN) in radio waves will be analyzed using Very Long-Baseline Interferometry (VLBI) observations from public domain. Observations from this and other AGNs show the existence of jets, originating in their nucleus, with more intense components moving away from it with apparent superluminal velocities. The direction of new ejected components, both in the sky plane and in the line of sight, may vary from one component to another, the problem is how to identify the same component in maps at different epochs. The traditional method fits an arbitrary number of elliptic gaussians represented as jet components and positioned at different distances from the core, and their parameters are determined through the visibility function. Caproni et al. (2009) adapted the Cross-Entropy (CE) method to fit the parameters of jet components through bi-dimensional gaussians on the image plane. The CE is able to calculate the parameters of the sources with similar accuracy than those obtained from the traditional method that have been used in the literature and has the advantage that is independent of the initial parameters of the model and allows the determination of the number of components present in the jet. In this work, we have used the CE technique to model 17 public domain images of the jet of TXS 0506+056 monitored by the MOJAVE project through the Very Long Baseline Array at $15 \mathrm{GHz}$. Additionally, we have developed an analysis using Fermi-LAT data from $300 \mathrm{MeV}$ to $300 \mathrm{GeV}$ to generate a $\gamma$-ray light curve and verify a possible correlation between the ejection of new jet components and the occurrence of $\gamma$-ray flares. We have identified 12 distinct components, 
through their density flux and position angles in sky plane, receding in a ballistic trajectory from the core with superluminal velocities varying in the range $10.1 \leq \beta_{\text {app }} \leq 18.6$. In this dissertation, we propose a new kinematic scenario for those components as well an analysis of the position angles with the aim of verifying a precession in the parsec scale jet of the blazar, following the model developed by Abraham e Carrara (1998). However, neither precession nor $\gamma$-ray periodicity was not found in TXS 0506+056.

Keywords: radioastronomy; AGN jets; blazars 


\section{Lista de Figuras}

1.1 Modelo unificado de Núcleos Ativos de Galáxias . . . . . . . . . . . . . . . 21

1.2 Espectro síncrotron para uma distribuição de potências de elétrons . . . . 23

1.3 Modelo de uma distribuição espectral de energia em um AGN radio-loud . 24

1.4 Modelo de choque desenvolvido por Marscher e Gear (1985) . . . . . . . . 25

1.5 Representação de um par de antenas e a geometria das frentes de onda . . 28

1.6 Representação geométrica das velocidades aparentemente superluminais . . 32

1.7 Variação das velocidades aparentes como função do ângulo com a linha de visada .................................... 33

1.8 Geometria do modelo de precessão . . . . . . . . . . . . . . . . 35

2.1 Distribuição das antenas do VLBA . . . . . . . . . . . . . . . . . 39]

2.2 Representação da trajetória percorrida por um fóton no Fermi-LAT . . . . 41

2.3 Variação do ângulo de contaminação com função da energia para o Fermi

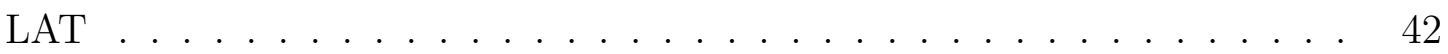

3.1 Curvas de Luz em diversos comprimentos de onda - IceCube Collaboration

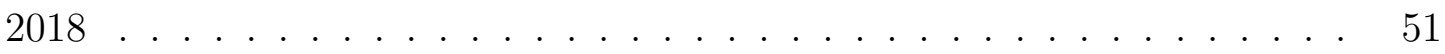

3.2 Distribuição Espectral de Energia - IceCube Collaboration 2018 . . . . . . 52

3.3 Separação das componentes ao longo do tempo - Lister et al. (2019) . . . . 53

3.4 Separação das componentes ao longo das épocas - Kun et al. (2019) . . . . 555

3.5 Curvas de luz em $15 \mathrm{GHz}$ - Kun et al. $(2019) \ldots \ldots \ldots$

4.1 Ajuste de gaussianas bidimensionais bem como os resíduos em imagens de TXS 0506+056 para as datas 28/02/2013, 25/01/2014 e 18/01/2015 . . . 60

4.2 Curva de luz de TXS 0506+056 em 15 GHz obtida pelo CE . . . . . . . . . 63 
4.3 Novo cenário cinemático proposto para as componentes de TXS 0506+056 64

4.4 Velocidades aparentes versus a data de ejeção de cada componente . . . . . 65

4.5 Data de ejeção das componentes versus data de flares em altas energias . . 66

4.6 Densidade de fluxo das componentes ajustadas pelo CE ao longo do tempo 67

4.7 Movimento as componentes do jato com relação ao núcleo ao longo das épocas 68

4.8 Ângulo de posição das componentes como função de suas datas de ejeção . 69

4.9 Mapa de contagens de eventos em raios- $\gamma$ obtido através de dados do Fermi-

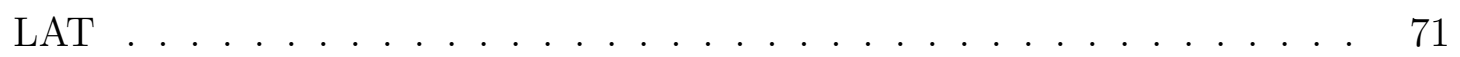

4.10 Modelo do mapa de contagens de fótons em raios- $\gamma$ gerado a partir de modelos espectrais ............................ 72

4.11 Mapa de resíduos das contagens observadas e modeladas . . . . . . . . 73

4.12 Histograma dos resíduos medidos a partir da subtração do modelo menos imagem ................................. 74

4.13 SED de TXS 0506+056 entre $300 \mathrm{MeV}$ e $300 \mathrm{GeV} \ldots \ldots$. . . . . . 75

4.14 Curva de luz de TXS 0506+056 em bins de 10 dias . . . . . . . . . 77

A.1 Ajuste de gaussianas bidimensionais bem como os resíduos em imagens de TXS 0506+056 para as datas 13/11/2010, 27/02/2011 e 06/02/2012 . . . 94

A.2 Ajuste de gaussianas bidimensionais bem como os resíduos em imagens de TXS 0506+056 para as datas 28/02/2013, 25/01/2014 e 18/01/2015 . . . .

A.3 Ajuste de gaussianas bidimensionais bem como os resíduos em imagens de TXS 0506+056 para as datas 06/09/2015, 22/01/2016 e 16/06/2016 . . . 96

A.4 Ajuste de gaussianas bidimensionais bem como os resíduos em imagens de TXS 0506+056 para as datas 18/11/2016, 17/06/2017 e 22/04/2018 . . . .

A.5 Ajuste de gaussianas bidimensionais bem como os resíduos em imagens de TXS 0506+056 para as datas $31 / 05 / 2018$ e 16/12/2018 . . . . . . . 98 


\section{Lista de Tabelas}

2.1 Propriedades dos mapas interferométricos em $15 \mathrm{GHz}$. . . . . . . . . 39

2.2 Ajuste das componentes do jato de TXS 0506+056 realizados por Lister et al. $2019 \ldots \ldots \ldots \ldots \ldots \ldots \ldots \ldots$

3.1 Resultados da análise cinemática obtidos por Lister et al. (2019) . . . . . . 53

4.1 Número de componentes ajustadas ao longo das épocas . . . . . . . . . 59

4.2 Resultados da análise cinemática ajustados pelo CE . . . . . . . . . . . 64

4.3 Parâmetros utilizados no tratamento dos dados do Fermi-LAT . . . . . . . 70

B.1 Valores dos parâmetros de cada componente ajustada ao longo das épocas 99 



\section{Sumário}

1. Introdução . . . . . . . . . . . . . . . . . . . . . [19

1.1 Núcleos Ativos de Galáxias . . . . . . . . . . . . . . . . . . . . . . . . 19

1.1.1 Classificação e Emissão de AGNs . . . . . . . . . . . . . . . . 20 20

1.1 .2 Emissão em rádio . . . . . . . . . . . . . . . . . . 22 22

1.1.3 Distribuição Espectral de Energia de AGNs radio-louds . . . . . . . 23

1.2 Jatos Relativísticos em AGNs . . . . . . . . . . . . . . . . . . . 24

1.3 Interferometria de Longa Linha de Base . . . . . . . . . . . . . . . . . 26

1.3.1 Interferometria . . . . . . . . . . . . . . 26

1.3.2 Processo de imageamento de fontes extensas . . . . . . . . . . . 29 29

1.4 Cinemática de jatos em escalas de parsecs e o modelo de precessão . . . . . 30

1.4.1 Velocidades Superluminais . . . . . . . . . . . . 30

1.4.2 Cinemática de jatos em escala de parsecs . . . . . . . . . . 32

2. Base de dados e Procedimentos . . . . . . . . . . . . . . . . . . . . . . . . 37

2.1 Observações . . . . . . . . . . . . . . . . . . . . . . . 37

2.1.1 Observações em 2 centímetros . . . . . . . . . . . 37

2.1.2 Fermi Large Area Telescope . . . . . . . . . . . . . . . . . . . . . . 40

2.2 Métodos de identificação das componentes em jatos . . . . . . . . . . . 42

2.2.1 Método tradicional . . . . . . . . . . . . . . . . 42

2.2.2 Algoritmo do Cross-Entropy . . . . . . . . . . . . . . . . . . . 44

2.2.2.1 Cálculo dos parâmetros e suas incertezas . . . . . . . . . 45

2.2.2.2 Função de mérito . . . . . . . . . . . . . . . . . 46 
3. O Blazar TXS $0506+056 \ldots \ldots \ldots \ldots \ldots \ldots$

3.1 Revisão bibliográfica . . . . . . . . . . . . . . . . . . . . . 49

3.1.1 Propriedades do blazar TXS $0506+056 \ldots \ldots \ldots$

3.1.2 Estudos da cinemática do jato em escalas de parsecs . . . . . . 5 51

4. Resultados e Discussão . . . . . . . . . . . . . . . . . . . . . 57

4.1 Identificação de componentes do jato em escala de parsec . . . . . . . . . 57

4.1.1 Cálculo da distância ao núcleo, densidade de fluxo e ângulo de posição no céu . . . . . . . . . . . . . . . . . . . . 6 61

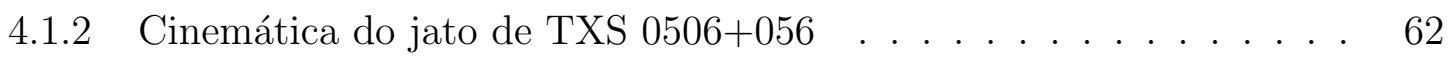

4.2 Redução e análise dos dados em raios- $\gamma \ldots \ldots$. . . . . . . . . . 69

5. Conclusões. . . . . . . . . . . . . . . . . . . . . . . . . . . . . 779

Referências ........................ 83

Apêndice 91

A. Resultados complementares . . . . . . . . . . . . . 93

A.1 Ajuste de gaussianas bidimensionais e os respectivos resíduos em imagens de TXS $0506+056 \ldots \ldots \ldots \ldots \ldots$

B. Tabela com os parâmetros das gaussianas ajustadas através do CE . . . . 99 
Capítulo 1

\section{Introdução}

\subsection{Núcleos Ativos de Galáxias}

Ao observar a radiação de uma galáxia normal, nota-se que ela é proveniente, da superposição da emissão, de estrelas de diversos tipos. No entanto, há um tipo específico de galáxias que chamou atenção dos astrônomos há algumas décadas, nas quais a radiação emitida a partir de sua região central bastante compacta, não apresenta as características de uma galáxia normal, sendo classificada como Núcleo Ativo de Galáxia (AGN, em inglês). AGNs podem emitir desde as baixas frequências em rádio até as bandas mais energéticas de raios- $\gamma$, diferente de galáxias tradicionais, estes objetos em geral não apresentam radiação característica de emissão por estrelas, e sim por processos radioativos não-térmicos (Peterson, 1997; Beckmann e Shrader, 2012; Padovani et al., 2017).

Os núcleos ativos podem apresentar altas luminosidades $\left(L \geq 10^{11} L_{\text {Sun }}\right)$ comparadas às outras galáxias, e com isso, podem ser detectados em altos redshift chegando à $z=7.54$ (Bañados et al., 2018). Entretanto, em muitos casos, o intenso brilho do núcleo ativo acaba dificultando a observação da galáxia hospedeira. O paradigma atual que busca explicar a emissão destes objetos foi inicialmente proposto por Salpeter (1964), onde o autor propôs a existência de um 'motor central' constituído por um disco de acreção orbitando ao redor de uma região central compacta muito densa, nessa região encontra-se um buraco negro supermassivo (SMBH em inglês). A energia gravitacional gerada pela queda de matéria faz com que o disco atinja altas temperaturas, explicando a grande quantidade de energia gerada em uma região bastante compacta bem como a curta variabilidade destes objetos.

A classificação de AGNs em subgrupos se desenvolveu por causa da comparação de suas propriedades observacionais do processo de formação das linhas de emissão, e do fato 
de que muitas das características observacionais variem conforme a linha de visada do observador. Atualmente se acredita que a estrutura de AGNs é caracterizada por: um ou mais buracos negros supermassivos, um disco de acreção, e regiões de linhas largas (BLR, Broad Line Regions) e linhas estreitas (NLR, Narrow Line Regions) (Schneider. 2006). Em geral, as NLR estão na região externa de um toroide formado por gás e poeira, e seu espectro é conhecido pela presença de linhas proibidas. As BLR contém linhas permitidas e semi-proibidas, e dependendo do ângulo com a linha de visada do observador elas podem ser ocultadas pelo toroide. Em alguns AGNs é possível observar jatos emitidos perpendicularmente ao plano do disco de acreção com velocidades relativísticas. Os jatos podem ser encontrados tanto em escalas de parsec quanto em escalas de quilo e megaparsec, neste último caso terminados em lóbulos que emitem tanto em ondas de rádio quanto em raios-X.

\subsubsection{Classificação e Emissão de AGNs}

O modelo unificado de AGNs busca classificar estes objetos em subgrupos a partir de observações no espectro óptico, considerando também o ângulo de inclinação da AGN com relação ao observador, conforme figura 1.1. Nesta classificação, os principais objetos são: Seyfert tipo 1 e 2, radiogaláxias, quasares, e blazares. No entanto, apesar da classificação através das emissões de linhas na faixa óptica, é também possível caracterizar AGNs por suas emissões em rádio frequências. Dois subgrupos surgem desta classificação, os radio-quiet com baixa emissão em rádio comparada à outras bandas e os radio-loud que apresentam alta emissão em rádio.

Os AGNs radio-quiet são dividos em dois grupos: as galáxias Seyfert e os QSO. As Seyfert foram descobertas por Seyfert (1943), e se diferenciam de galáxias ditas 'normais' pelo intenso brilho em sua região central, sendo classificadas em dois tipos. As Seyfert tipo 1 apresentam tanto linhas largas quanto estreitas em seus espetros, em contrapartida, as Seyfert tipo 2 contém apenas linhas estreitas por conta do obscurecimento causado pelo toroide. Os QSO (Quasi Stellar Objects) são quasares selecionados por suas propriedades ópticas, apesar de sua distribuição de energia espectral (SED em inglês) ser similar aos AGNs radio-loud, estes objetos apresentam emissão pouco intensa em ondas de rádio comparada às suas emissões no infravermelho e no ótico, podendo ser tratados como quasares radio-quiet. Além do mais, escalas de variabilidade de dias à meses podem ser encontradas 


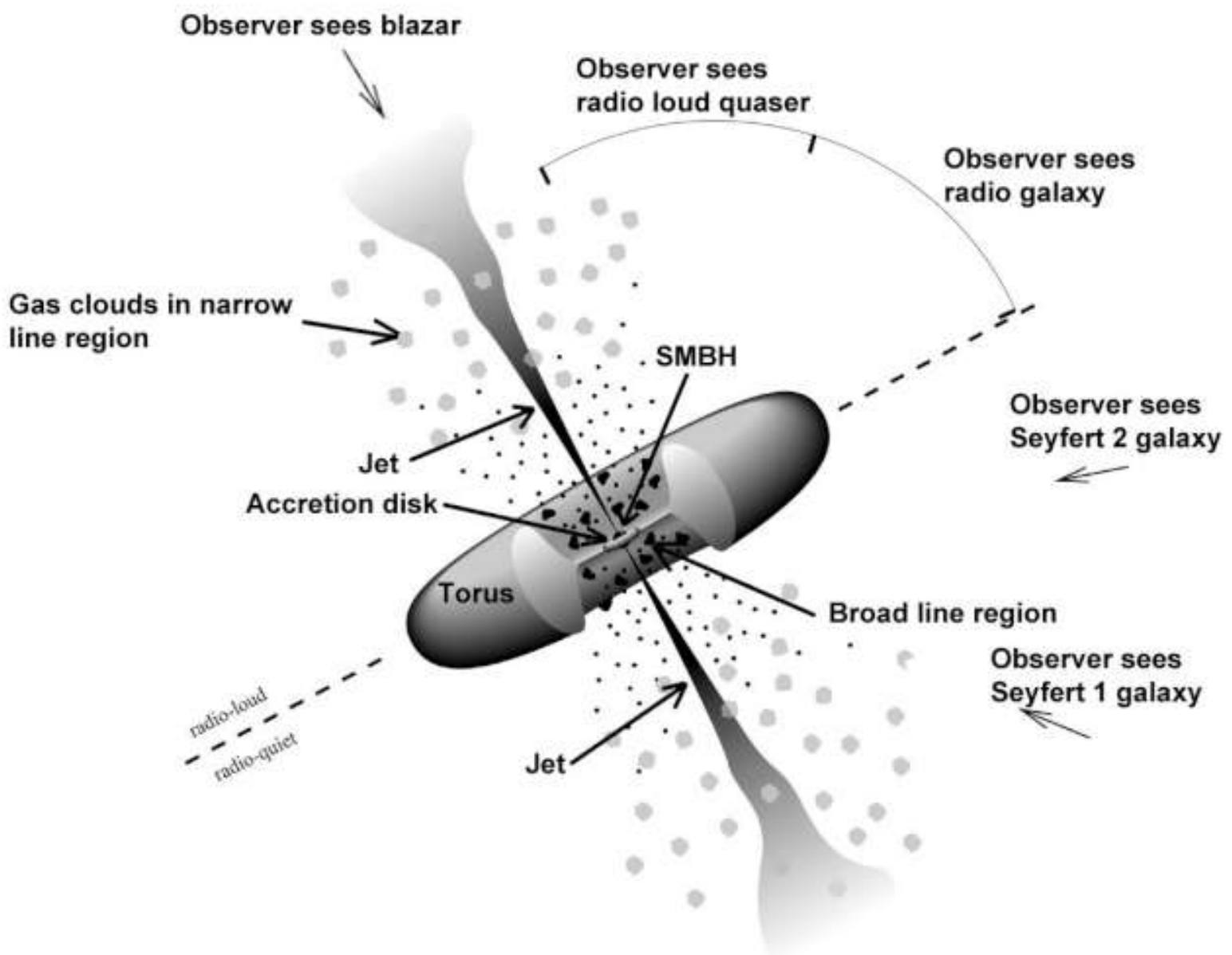

Figura 1.1: Modelo unificado de Núcleos Ativos de Galáxias, este modelo foi construído a partir de suas características ópticas. Fonte: Fermi/NASA.

em QSO.

Como citado anteriormente, AGNs radio-loud apresentam intensa emissão em ondas de rádio comparadas à outras faixas do espectro eletromagnético, e são classificados em: radiogaláxias, quasares, e blazares. As radiogaláxias são, em geral, galáxias elípticas gigantes, e têm sua morfologia dividida em duas classes de luminosidade (Fanaroff e Riley, 1974): Fanaroff-Riley I (FR-I) e Fanaroff-Riley II (FR-II). As FR-I têm uma região central bastante brilhante, mas seu brilho decresce nas partes mais externas da galáxia. Já os objetos FR-II são bastante luminosos e apresentam em sua região externa uma estrutura conhecida por hot spot de intensa emissão em rádio. Os quasares radio-loud são fontes do tipo FR-II estando no grupo dos mais luminosos AGNs conhecidos. Estes objetos apresentam emissão intensa bem como variabilidade em praticamente todos as faixas do espectro. A emissão térmica do disco de acreção dos quasares faz com que haja um excesso na faixa 
do ultravioleta conhecida por big blue bump, e como são fontes muito intensas podem ser detectados em redshift altos (Mortlock et al., 2011; Bañados et al., 2018).

Por fim, os blazares apresentam emissões de jatos relativísticos próximos à linha de visada do observador. Estes objetos apresentam intensa emissão e variabilidade em raios$\gamma$, e seus espectros são compostos por linhas largas e/ou estreitas fracas. A maioria destes objetos são rádio fontes de espectro plano (FSRQ), e essa característica pode ser atribuída a componentes discretas não-resolvidas dentro do núcleo compacto do blazar. A subclasse de blazares pode ser dividida entre dois outros tipos de objetos: BL Lac, os quais apresentam intensa emissão no contínuo sem linhas de emissão; e objetos violentamente variáveis no óptico (OVVs, em inglês), com intensas variações de brilho no óptico em escalas de tempo curtas (Padovani et al., 2017).

\subsubsection{Emissão em rádio}

Na faixa de rádio do espectro eletromagnético, o processo emissor dominante é o síncrotron, isto é, a radiação é devida a partículas carregadas com velocidades relativísticas que espiralam ao longo de campos magnéticos. Com sua origem não-térmica, essa emissão é normalmente caracterizada por um espectro em forma de lei de potência do tipo $S_{\nu} \propto \nu^{-\alpha}$, sendo $S_{\nu}$ a densidade de fluxo à uma frequência $\nu$, e $\alpha$ um índice espectral. O detalhamento teórico acerca dos processo síncrotron pode ser encontrado em Rybicki e Lightman (1986).

A potência isotrópica da radiação emitida pelo processo síncrotron por uma partícula é dada pela equação:

$$
P \propto \frac{4 e^{2} \gamma^{2} \beta^{2} B^{2}}{m^{2}}
$$

com $e, \gamma, \beta, B$ e $m$ sendo a carga da partícula, o fator de Lorentz, a velocidade da partícula (em unidades de velocidade da luz), a intensidade do campo magnético e a massa da partícula respectivamente. É possível verificar que a potência emitida é inversamente proporcional a massa da partícula, e por esse motivo, partículas mais leves, como elétrons, são mais eficientes como emissores síncrotron. No cenário atual, os elétrons são os responsáveis pela emissão não térmica (síncrotron) de AGNs em ondas de rádio.

Como a radiação síncrotron é gerada a partir de elétrons com uma distribuição de energia em forma de lei de potência, seu espectro tem também a forma de lei de potência, conforme apresentado na figura 1.2. Se o livre caminho médio de um fóton numa região for maior que a mesma, o fóton possivelmente passará sem ser absorvido por um elétron, 
esse é o regime opticamente fino, com isso seu espectro é descrito pela soma de espectros de potência de elétrons individuais, com o índice espectral $\alpha<0$. No regime opticamente espesso ocorre a auto-absorção da radiação síncrotron de baixas frequências pelos próprios elétrons emissores, e o índice espectral tem valor $\alpha=5 / 2$.

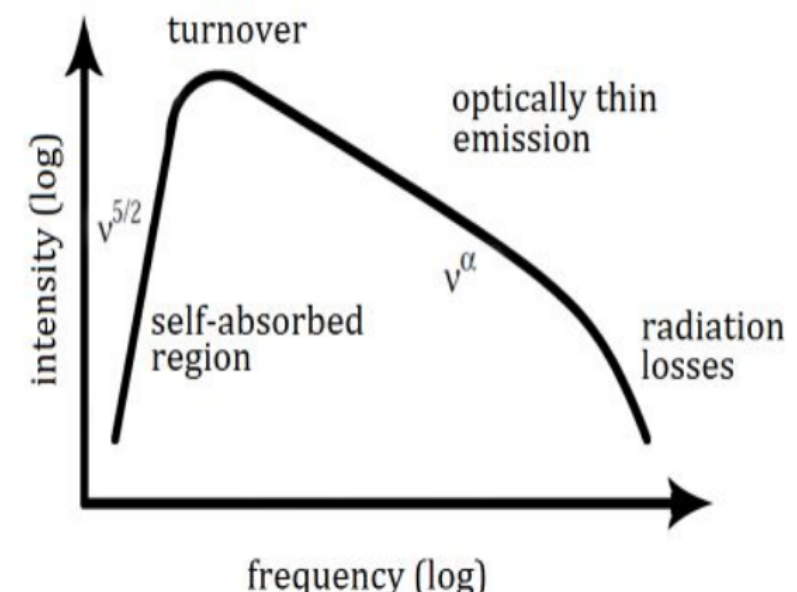

Figura 1.2: Espectro síncrotron para uma distribuição de potências de uma família de elétrons. O turnover representa a transição entre o regime opticamente espesso e fino. Fonte: $\mathrm{SAO} / \mathrm{RAS}$.

\subsubsection{Distribuição Espectral de Energia de AGNs radio-louds}

De modo geral, a SED de AGNs radio-loud é caracterizada por dois picos, um na região do rádio-óptico e outro na faixa dos raios-X e raios- $\gamma$ (Fossati et al., 1998; Ghisellini, 2016; Padovani et al., 2017). Na figura 1.3 é apresentada uma SED típica de um AGN caracterizada a partir diversas estruturas. A origem do pico em baixas energias é proveniente da radiação síncrotron, citada na seção anterior, produzida a partir de elétrons relativísticos espiralando ao redor de linhas de campos magnéticos. Há dois modelos possíveis que visam explicar a emissão em altas energias, são eles: o hadrônico e o leptônico (Böttcher et al. 2013).

Os modelos leptônicos consideram que a emissão é dominantemente proveniente de elétrons e pósitrons, enquanto que partículas mais pesadas como prótons não são aceleradas o suficiente a ponto de emitirem radiação. Nestes modelos, a emissão de radiação é devida ao efeito Compton Inverso (IC), onde os elétrons relativísticos interagem com fótons pouco energéticos, fazendo com que os fótons ganhem energia, e alcancem energias da ordem de raios-X e raios- $\gamma$. Se os fótons de baixa energia forem provenientes da própria emissão 


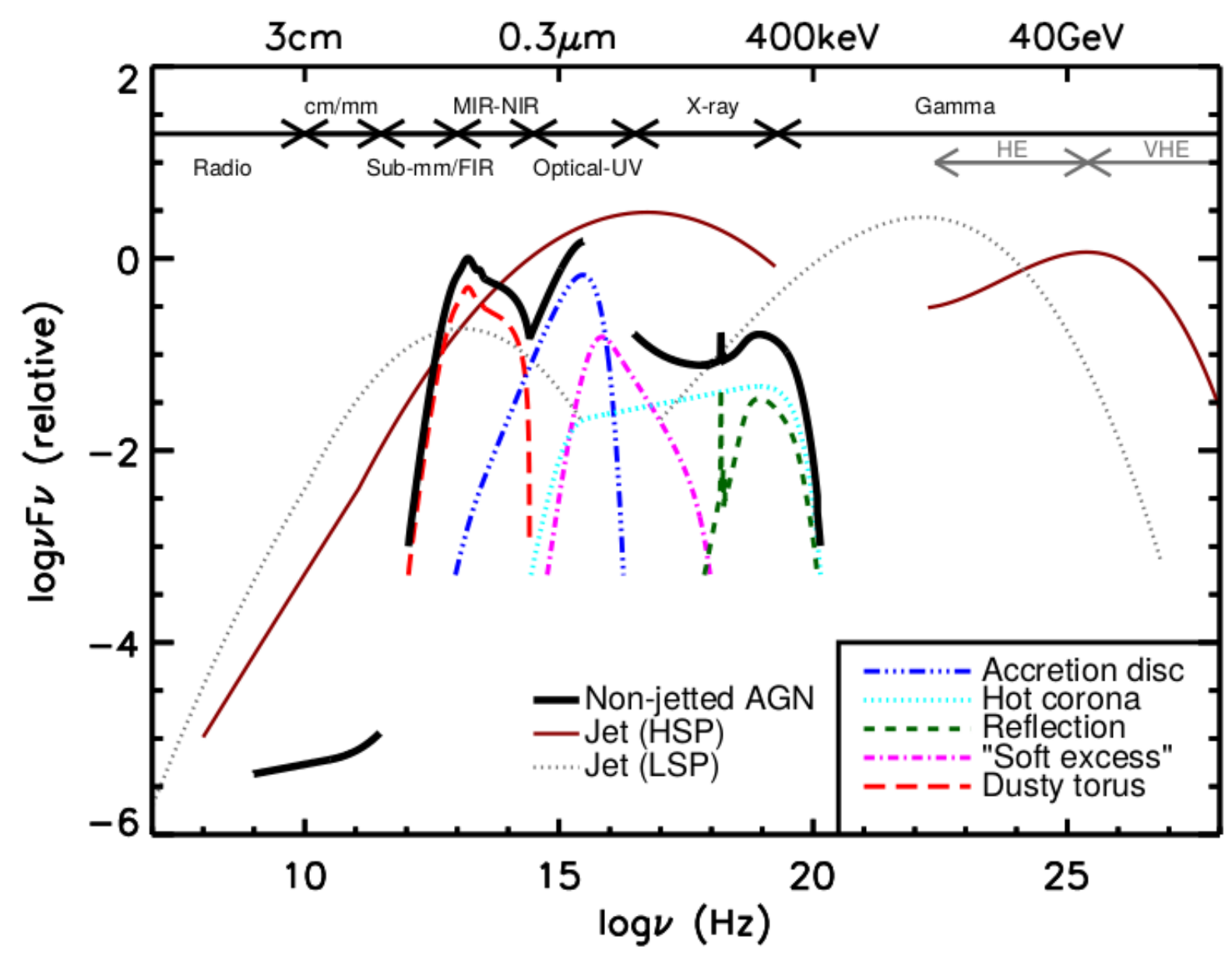

Figura 1.3: Modelo de uma distribuição espectral de energia em AGNs com ou sem jatos relativísticos. Fonte: Padovani et al. (2017).

síncrotron, o fenômeno é chamado de Síncrotron Self-Compton (Bloom e Marscher, 1996). Contudo, se os fótons pouco energéticos fossem provenientes de outras fontes, como BLR por exemplo Sikora et al. (1994), o processo é tratado por Compton Externo (EC).

Os modelos hadrônicos contam tanto com prótons quanto elétrons acelerados até energias relativísticas. Quando prótons acelerados interagem com fótons menos energéticos acabam produzindo píons neutros - que decaem em raios- $\gamma$ - e píons carregados, que decaem em neutrinos e léptons (Böttcher et al., 2013). Os fótons de baixa energia continuam sendo provenientes do processo síncrotron.

\subsection{Jatos Relativísticos em AGNs}

Os modelos para jatos relativísticos em AGNs mais aceitos no cenário atual foram desenvolvido por Readhead et al. (1979) e Blandford e Königl (1979). Nestes modelos, o 
AGN contém um SMBH em seu centro e é alimentado por um disco de acreção que orbita ao redor de seu equador, enquanto que o jato é constituído principalmente de elétrons e prótons relativísticos orbitando ao longo de campos magnéticos, sendo essas partículas aceleradas por de ondas de choque.

Marscher e Gear (1985) desenvolveram um modelo para explicar a variabilidade em diversos comprimentos de onda observada em blazares. Neste modelo, uma onda de choque se propaga através do jato do objeto fazendo com que as partículas sejam aceleradas. As partículas que ficam atrás da onda de choquem acabam dissipando energia através de três principais processos, inicialmente o Compton, e após através do processo síncrotron e da expansão adiabática, sendo que a frequência do máximo do espectro diminui conforme a região emissora aumenta. Este modelo é ilustrado na figura 1.4.

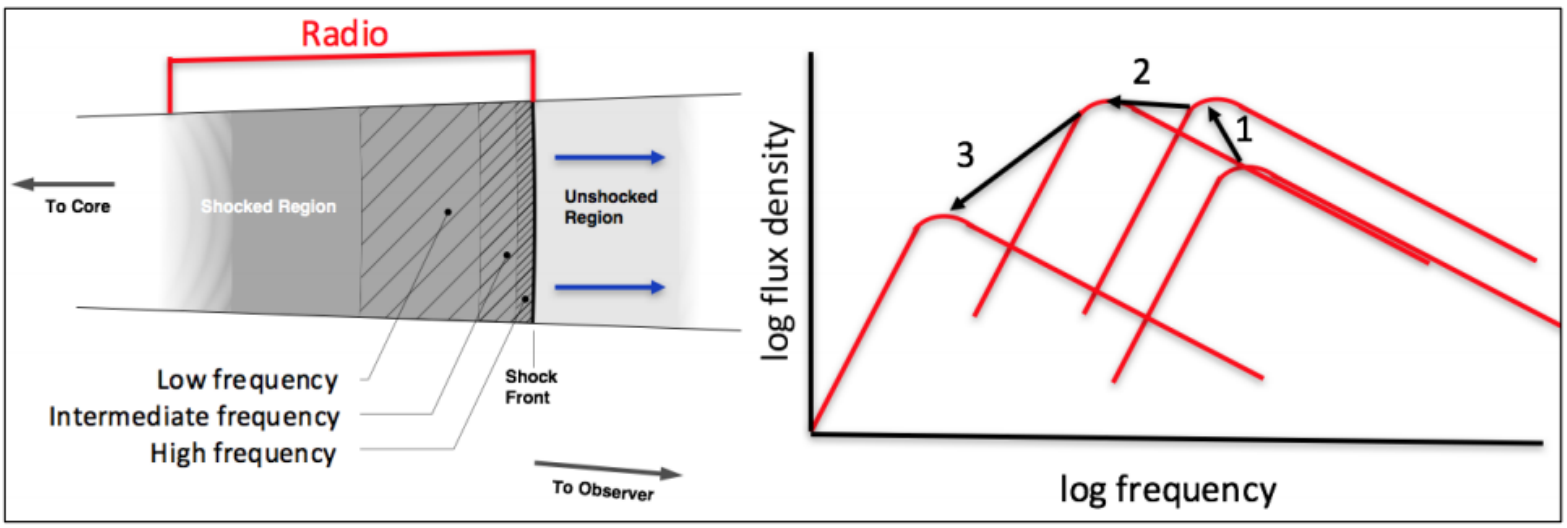

Figura 1.4: Modelo de choque desenvolvido por Marscher e Gear 1985). O painel à esquerda representa a onda de choque se propagando na direção oposta a um núcleo compacto e não resolvido. À direita é representado a emissão do espectro contínuo calculado a partir das seguintes fases: Compton (fase 1), síncrotron (fase 2), e expansão adiabática (fase 3). Fonte: Marscher (2016).

Com a onda de choque próxima ao núcleo, durante a fase Compton, o jato está sujeito à ocorrência de flares em raios-X e raios- $\gamma$, e nesta fase os fótons de baixa energia interagem com os elétrons energéticos que acabam por produzir fótons de alta energia através do IC, porém, os elétrons menos energéticos produzem fótons de baixa energia através do processo síncrotron. Com a expansão da componente do jato, a densidade de fótons diminui, e com isso a componente passa a se tornar opticamente fina à frequências menores, e o processo síncrotron passa a dominar a emissão. Após a perda energética da componente através das fases Compton e síncrotron, o campo magnético se torna menos relevante, e a perda de 
energia da componente passa a ser dominada pela expansão adiabática. Diversos trabalhos na literatura concordam com o modelo proposto por Marscher e Gear (1985), por exemplo, foram encontrados atrasos de 170 dias entre flares em raios- $\gamma$ e $7 \mathrm{~mm}$ para o objeto $3 \mathrm{C} 273$ (Beaklini e Abraham, 2014), e outro atraso de 170 \pm 30 em 3C279 foi recentemente reportado entre flares na banda-R e $43 \mathrm{GHz}$ por Beaklini et al. (2019).

Com o intuito de melhor compreender o cenário de jatos de AGNs, em especial blazares, fez-se necessário observá-los não somente em larga escala, mas também investigar seus processos físicos em escalas de parsec, para tal, foi necessário o desenvolvimento da técnica chamada Interferometria de Longa Linha de Base (VLBI), e este é o conteúdo da seção a seguir.

\subsection{Interferometria de Longa Linha de Base}

\subsubsection{Interferometria}

A técnica de VLBI necessita de ao menos um par de antenas, que estejam separadas espacialmente e realizando a observação de uma determinada fonte no mesmo momento, para certificar-se que as radiações atingidas no receptor sejam coerentes é, em geral, utilizado um relógio atômico. Para entender melhor o princípio da interferometria consideremos como se forma uma imagem em um único radiotelescópio. Podemos supor que a superfície de cada antena pode ser dividida em $\mathrm{N}$ elementos, e considerando a voltagem recebida ao longo do tempo por estes, obtemos a relação:

$$
V(t)=\sum_{i}^{N} \Delta V_{i}(t)
$$

Como a potência recebida é proporcional ao quadrado da voltagem $P \propto V^{2}$, se for realizada uma média temporal em cada par de elementos na equação 1.2, obtém-se:

$$
\langle P\rangle \propto\left\langle\left(\sum_{i}^{N} \Delta V_{i}(t)\right)\right\rangle=\sum_{i}^{N} \sum_{j}^{N}\left\langle\left(\Delta V_{i} \Delta V_{j}\right)\right\rangle,
$$

a relação pode ser reescrita da seguinte forma:

$$
\langle P\rangle \propto \sum_{i}^{N}\left\langle\Delta V_{i}(t)\right\rangle+\sum_{i}^{N} \sum_{j \neq i}^{N}\left\langle\Delta V_{i} \Delta V_{j}\right\rangle,
$$

sendo o primeiro termo conhecido por auto-correlação, e o segundo por correlação-cruzada respectivamente. Do mesmo modo, o termo de correlação-cruzada pode ser interpretado 
como a voltagem obtida por duas antenas fisicamente separadas, cada qual à uma localização $i$ e $j$. Um interferômetro com $\mathrm{N}$ antenas contém $\frac{N \cdot(N-1)}{2}$ pares de antenas, e cada qual podendo ser tratado como um interferômetro.

A resposta de uma antena para uma fonte pontual obtida através da média da saída de todos os pares de antenas é chamada de "feixe sintetizado", e se aproxima de uma gaussiana quanto maior for o número de pares (Condon e Ransom, 2016). Na figura 1.5 é apresentado um esquema 1-D de uma observação interferométrica utilizando duas antenas, 1 e 2 , separadas fisicamente por uma linha de base $(\vec{b})$, ambas observam simultaneamente uma fonte à determinada frequência na direção $\hat{s}_{0}$. No entanto, para as frentes de onda alcançarem a antena 1, elas precisam percorrer uma trajetória extra de:

$$
\tau_{g}=\frac{<\vec{b}, \hat{s}_{0}>}{c}=\frac{|\vec{b}| \cdot \sin (\theta)}{c}
$$

como $<\vec{b}, \hat{s}_{0}>$ sendo o produto interno entre o vetor de linha de base e o da direção da fonte. Por conta do atraso geométrico da equação 1.5, o sinal de ambas as antenas apresentam fases diferentes. Com o intuito de corrigir o atraso geométrico da frente de onda, insere-se um novo atraso na antena 2. O atraso geométrico desta antena pode ser gerado de duas formas: fazendo com que o sinal percorra uma trajetória maior dentro do circuito elétrico (de forma mecânica); ou pode-se simplesmente inseri-lo através de equipamentos eletrônicos em um sistema digitalizado.

Considerando uma pequena variação off-axis através de um ângulo $\alpha$ medido entre a perpendicular a antena 1 e uma frente de onda, pode-se determinar uma posição 1-D no céu como $l=\sin \alpha$. A trajetória extra que essa frente de onda off-axis terá que percorrer para alcançar a antena 1 pode ser medido como $x=u \sin \alpha=u \cdot l$ (em unidades de comprimento de onda). Devido ao atraso geométrico em 1-D, as voltagens podem ser relacionadas através da equação:

$$
V_{2}=V_{1} e^{2 \pi i(u \cdot l)}
$$

Se considerarmos o plano do céu, então é necessário introduzir um $\beta$ ortogonal a $\alpha$, e por consequência, definimos $m=\sin \beta$ análogo a $l$ nesta nova direção. A nova trajetória extra percorrida acaba sendo $y=v \sin \beta=v \cdot m$. Com isso, podemos obter a relação 2-D entre as voltagens da seguinte forma:

$$
V_{2}=V_{1} e^{2 \pi i(u \cdot l+v \cdot m)}
$$


Onde $u$ e $v$ são conhecidos por frequência espacial sinusoidal nas respectivas direções E-W e N-S, enquanto que $l$ e $m$ são os cossenos diretores relativos às mesmas posições. Tipicamente, na direção $\hat{s}_{0}$ tanto $l$ quanto $m$ são zero, e essa posição é conhecida por centro de fase.

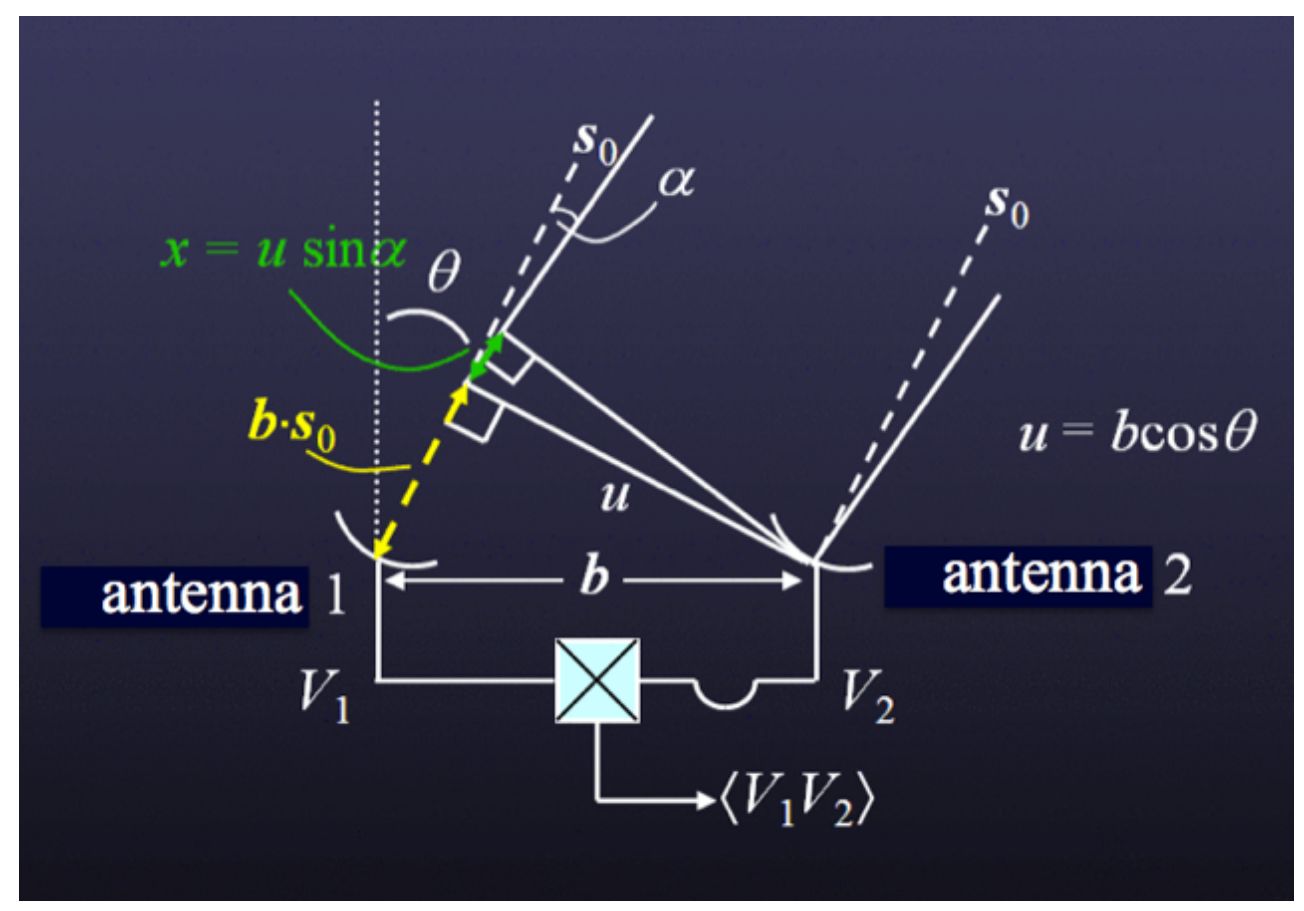

Figura 1.5: Representação em 1-D de um interferômetro com um par de antenas 1 e 2 separadas fisicamente por uma linha de base $(\vec{b})$. As antenas estão apontadas para a mesma fonte na direção $\vec{s}_{0}$ com um ângulo $\theta$ do meridiano. As voltagens obtidas em cada telescópio são correlacionadas para obter um sinal com saída dada por R. Fonte: ALMA Ciclo 5 Handbook.

A resposta do correlacionador é dada pela média temporal de ambas as voltagens através da equação:

$$
\left\langle V_{1} V_{2}\right\rangle=\left\langle\iint V_{1}(l, m) d l d m \cdot \iint V_{2}(l, m) d l d m\right\rangle
$$

supõe-se que os sinais de diferentes partes do céu são incoerentes, então a média da correlação entre os sinais será zero, com isso, a equação 1.8 pode ser simplificada para:

$$
\left\langle V_{1} V_{2}\right\rangle=\iint\left\langle V_{1}(l, m) V_{2}(l, m)\right\rangle d l d m,
$$

substituindo a equação 1.7 na equação acima, obtém-se:

$$
\left\langle V_{1} V_{2}\right\rangle=\iint\left\langle V_{1}(l, m)^{2}\right\rangle e^{2 \pi i(u \cdot l+v \cdot m)} d l d m .
$$


Portanto, a partir das relações $V^{2} \propto P \propto I_{\nu}$, podemos calcular a média temporal das voltagens:

$$
\left\langle V_{1} V_{2}\right\rangle \propto \iint I(l, m) e^{2 \pi i(u \cdot l+v \cdot m)} d l d m,
$$

onde $I(l, m)$ é a intensidade da fonte em uma dada frequência. O correlacionador mede uma quantidade conhecida por visibilidade complexa, que formalmente, é a transformada de Fourier da distribuição de intensidade de uma fonte (Thompson et al., 1989):

$$
\vartheta(u, v)=\int_{-\infty}^{+\infty} \int_{-\infty}^{+\infty} I(l, m) e^{2 \pi i(u \cdot l+v \cdot m)} d l d m=A e^{i \phi}
$$

com $A$ e $\phi$ sendo a amplitude e a fase respectivamente.

\subsubsection{Processo de imageamento de fontes extensas}

A relação entre a distribuição de brilho do céu e a distribuição de visibilidade complexa é a base da síntese de abertura. Como a visibilidade complexa (equação 1.12 é a transformada de Fourier da distribuição de brilho de uma fonte no plano da imagem, então a distribuição de brilho de uma fonte no céu é a transformada inversa da distribuição de visibilidade no plano $\mathrm{u}, \mathrm{v}$ :

$$
I(l, m)=\int_{-\infty}^{+\infty} \int_{-\infty}^{+\infty} \vartheta(u, v) e^{-2 \pi i(u \cdot l+v \cdot m)} d u d v .
$$

Todavia, não é possível recuperar completamente as distribuições verdadeiras do brilho do céu e da fonte, isto é, na prática, é impossível obter uma amostra completa do plano u-v. Devido a isto, há um limite fundamental ao nível de detalhamento na distribuição de brilho da fonte, que é então definido como a resolução do interferômetro. Portanto, a resolução da imagem de um interferômetro é definida pela amostragem de visibilidades disponíveis que, em geral, é finita e discretizada. Em contrapartida, a ausência de informação em escalas angulares não observadas pelo interferômetro, como por exemplo, a falta de coberturas dos espaços que sejam menores do que $\vec{b}_{\text {min }}$, acabam resultando em uma ausência de sensibilidade para a emissão em larga escala do objeto.

A amostragem das visibilidades é denominada $S(u, v)$ e através da transformada de Fourier da função visibilidade e a distribuição de brilho da fonte, obtém-se a relação:

$$
I^{D}(l, m)=\int_{-\infty}^{+\infty} \int_{-\infty}^{+\infty} S(u, v) \vartheta(u, v) e^{2 \pi i(u \cdot l+v \cdot m)} d u \cdot d v
$$


sendo $I^{D}$ conhecido por "Dirty image" ou mapa sujo.

Ademais, a visibilidade é assumida como sendo zero onde não há cobertura. Para se obter a distribuição de brilho real através de $I^{D}$, é necessário utilizar o teorema da convolução:

$$
I^{D}(l, m)=I(l, m) * b(l, m)
$$

A função $b(l, m)$, conhecida por "dirty beam" ou "Point Spread Function"(PSF), é a transformada de Fourier da visibilidade de uma fonte pontual, e é calculada através da equação:

$$
b(l, m)=\iint S(u, v) e^{2 \pi i(u l+v m)} d u d v .
$$

A distribuição de brilho real convoluída com a PSF gera o mapa sujo $I^{D}$, a geração da imagem, portanto, está diretamente relacionada com o processo de deconvolução do mapa sujo. Por conseguinte, a sensibilidade e a resolução são as principais limitações das técnicas interferométricas modernas, porém alguns algoritmos modernos foram desenvolvidos com o intuito de minimizar as limitações, e o mais conhecido deles é o CLEAN, desenvolvido por Högbom (1974).

O método numérico CLEAN aplica a deconvolução no domínio da imagem, e idealmente trata cada ponto da imagem como sendo uma função delta. Inicialmente, o método procura no mapa sujo $I^{D}(l, m)$ o ponto de maior intensidade e subtrai a PSF multiplicada por um fator de atenuação e a intensidade máxima. Com isso, é obtida a primeira imagem residual, e este procedimento repete-se até que a imagem tenha a mesma ordem dos resíduos que os dados. Por fim, o mapa final é produzido pela convolução do feixe com os pontos obtidos pelo algoritmo CLEAN, de forma que a resolução seja mantida. Em geral, a PSF é uma gaussiana elíptica ajustada ao lóbulo central de $b(l, m)$, e essas componentes são, no final do processo, adicionadas ao mapa de resíduos, e por fim, resultam na imagem final, conhecida por mapa limpo.

\subsection{Cinemática de jatos em escalas de parsecs e o modelo de precessão}

\subsubsection{Velocidades Superluminais}

Uma das principais consequências da técnica de VLBI foi a detecção de movimentos aparentemente superluminais em jatos de AGNs. As velocidades superluminais encontradas nas componentes dos jatos relativísticos (figura 1.6) não violam a Relatividade Especial 
por se tratar da consequência de uma projeção no plano do céu. Para explicar a origem dessas velocidades superluminais, nós consideramos uma componente da fonte movendo-se com velocidade $v$ formando um ângulo $\phi$ com a linha de visada (Rees, 1966). Vamos considerar o tempo inicial $t=0$ sendo o tempo para o qual a componente ainda está próxima ao núcleo. No momento $t=t_{e}$ a fonte está a uma distância $v \cdot t_{e}$ da posição original. A separação observada por um observador na Terra é:

$$
\Delta r=v \cdot t_{e} \sin \phi
$$

Como no tempo $t_{e}$ a componente tem uma distância menor da Terra do que em $t=0$, fótons emitidos nos dois tempos nos alcançaram com uma diferença de tempo:

$$
\Delta t=t_{e}-\frac{v t_{e} \cos \phi}{c}=t_{e}(1-\beta \cos \phi)
$$

sendo $\beta=\frac{v}{c}$, então, obtemos que a velocidade aparente em termos da velocidade da luz é:

$$
\beta_{a p}=\frac{\Delta r}{\Delta t}=\frac{\beta \sin \phi}{1-\beta \cos \phi} .
$$

Substituindo a relação $\beta=\gamma^{-1} \cdot \sqrt{\gamma 2-1}$ na equação 1.19 e após simples álgebra, obtemos:

$$
\beta_{a p}=\frac{\sin (\phi) \sqrt{\gamma^{2}-1}}{\gamma-\cos (\phi) \sqrt{\gamma^{2}-1}}
$$

$\mathrm{Na}$ figura 1.7 apresentamos um gráfico da a variação da velocidade aparente como função do ângulo de visada para diferentes valores do fator de Lorentz. É possível observar que a velocidade será máxima em $\beta_{a p}=\sqrt{\gamma^{2}-1}$.

A velocidade aparentemente pode ser relacionada com o movimento próprio $\mu$ das componentes através da equação:

$$
\beta_{a p}=\frac{D_{L} \mu}{c(1+z)}
$$

sendo $z$ e $D_{L}$, o redshift e a distância de luminosidade. A distância de luminosidade pode ser calculada como:

$$
D_{L}=\frac{c(1+z)}{H_{0}} E\left(\Omega_{M}, \Omega_{\gamma}, \Omega_{\Lambda}, \Omega_{k}, z\right),
$$

onde $E\left(\Omega_{M}, \Omega_{\gamma}, \Omega_{\Lambda}, \Omega_{k}, z\right)$ é obtido através de uma integral até determinado redshift e é uma função dos parâmetros de densidade dos constituintes do universo. Portanto, as velocidades aparentemente superluminais são apenas consequências de um ângulo pequeno entre a direção do jato e a linha visada, ou seja, a velocidade no referencial dos jatos não é superior a luz, no entanto, ainda é relativística. 


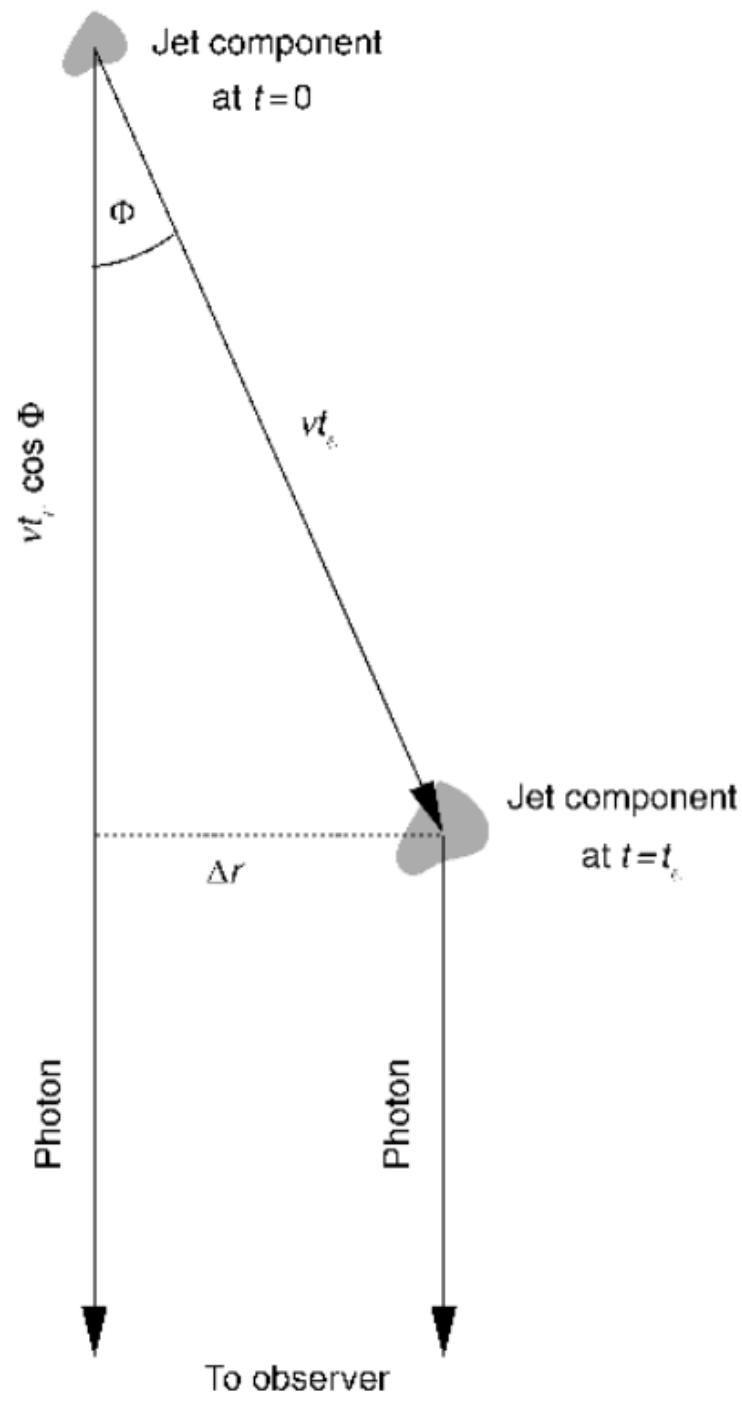

Figura 1.6: Uma componente da fonte está se movendo com velocidade $v$ e formando um ângulo $\phi$ com a linha de visada. Os fótons são emitidos em diferentes momentos $t=0 \mathrm{e}$ $t=t_{e}$. Fonte: Schneider 2006).

\subsubsection{Cinemática de jatos em escala de parsecs}

A partir das observações de VLBI e do monitoramento de componentes do jato de AGNs, percebeu-se que as velocidades aparentes das componentes de um mesmo objeto variavam ao longo do tempo bem como os seus respectivos ângulos de posição no plano do céu. Alguns autores como Hough et al. (1996) e Abraham et al. (1996) argumentam que as componentes seguem trajetórias balísticas, outros citam que as componentes seguem trajetórias curvas no plano do céu (Jorstad et al., 2004; Kun et al., 2014). Ao estudar o jato de 3C 273 em $10.7 \mathrm{GHz}$ identificaram oito componentes distintas e apresentaram um cenário cinemático para essas componentes assumindo trajetórias balísticas em diferentes 


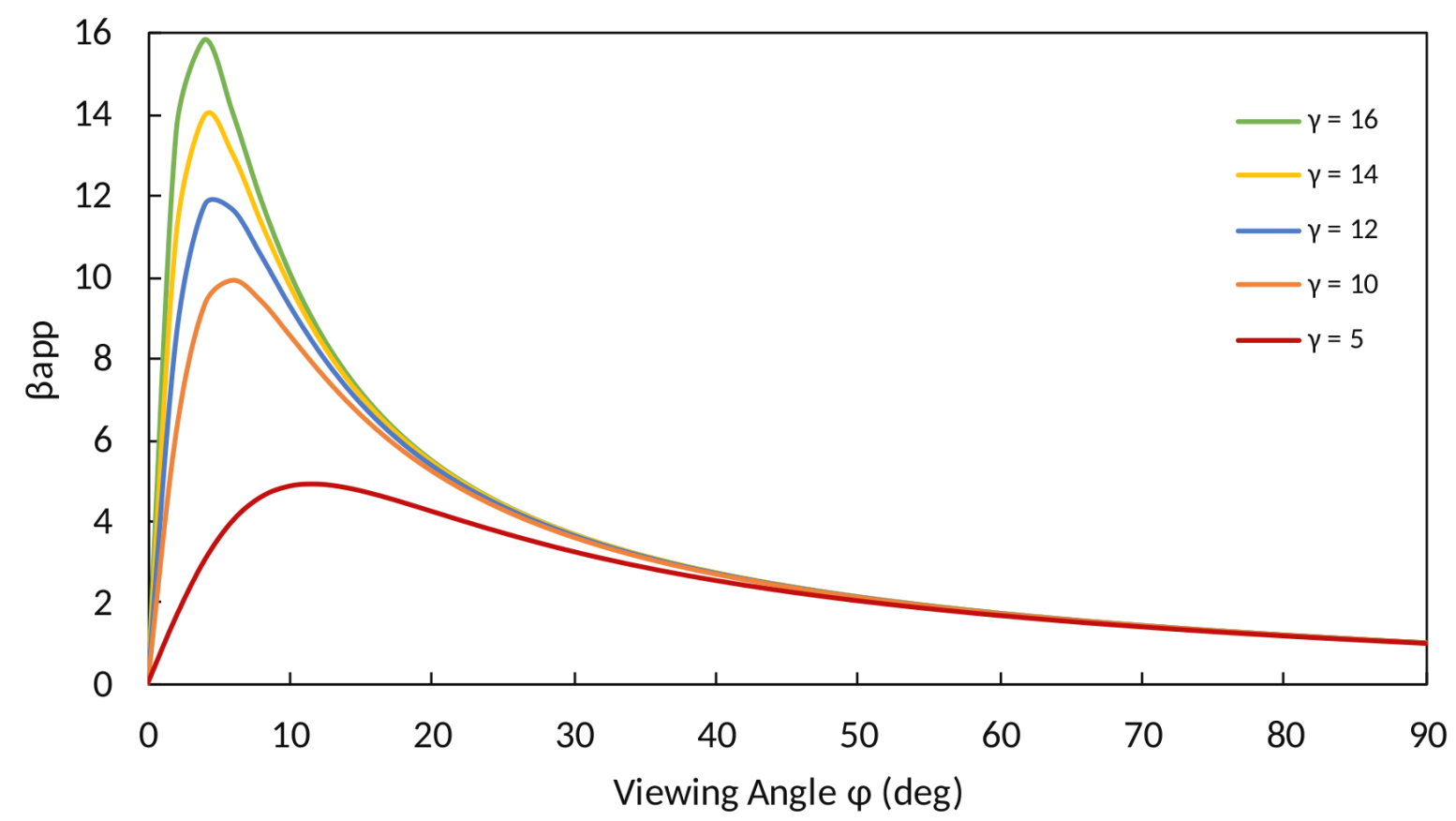

Figura 1.7: Gráfico da velocidade aparente $\left(\beta_{a p}=\frac{v_{a p}}{c}\right)$ como função do ângulo de visada $\phi$ para diferentes valores de $\gamma$.

direções.

Abraham e Carrara (1998) associaram os resultados de 3C 279 à precessão do jato em escala de parsecs, este modelo sugere um sistema binário de buracos negros no qual a órbita do companheiro secundário não encontra-se alinhada com o plano do disco de acreção do primário, por conta disso, torques são induzidos nas regiões internas Katz, 1997; Abraham, 2018). Além do mais, a precessão pode ser explicada como consequência da orbita de discos de acreção ao redor de buracos negros em rotação (Bardeen e Petterson, 1975). Neste cenário, como os momentos angulares tanto do buraco negro quanto do disco não se encontram alinhados, a precessão é causada pela tentativa de alinhamento.

A geometria do modelo de precessão do jato em escala de parsec é apresentada na figura 1.8. Neste modelo, o jato e o contra-jato se afastam do núcleo em direções opostas. A direção instantânea do jato é dada pelas equações (Caproni et al., 2009):

$$
\begin{aligned}
& e_{x, s}=\sin \left(\varphi_{0}\right) \sin \left[\omega_{s}\left(t_{s}-t_{0, s}\right)\right], \\
& e_{y, s}=\cos \left(\varphi_{0}\right) \sin \left[\omega_{s}\left(t_{s}-t_{0, s}\right)\right],
\end{aligned}
$$


e

$$
e_{z, s}=\cos \left(\varphi_{0}\right)
$$

onde $\omega_{s}=\frac{2 \pi}{P_{\text {prec }, s}}$. Realizando duas rotações no sentido horário das coordenadas no referencial da fonte, uma delas pelo ângulo $\varphi_{0}$ e outra por $\eta_{0}$, obtém-se as equações no referencial do observador (Caproni e Abraham, 2004):

$$
\begin{aligned}
& e_{x, o b s}=A\left(t_{s}\right) \cos \left(\eta_{0}\right)-e_{y, s}\left(t_{s}\right) \sin \left(\eta_{0}\right), \\
& e_{y, o b s}=A\left(t_{s}\right) \sin \left(\eta_{0}\right)+e_{y, s}\left(t_{s}\right) \cos \left(\eta_{0}\right),
\end{aligned}
$$

e

$$
e_{z, o b s}=-e_{x, s}\left(t_{s}\right) \sin _{\phi_{0}}+e_{z, s}\left(t_{s}\right) \cos \left(\phi_{0}\right) \text {, }
$$

onde $A\left(t_{s}\right)=e_{x, s}\left(t_{s}\right) \cos \left(\phi_{0}\right)+e_{z, s}\left(t_{s}\right) \sin \left(\phi_{0}\right)$. O ângulo instantâneo entre o jato e a linha de visada $\phi\left(t_{s}\right)$ é definido pela equação:

$$
\phi\left(t_{s}\right)=\operatorname{arcos}\left[e_{z, o b s}\left(t_{s}\right)\right]
$$

e o ângulo de posição no plano do céu:

$$
\eta\left(t_{s}\right)=\arctan \left[\frac{e_{y, o b s}\left(t_{s}\right)}{e_{x, o b s}\left(t_{s}\right)}\right] .
$$

Resumidamente, a precessão ocorre entorno do eixo fixo $z_{s}$, e por conta da precessão o ângulo das componentes no plano do céu $\eta_{0}$ varia em um período $P_{\text {prec,s }}$ (referencial da fonte) através de um cone com ângulo de abertura $\varphi_{0}$. O movimento pode ocorrer tanto no sentido horário quanto no anti-horário, e o ângulo que o eixo $z_{s}$ forma com a linha de visada do observador é dado por $\phi_{0}$ (Caproni et al. 2009). A partir da velocidade aparente observada para as componentes é possível calcular:

$$
\beta_{o b s}\left(t_{s}\right)=\gamma \beta \delta\left(t_{s}\right) \sin \left[\phi\left(t_{s}\right)\right]
$$

onde o $\delta\left(t_{s}\right)$ conhecido por fator Doppler é

$$
\delta\left(t_{s}\right)=\frac{1}{\gamma\left[1-\beta \cos \left[\phi\left(t_{s}\right)\right]\right]} .
$$

Devido à aberração relativística entre os referenciais do observador e da partícula, a radiação síncrotron sofre uma amplificação (ou beaming) na direção do movimento, com 
isso, Blandford e Königl (1979) derivaram a equação que descreve a amplificação da densidade de fluxo a uma dada frequência $\nu$ para um conjunto de componentes não resolvidas, como é o caso do jato de um AGN, sendo ela:

$$
S_{\nu}=\delta(\gamma, \phi)^{p+\alpha}
$$

sendo $\alpha$ o índice espectral calculado para um espectro síncrotron, $p=2$ para o fluxo contínuo do jato, e $p=3$ para as componentes discretas (Blandford e Königl, 1979).

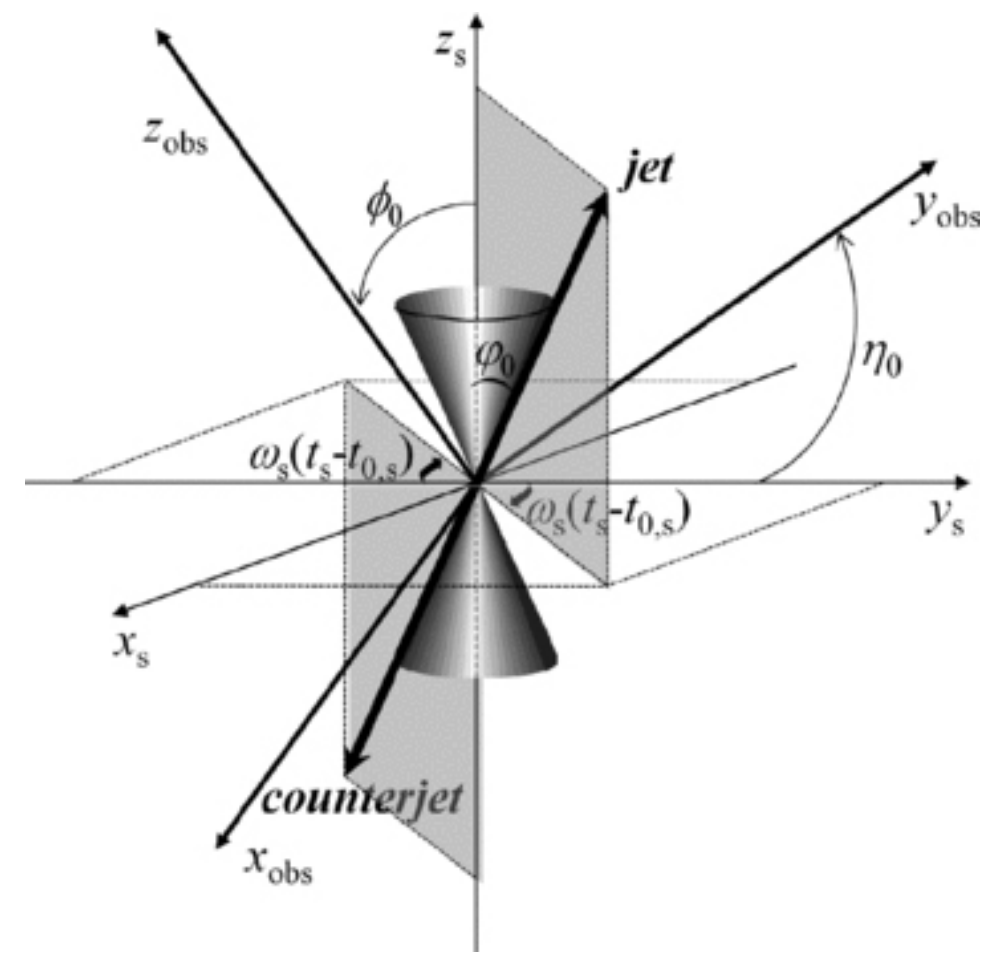

Figura 1.8: Apresentação da geometria do modelo de precessão, onde as medidas dos parâmetros são feitas no referencial da fonte. Fonte: Caproni et al. (2009).

O modelo de precessão tem sido aplicado em diversos outros AGNs nas últimas décadas sendo alguns deles: 3C 279 (Abraham e Carrara, 1998), OJ287 (Abraham, 2000), 3C 120 e 3C 345 (Caproni e Abraham, 2004), BL Lac (Caproni et al., 2013) e PG 1553+113 (Caproni et al. 2017). Outros modelos que explicam o movimento das componentes do jato são encontrados na literatura mas não serão tratados neste trabalho.

Finalmente, o principal objetivo deste trabalho foi buscar evidências de precessão a partir do modelo desenvolvido por Abraham e Carrara (1998) no jato do blazar TXS 0506+056 e relacioná-las com a formação de novas componentes e flares em raios- $\gamma$. Para tal, fez-se necessário utilizar imagens de VLBI obtidas em $15 \mathrm{GHz}$, e dados em raios- $\gamma$ obtidos pelo 
Fermi-LAT. Mais detalhes acerca da base de dados e metodologia empregada serão apresentadas no capítulo 2, A revisão bibliográfica realizada na literatura, referente ao blazar em questão, é apresentada no capítulo 3. Por fim, no capítulo 4 é apresentado o processo de identificação de componentes do jato, e como consequência o cenário cinemático proposto, bem como a associação de ejeção de novas componentes à flares em raios- $\gamma$. 
Capítulo 2

\section{Base de dados e Procedimentos}

Neste capítulo serão apresentadas a base de dados utilizada e a metodologia empregada para o ajuste das componentes do jato, bem como o tratamento dos dados em raios$\gamma$. Serão discutidos tópicos acerca das observações, os programas de monitoramento, o método tradicional utilizado por outros grupos para ajuste de componentes, e por fim, será apresentado o algoritmo para identificação de componentes em jatos que foi aplicado nesta dissertação.

\subsection{Observações}

\subsubsection{Observações em 2 centímetros}

Os mapas interferométricos utilizados neste trabalho são oriundos do MOJAVE[1 survey (Monitoring Of Jets in Active Galactic Nuclei with VLBA Experiments Lister e Homan, 2005), uma continuidade do survey de monitoramento construído entre os anos de 1994 e 2002 conhecido por VLBA $2 \mathrm{~cm}$ survey ${ }^{2}$ (Kellermann et al., 1998; Zensus et al., 2002; Kellermann et al., 2004; Lister et al., 2013).

O programa MOJAVE realiza observações na frequência de $15 \mathrm{GHz}$ com o Very Long Baseline Array, um interferômetro de longa linha de base formado por dez antenas idênticas de 25 metros de diâmetro distribuídas ao longo da América do Norte (figura 2.1). Cada antena opera entre as frequências $312 \mathrm{MHz}$ e $96 \mathrm{GHz}$, as linhas de base do interferômetro podem variar de $b_{\min }=200 \mathrm{~km}$ a $b_{\max }=8600 \mathrm{~km}$ (distribuídas entre o Havaí e as Ilhas de Virgens). Consequentemente, as resoluções alcançadas por este interferômetro são $0.17-22$

\footnotetext{
${ }^{1}$ http://physics.purdue.edu/MOJAVE

2 https://www.cv.nrao.edu/2cmsurvey/
} 
mas. Usualmente as observações são realizadas remotamente do centro de controle situado em Socorro, Novo México - EUA. Durante as operações do VLBA, a obtenção do sinal pelas antenas é realizada individualmente, isto é, em cada sítio o sinal é amplificado, digitalizado e gravado para depois ser correlacionado com as demais antenas no centro de operações.

De acordo com Lister et al. (2009), o programa MOJAVE tem por objetivo promover um monitoramento sistemático de longo período analisando os movimentos relativísticos de jatos de AGNs em escalas de parsec, para tal o programa visa: a) promover um significante aperfeiçoamento em prévias base dados em termos de resolução e tamanho da imagem, e completeza estatística; b) caracterizar a cinemática e a evolução de polarização dos jatos de AGN para então relacionar-los à outras propriedades das fontes. Os atuais critérios seguidos para definição de amostragem de AGNs, definidos por Lister et al. (2019), são:

1. Limite de declinação $\mathrm{J} 2000>-30^{\circ}$

2. Densidade de fluxo que ultrapasse 1.5 Jy obtida em $15 \mathrm{GHz}$ em qualquer época de observação anterior.

Em edições anteriores do programa havia também limitações quanto a observações em determinadas latitudes Galácticas (Lister et al., 2009, 2011, 2013), que nesta última edição foram retiradas. Atualmente, o programa vem monitorando cerca de 232 fontes, dentre estas, em sua grande maioria blazares.

Os processos de calibração e redução dos dados são realizados através do software $A s$ tronomical Image Processing System (AIPS) seguindo os procedimentos padrões sugerido pelos desenvolvedores. Contudo, as imagens finais disponibilizadas pelo MOJAVE são construídas através do pacote Difmap. Por fim, todas os mapas interferométricos disponibilizados apresentam uma escala de $0.1 \mathrm{mas} /$ pixel.

Os mapas interferométricos utilizados neste trabalho têm as propriedades apresentadas na tabela 2.1. As colunas são listadas na seguinte ordem: data de observação, intensidade máxima, comprimentos do semi-eixo maior e menor do feixe, ângulo de posição medido a partir do norte e ruído da imagem. Em épocas anteriores ao ano de 2014, os mapas apresentavam dimensões de 1024x1024 pixeis, e a partir desta época passaram a ter dimensão 512 x512 pixeis. Todas as épocas disponíveis foram analisadas nesta dissertação, totalizando 17 observações distintas, porém o objeto em questão continua a ser monitorado pelo MOJAVE. 


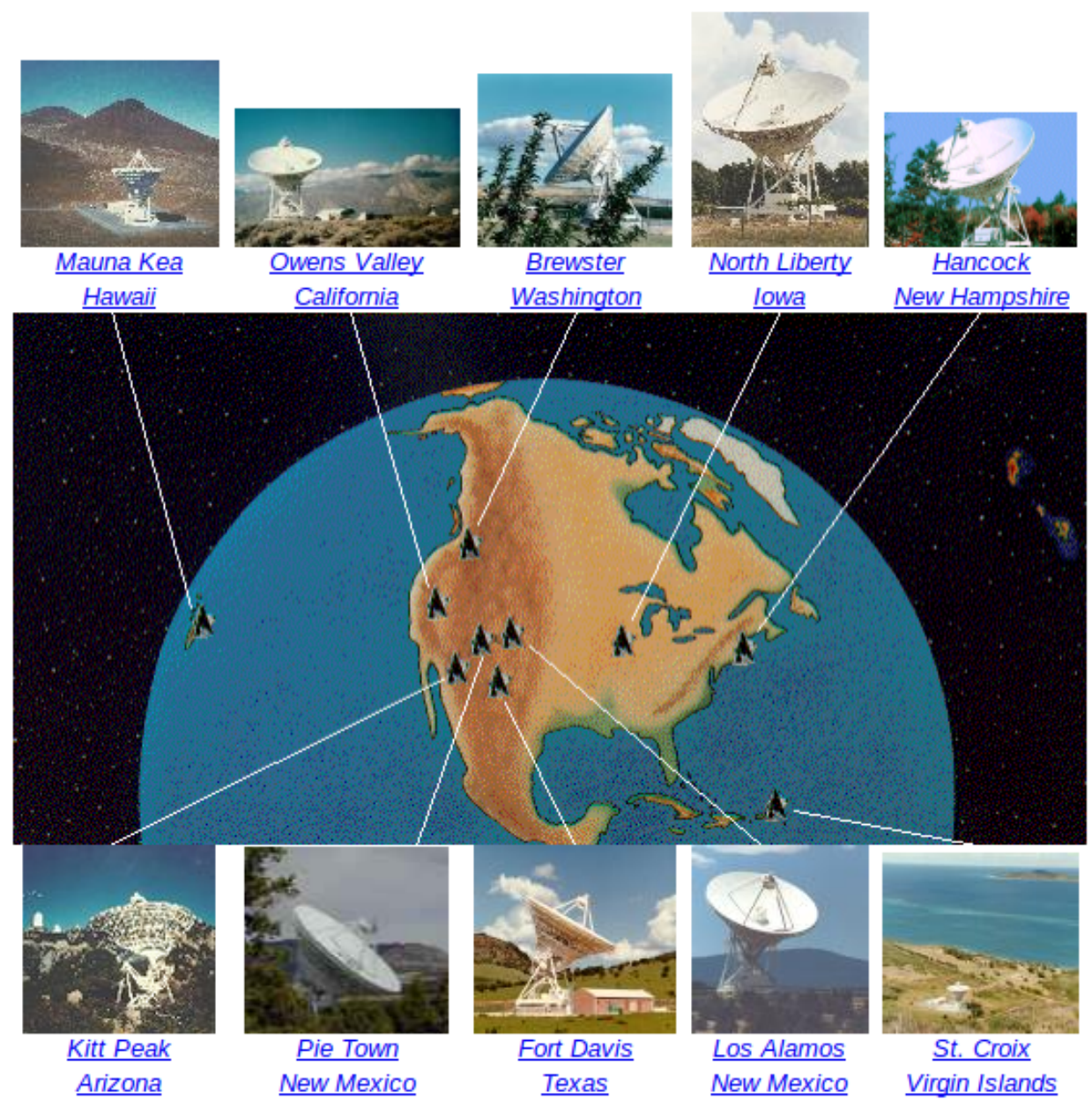

Figura 2.1: Distribuição geográfica das dez antenas ao longo da América do Norte que compõe o VLBA. Fonte: NRAO/AUI

Tabela 2.1 - Propriedades dos mapas obtidos em $15 \mathrm{GHz}$ do objeto TXS 0506+056. As colunas correspondem respectivamente à época de observação, densidade de fluxo pelo feixe, semi-eixo maior e menor, inclinação do feixe, e por fim, o rms (root mean square) da observação.

\begin{tabular}{cccccc}
\hline \hline Época & $S_{\text {max }}(\mathrm{Jy} /$ beam $)$ & $\mathrm{a}_{M A J}($ mas $)$ & $\mathrm{a}_{M I N}($ mas $)$ & BPA (graus) & rms (mJy/beam) \\
\hline $22 / 07 / 2009$ & 0,420 & 1,40 & 0,63 & $-3,9$ & 0,20 \\
$03 / 06 / 2009$ & 0,440 & 1,34 & 0,58 & $-6,9$ & 0,20 \\
$12 / 07 / 2010$ & 0,270 & 1,38 & 0,51 & $-8,5$ & 0,20 \\
$13 / 11 / 2010$ & 0,250 & 1,37 & 0,58 & $-9,1$ & 0,18 \\
$27 / 02 / 2011$ & 0,232 & 1,18 & 0,54 & $-0,8$ & 0,23 \\
$06 / 02 / 2012$ & 0,236 & 1,29 & 0,58 & $-5,4$ & 0,15 \\
$28 / 02 / 2013$ & 0,238 & 1,24 & 0,55 & $-3,8$ & 0,15 \\
$25 / 01 / 2014$ & 0,232 & 1,20 & 0,57 & $-5,5$ & 0,10 \\
$18 / 01 / 2015$ & 0,310 & 1,34 & 0,52 & $-4,8$ & 0,10
\end{tabular}

Continua na próxima página... 
Tabela 2.1 - Continuação

\begin{tabular}{cccccc}
\hline \hline Época & $S_{\text {max }}(\mathrm{Jy} /$ beam $)$ & aMAJ (mas) & $\mathrm{a}_{M I N}($ mas $)$ & BPA (graus) & rms (mJy/beam) \\
\hline $06 / 09 / 2015$ & 0,272 & 1,27 & 0,52 & $-6,2$ & 0,10 \\
$22 / 01 / 2016$ & 0,212 & 1,33 & 0,54 & $-9,8$ & 0,10 \\
$16 / 06 / 2016$ & 0,320 & 1,17 & 0,52 & $-2,4$ & 0,10 \\
$18 / 11 / 2016$ & 0,410 & 1,19 & 0,53 & $-4,7$ & 0,10 \\
$17 / 06 / 2017$ & 0,454 & 1,18 & 0,5 & $-5,9$ & 0,10 \\
$22 / 04 / 2018$ & 0,720 & 1,21 & 0,52 & $-5,6$ & 0,10 \\
$31 / 05 / 2018$ & 0,800 & 1,19 & 0,51 & $-3,2$ & 0,10 \\
$16 / 12 / 2018$ & 0,842 & 1,21 & 0,57 & $+2,4$ & 0,30 \\
\hline
\end{tabular}

\subsubsection{Fermi Large Area Telescope}

Dados em raios- $\gamma$ foram utilizados neste trabalho com o intuito de reproduzir a curva de luz em altas energias do AGN TXS 0506+056, sendo estes públicos disponíveis no Fermi Data Archive ${ }^{3}$. Estes dados foram obtidos através do instrumento Large Area Telescope (Atwood et al., 2009), LAT daqui em diante, parte do antes conhecido por Gamma-Ray Large Area Space Telescope (GLAST), e atualmente por Telescópio Espacial Fermi. Como complemento do LAT, o Fermi conta também com o instrumento Gamma-ray Burst Monitor (GBM) que monitora altas variações de raios- $\gamma$ no céu sendo sensível inclusive a Raios-X. O telescópio completa uma orbita ao redor da Terra em cerca de 96 minutos, e em duas órbitas o instrumento é capaz de obter dados de todo o céu.

A figura 2.2 representa a trajetória que um fóton percorre dentro Fermi-LAT, os raios$\gamma$ passam livremente por uma camada de plástico, enquanto que partículas como raios cósmicos interagem com o plástico e geram uma emissão característica de luz, fazendo com que seja possível separar os fótons em raios- $\gamma$. Os fótons atingem então uma folha de tungstênio, na qual ao interagirem, produzem um elétron e um pósitron. Essas partículas carregadas encontram uma camada de sílico semicondutor onde são marcadas suas posições x e y. Após atravessarem a camada de silício, as partículas são detectadas em um calorímetro de iodeto de Sódio e têm suas energias medidas. As medidas do detector anticoincidente, do rastreador no silício, e no calorímetro são combinadas para reconstruir a direção da partícula de raios- $\gamma$.

\footnotetext{
${ }^{3}$ https://fermi.gsfc.nasa.gov/ssc/data/access/
} 


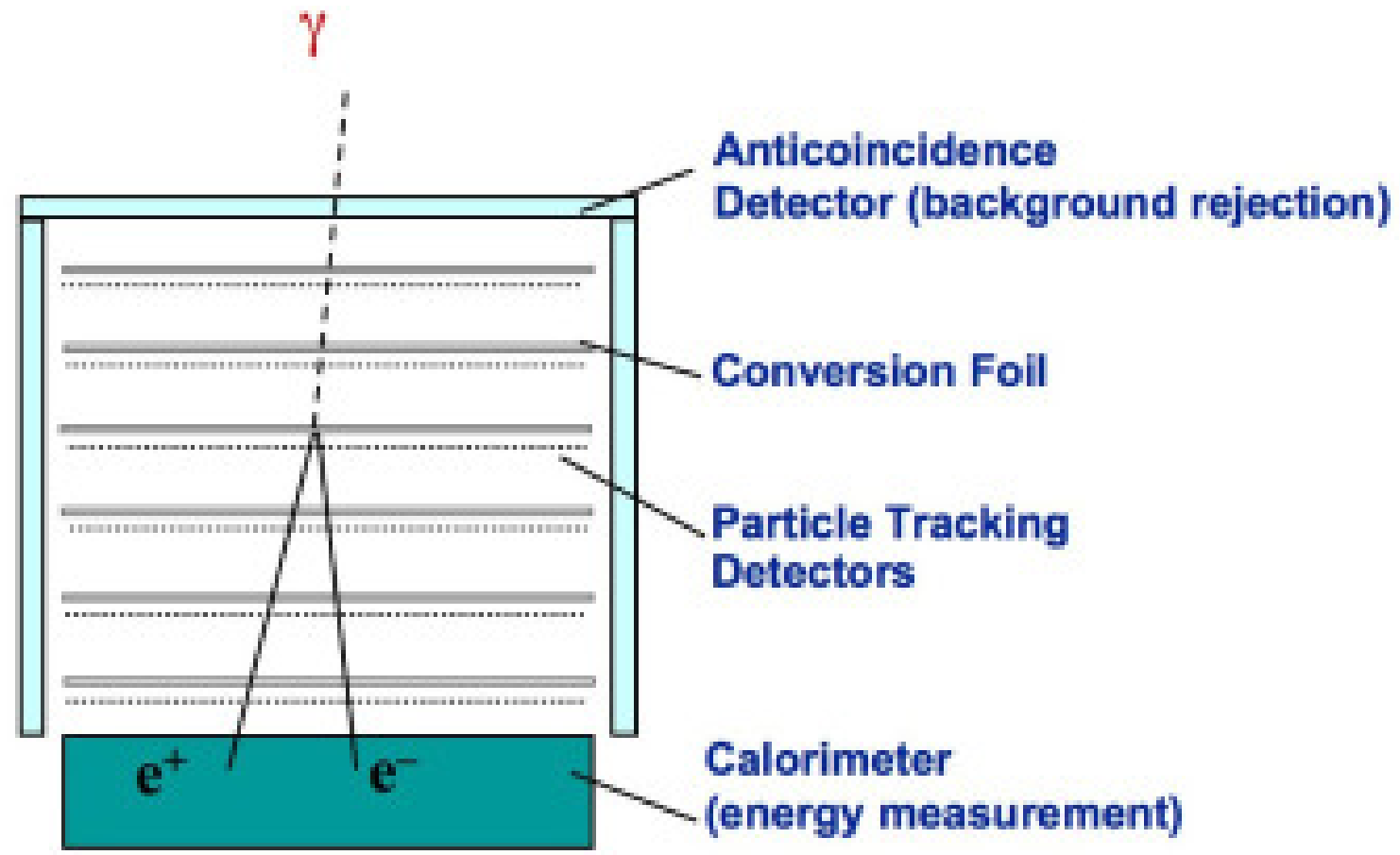

Figura 2.2: Representação das camadas dentro do Large Area Telescope que os raios- $\gamma$ percorrem até atingir o calorímetro e ter sua energia e trajetória computada. Fonte: Stanford University/SLAC

O telescópio Fermi foi lançado em 11 de Junho de 2008 e tem operado entre $20 \mathrm{MeV}$ e $300 \mathrm{GeV}$ com um campo de visão maior que $2.4 \mathrm{sr}$, alcançando resolução angular $<3.5^{\circ} \mathrm{em}$ $100 \mathrm{MeV}$ ou $<0.15^{\circ}$ para $>10 \mathrm{GeV}$ ). Para reprodução da curva de luz deste trabalho os dados utilizados foram obtidos entre $300 \mathrm{MeV}$ e $300 \mathrm{GeV}$, isso deve-se principalmente a PSF (Point Spread Function) do instrumento ter uma qualidade inferior em menores energias observadas (Bruel et al., 2018), conforme apresentado na figura 2.3. Este gráfico apresenta o ângulo de contenção (PSF) como função da energia detectada para o FermiLAT, e como é possível verificar, a qualidade da PSF diminui quanto menor a energia, e para minimizar a contaminação proveniente de outras fontes, decidiu-se utilizar energias acima de $300 \mathrm{MeV}$ neste presente trabalho.

A colaboração do Fermi-LAT gera a curva de luz de diversos objetos a partir da técnica de fotometria de abertura $a^{4}$ entretanto, os autores não recomendam utilizar as curva de luz para uma análise científica, apenas para reportar aspectos gerais. Existe um processo

\footnotetext{
${ }^{4}$ https://fermi.gsfc.nasa.gov/ssc/data/access/lat/4yr_catalog/ap_lcs.php
} 


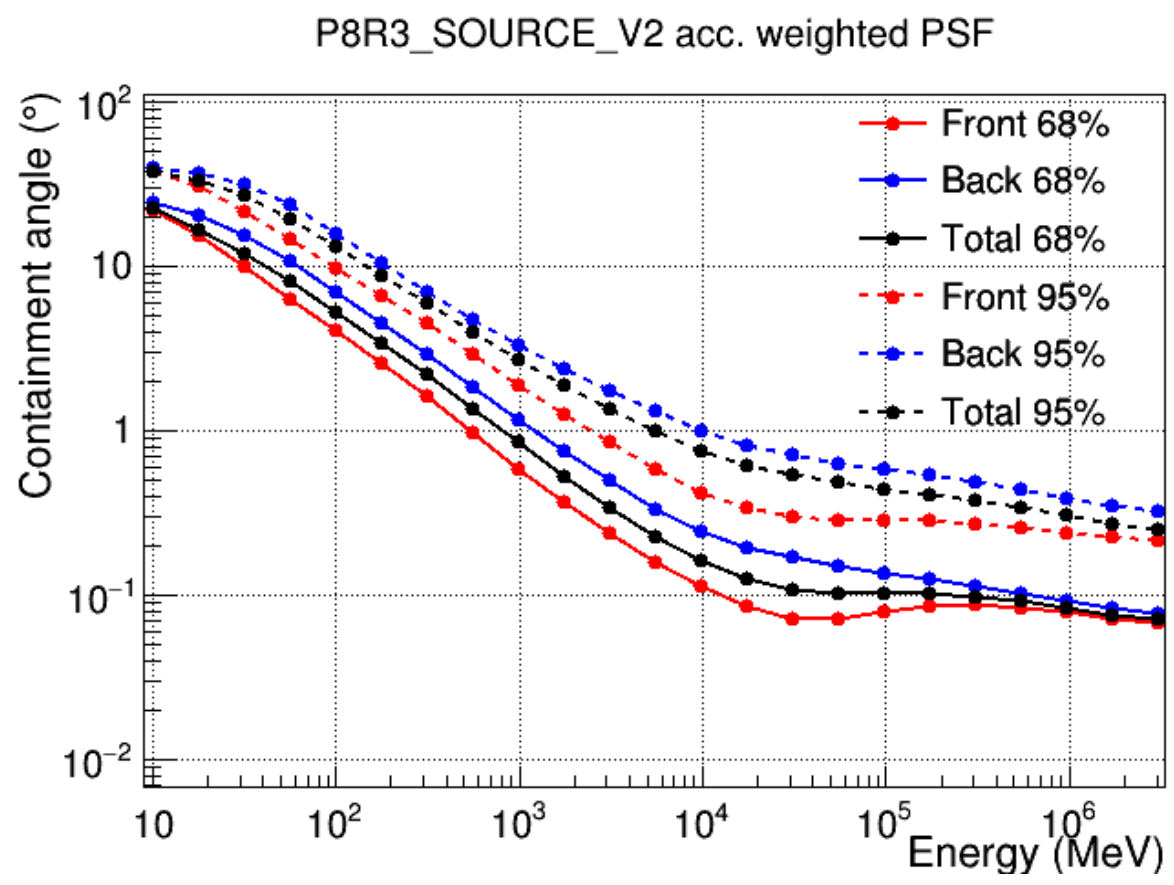

Figura 2.3: Ângulo contido como função da energia em $\mathrm{MeV}$, este gráfico reflete o comportamento da PSF ao longo do range de energias detectáveis pelo Fermi-LAT. Os níveis de porcentagem refletem a quantidade de área efetiva integrada sobre o ângulo sólido. Fonte: Stanford University/SLAC

automatizado de calibração, redução dos dados e geração de curvas de luz para fontes que apresentam fluxo acima de $1 \cdot 10^{-6} \mathrm{~cm}^{-2} \mathrm{~s}^{-1}$ (até Junho de 2009 esse valor era o dobro). Para o blazar TXS 0506+056 o procedimento automático não é realizado, portanto, para obtenção da curva da luz seguimos o procedimento descrito pela ferramenta Fermipy v0.17.35 (Wood et al., 2017), e os resultados da redução e análise dos dados serão apresentados no capítulo 4.

\subsection{Métodos de identificação das componentes em jatos}

\subsubsection{Método tradicional}

Para a identificação das componentes discretas observadas nos jatos de blazares tem-se utilizado modelos que ajustam gaussianas bidimensionais e o método que tem sido empregado por Lister et al. (2009, 2019) é tradicionalmente realizado no plano das visibilidades $(\mathrm{u}, \mathrm{v})$. Os autores utilizam a tarefa 'modelfit' do 'Difmap' (Shepherd, 1997). De acordo com Lister et al. (2009), o método oferece vantagens sobre ajustes realizados no plano da

\footnotetext{
${ }^{5}$ https://fermipy.readthedocs.io/en/latest/
} 
imagem pois utiliza a capacidade de resolução completa do VLBA (Kovalev et al., 2005), entretanto, de acordo com os próprio autores, algumas componentes do ajuste podem ser meras concepções matemáticas necessárias para reproduzir a distribuição de brilho complexo. As componentes são classificadas em robustas e não robustas, sendo o critério de robustez definido por: continuidade na posição, densidade de fluxo e tamanho das gaussianas ajustadas em pelo menos cinco épocas.

Os ajustes das componentes do jato de TXS 0506+056 apresentados por Lister et al. (2019), para cada época observada, contém informações acerca das posições das componentes, tamanhos e densidades de fluxo, conforme é mostrado na tabela 2.2. As componentes ajustadas pelo método tradicional podem ser funções delta, gaussianas elípticas ou circulares. Neste artigo, os autores utilizam gaussianas circulares para as componentes do jato e elípticas para ajustes do núcleo, e justificam que para o núcleo, inserir o parâmetro de elipticidade descomplica o ajuste já que trata-se de uma estrutura não resolvida. Para as demais componentes a escolha por gaussianas circulares diminui a quantidade de parâmetros livres fazendo com que a posição do centroide seja mais precisa. Algumas componentes podem ser inseridas 'manualmente' caso ao analisarem os resíduos seja encontrada alguma região com densidade de fluxo da ordem de 5 mJy.

Os principais problemas levantados por esta metodologia são: a não unicidade das soluções, limitação quanto ao número de componentes ajustadas simultaneamente, e por fim, o método utiliza ajustes de datas anteriores como dados iniciais de entrada. Em contrapartida, o método empregado nesta dissertação supera algumas algumas destas arbitrariedades, a discussão acerca deste método, o Cross-Entropy, é tratada na próxima seção.

Tabela 2.2 - Ajuste das componentes do jato de TXS 0506+056 realizados por Lister et al. (2019). As colunas correspondem, respectivamente, a época de observação, identificação da componente, densidade de fluxo da componente em $15 \mathrm{GHz}$, distância da componente ao núcleo, ângulo de posição no plano do céu, tamanho da componente convoluída com o feixe, razão entre os semi-eixos maior e menor da elipse, e o critério de Robustez da componente.

\begin{tabular}{cccccccc}
\hline \hline Época & ID & $I_{15 G H z}(\mathrm{mJy})$ & $\mathrm{r}$ (mas) & P.A. (graus) & MAJ. (mas) & Razão & Robusta? \\
\hline $12 / 07 / 2010$ & 0 & 207. & 0.10 & 7.6 & 0.07 & 1. & Sim \\
$12 / 07 / 2010$ & 1 & 23.4 & 3.45 & 170.4 & 1.86 & 1. & Sim
\end{tabular}

Continua na próxima página... 
Tabela 2.2 - Continuação

\begin{tabular}{cccccccc}
\hline \hline Época & ID & $I_{15 G H z}(\mathrm{mJy})$ & r (mas) & P.A. (graus) & MAJ. (mas) & Razão & Robusta? \\
\hline $12 / 07 / 2010$ & 2 & 53.1 & 1.80 & 188.2 & 0.86 & 1. & Sim \\
$12 / 07 / 2010$ & 3 & 21.9 & 1.26 & 216.5 & 0.49 & 1. & Sim \\
$12 / 07 / 2010$ & 4 & 117. & 0.49 & 190.3 & 0.31 & 1. & Não \\
\hline
\end{tabular}

\subsubsection{Algoritmo do Cross-Entropy}

O algoritmo do Cross-Entropy (CE, daqui em diante) foi inicialmente introduzido por Rubinstein (1997) com o intuito de simular eventos contínuos, porém, Rubinstein (1999) reformulou o algoritmo para modelar e resolver problemas com optimização discreta. Apesar de que alguns exemplos da robustez do método foram citados em Boer et al. (2005), Caproni et al. (2009) foram os primeiros a aplicar este método para obtenção de parâmetros relativos à precessão de jatos em AGNs. Já Monteiro et al. (2010) aplicaram a metodologia em dados fotométricos para ajuste de isócronas em aglomerados estelares abertos. Enfim, Caproni et al. (2011) adaptaram o CE para modelar e ajustar as componentes do jato de quasares através de gaussianas bidimensionais no plano da imagem de dados interferométricos.

O método de CE utiliza uma imagem observada como arquivo de entrada, calcula uma imagem modelo formada por um número fixo de componentes escolhidas arbitrariamente e então calcula a função de mérito, seleciona os melhores candidatos entre todas as soluções geradas em cada iteração e constrói novos candidatos a partir delas. O procedimento básico que o método de CE realiza pode ser resumido em quatro etapas. A primeira delas é a geração aleatória de parâmetros iniciais que devem obedecer algumas condições e critérios pré-definidos, sendo a segunda etapa uma seleção das melhores amostras baseadas em alguns critérios de otimização. A terceira trata da geração aleatória de parâmetros melhorados a partir de prévios candidatos que serão utilizados na próxima iteração, e a quarta é uma etapa onde são refeitas as fases anteriores até que o número de iterações atinja um critério especificado pelo usuário. 


\subsubsection{Cálculo dos parâmetros e suas incertezas}

Os parâmetros de entrada do programa são: a imagem observada em um arquivo de texto composta pela intensidade em cada pixel $\left(N_{x}\right.$ e $\left.N_{y}\right)$; ângulo do feixe e seus semieixos maior e menor, fluxo máximo e rms. Ademais, para encontrar a melhor solução de otimização do CE é necessário definir um intervalo permitido para os parâmetros $\left(p_{j}^{\max }\right.$, $\left.p_{j}^{m i n}\right)$ : posição central da gaussiana $(x, y)$, excentricidade $(\epsilon)$, semi-eixo maior da elipse $(a)$, ângulo de inclinação $(\theta)$ e intensidade central $\left(I_{0}\right)$. Outros parâmetros de entrada são o número de componentes a serem ajustados $\left(N_{S}\right)$ bem como o número de iterações $\left(k_{\max }\right)$ que deverão ser realizadas.

O processo de otimização é realizado através da construção aleatória de $N=6$ parâmetros $\boldsymbol{x}_{\boldsymbol{i}}=\left(x_{i}, y_{i}, a_{i}, \epsilon_{i}, \theta_{i}, I_{0, i}\right)$, a cada iteração é calculada uma função de mérito $S_{i}(k)$ que, quanto mais próximo os parâmetros da componente alcancem a solução exata, deve tender a zero. O método se incia com os parâmetros $\bar{p}_{j}(k=0)=\left(p_{j}^{\max }-p_{j}^{\text {min }}\right) / 2$ e $\sigma_{j}(0)=\left(p_{j}^{\text {max }}-p_{j}^{\text {min }}\right) / 2$, para então calcular:

$$
X_{i j}(0)=\bar{p}_{j}+\sigma_{j}(0) \cdot G_{i j}
$$

onde $G_{i j}$ é uma matriz $N \times N_{p}$ de números aleatórios gerados através de uma distribuição normal de média nula e desvio padrão um.

A próxima etapa do algoritmo é calcular o $S_{i}(0)$ para cada conjunto $\boldsymbol{x}_{\boldsymbol{i}}$, selecionar os modelos com os menores valores da função de mérito para então formar a matriz $X^{\text {elite }}(0)$. Neste trabalho foi assumido $N^{\text {elite }}=20$ (Caproni et al. 2014 ). Com isso, calcula-se o valor médio dos parâmetros e o desvio padrão, a partir das equações:

$$
\bar{p}_{j}^{\text {elite }}(0)=\frac{1}{N^{\text {elite }}} \sum_{i=1}^{N^{e l i t e}} X_{i j}^{\text {elite }},
$$

e

$$
\sigma_{j}^{\text {elite }}(0)=\sqrt{\frac{1}{N_{\text {elite }}} \sum_{i=1}^{N^{\text {elite }}}\left[X_{i j}^{\text {elite }}(0)-\bar{p}_{j}^{\text {elite }}(0)\right]^{2}} .
$$

Através dos valores dos parâmetros e seu desvio padrão calculados nas equações $2.2 \mathrm{e}$ 2.3 calcula-se a matriz:

$$
X_{i j}(1)=\bar{p}_{j}(0)+\sigma_{j}(0) \cdot G_{i j},
$$

o processo descrito pelas equações 2.2, 2.3 e 2.4 é repetido até que o algoritmo que atinja $k_{\text {max }}$ ou $\sigma_{i}^{\text {elite }}(k)$ menor que o valor pré-definido, sendo que a cada iteração a matriz $G_{i j}$ é gerada novamente. Após diversos testes, definimos o valor de $k_{\max }$ como sendo 3500 . 
Entretanto, para que a convergência do método encontre um mínimo global, e não o local, Kroese et al. (2006) sugeriram uma parametrização com um valor de $\alpha$ para o cálculo dos parâmetros e de seu desvio padrão, como sendo:

$$
\bar{p}_{j}^{\text {elite }, s}(k)=\alpha^{\prime} p_{j}^{\text {elite }}(k)+\left(1-\alpha^{\prime}\right) p_{j}^{\text {elite }}(k-1),
$$

e

$$
\sigma_{j}^{\text {elite }, s}(0)=\alpha_{d}(k) \cdot \sigma_{j}^{\text {elite }}(k)+\left[1-\alpha_{d}(k)\right] \sigma_{j}^{\text {elite }}(k-1),
$$

sendo $\alpha_{d}$ calculado através da equação:

$$
\alpha_{d}(k)=\alpha-\alpha\left(1-\frac{1}{k}\right)^{q}
$$

com $\alpha=0.7$ e $q=5$ dentro das recomendações de Kroese et al. (2006) $(0<\alpha<1$ e $5<q<10)$.

Dentro do algoritmo do CE, foi implementada a técnica de convolução para feixes elípticos desenvolvida por Wild 1970 para calcular as distribuições de brilho observada nos pixeis da imagem. Neste trabalho utilizamos os parâmetros das gaussianas bidimensionais convoluídos com o feixe, ao invés dos parâmetros reais.

\subsubsection{Função de mérito}

Durante o processo de otimização do CE a função de desempenho é definida como o somatório do quadrado dos resíduos e suas variâncias. O resíduo quadrado em um determinado pixel $(m)$ e iteração $(k)$ é definido como sendo:

$$
R_{m}(k)=\left[I_{m}-M_{m}(k)\right]^{2},
$$

onde $I_{m}$ e $M_{m}(k)$ são, respectivamente, a densidade de fluxo da imagem observada e a da imagem modelo gerada a cada iteração. Com isso, a média quadrática residual é calculada da seguinte forma:

$$
\bar{R}(k)=\frac{1}{N_{\text {pixel }}} \sum_{m=1}^{N_{\text {pixel }}} R_{m}(k) .
$$

Portanto, a função de mérito $S_{\text {prod }}(k)$ foi definida como:

$$
S_{\text {prod }}(k)=\frac{\bar{R}(k)}{N_{\text {pixel }}} \sum_{m=1}^{N_{\text {pixel }}}\left[R_{m}(k)-\bar{R}(k)\right]^{2},
$$


sendo o termo entre colchetes corresponde a variância. A função de mérito tem unidades $J y^{6} \cdot$ beam $^{-6}$, já que $I_{m}$ e $M_{m}$ têm unidade de Jy/beam. Conforme dito anteriormente, em uma situação idealizada os parâmetros convergiriam para uma solução exata e com isso, a função de mérito tenderia a zero.

Finalmente, Caproni et al. (2009, 2011) utilizaram durante o cálculo final dos parâmetros uma equação com $k$ e $p(k)$ (iteração e o valor dos parâmetros naquela iteração, respectivamente) e suas incertezas foram calculadas a partir da média ponderada destes. Neste trabalho os parâmetros das componentes obtidos são provenientes do cálculo da última iteração, portanto, nenhum valor aleatório gerado através das primeiras iterações foi considerado no valor final. Quanto as incertezas, foram realizadas 4 rodadas adicionais do CE, com os mesmos parâmetros iniciais, para que fosse determinado o seu desvio padrão. 
Capítulo 3

\section{O Blazar TXS 0506+056}

Neste capítulo serão discutidos e apresentados os principais e mais recentes resultados disponíveis na literatura acerca do objeto TXS 0506+056. Além das propriedades do blazar, serão também discutidos as observações de neutrinos e suas possíveis correlações com os demais comprimentos de onda, bem como os resultados da análise cinemática das componentes do jato em $15 \mathrm{GHz}$ encontradas na literatura.

\subsection{Revisão bibliográfica}

\subsubsection{Propriedades do blazar TXS 0506+056}

O objeto TXS 0506+056 (ou 3FGL J0509.4+0541) encontra-se na direção da constelação de Órion a um redshift $z=0.3365 \pm 0.0010$ (Paiano et al., 2018). Trata-se de um núcleo ativo da galáxia do tipo BL Lac mascarado (Padovani et al., 2019) que, segundo os autores, apesar de ser um FSRQ (Flat-Spectrum Radio Quasar), apresenta linhas de emissão largas escondidas devido a um intenso e Doppler-boosted jato. O Blazar tornou-se conhecido devido ao evento de neutrinos IceCube-170922A (IceCube Collaboration, et al., 2018), sendo considerado a primeira detecção de neutrinos extragalácticos.

A detecção de neutrinos pelo IceCube South Pole Neutrino Observatory 1 , localizado na Antártica, ocorreu em 22 de Setembro de 2017 (IceCube-170922A), e neste mesmo período, foi também detectado um flare em raios- $\gamma$ pelo Fermi-LAT, entretanto, o blazar já encontrava-se há algum tempo em alta atividade nessa faixa do espectro eletromagnético. Simultaneamente às observações realizadas pelo LAT, outros observatórios e instrumentos acompanhavam a variabilidade da fonte, dentre eles: MAGIC (E > $90 \mathrm{GeV})$; VERITAS

\footnotetext{
${ }^{1}$ https://icecube.wisc.edu/
} 
$(\mathrm{E}>175 \mathrm{GeV})$; Swift $(0.3-10 \mathrm{keV})$; ASAS-SN (banda V); OVRO (15 GHz), os dados das curvas de luz obtida apartir destes equipamentos são apresentados na figura 3.1. Nesse artigo, os dados do Fermi-LAT foram binados em 28 dias, e apresentam, conforme citado acima, um aumento no fluxo a partir de 2017. Embora houvessem dados em diversos comprimentos de onda, de acordo com IceCube Collaboration, et al. (2018) e Padovani et al. (2018), nenhuma periodicidade ou atraso (com relação a demais comprimentos de onda) foram observados.

Após a detecção de neutrinos em Setembro de 2017, a colaboração do IceCube realizou uma análise histórica dos dados de TXS 0506+056, e observaram um excesso na quantidade de neutrinos detectados proveniente da mesma região do céu entre os período de Setembro de 2014 e Março de 2015 com 3.5 $\sigma$ de significância, neste caso, nenhuma contrapartida em raios- $\gamma$ foi detectada (IceCube Collaboration, et al. (2018) e Padovani et al. (2018)) até o momento (com o tamanho de bin utilizado).

TXS 0506+056 é conhecido por ser uma relativamente intensa fonte de raios- $\gamma$, tendo uma média de fluxo $\mathrm{F}(\mathrm{E}>100 \mathrm{MeV})=7.1 \cdot 10^{-8} \frac{\text { fotons }}{\mathrm{cm}^{2} \mathrm{~s}}$, sendo considerada entre as $4 \%$ fontes mais intensas do catálogo FERMI 3LAC (Ackermann et al., 2015). Na faixa de rádio, o objeto apresenta uma média na densidade de fluxo $S_{6 \mathrm{~cm}} \approx 1 \mathrm{Jy}$ Gregory e Condon, 1991) e $S_{20 \mathrm{~cm}} \approx 0.537 \mathrm{Jy}$, sendo uma das fontes mais brilhantes do NRAO VLA Sky Survey (Condon et al., 1998).

Na figura 3.2 é apresentada a Distribuição Espectral de Energia (SED, em inglês) calculada através dados disponíveis na literatura para o TXS 0506+056 catorze dias após o evento de neutrinos de 2017 (IceCube Collaboration, et al., 2018). Diversos trabalhos têm modelado o sinal de neutrinos proveniente deste flare (Murase et al., 2018; Keivani et al., 2018; Padovani et al., 2018; Cerruti et al., 2019; Gao et al., 2019; Oikonomou et al., 2019: Liu et al., 2019). Padovani et al. (2018) obtiveram uma SED semelhante à da figura 3.2, e modelaram a região do espectro em raios- $\gamma$ em diversas épocas, obtendo então limites máximos e mínimos possíveis para a SED nessa faixa do espectro.

Além disso, Padovani et al. (2018) estudaram os objetos dentro de 80 minutos de arco da fonte emissora de neutrino, cerca de 80 objetos estavam presentes nesta região, mas apenas 7 são emissores em rádio e raios- $\gamma$. Dentre estas, 4 fontes são blazares, sendo as mais intensas o próprio TXS 0506+056 e, também, PKS 0502+049 ( $z=0.954)$.

Curiosamente, em períodos anteriores e posteriores ao evento de IceCube-170922A, 


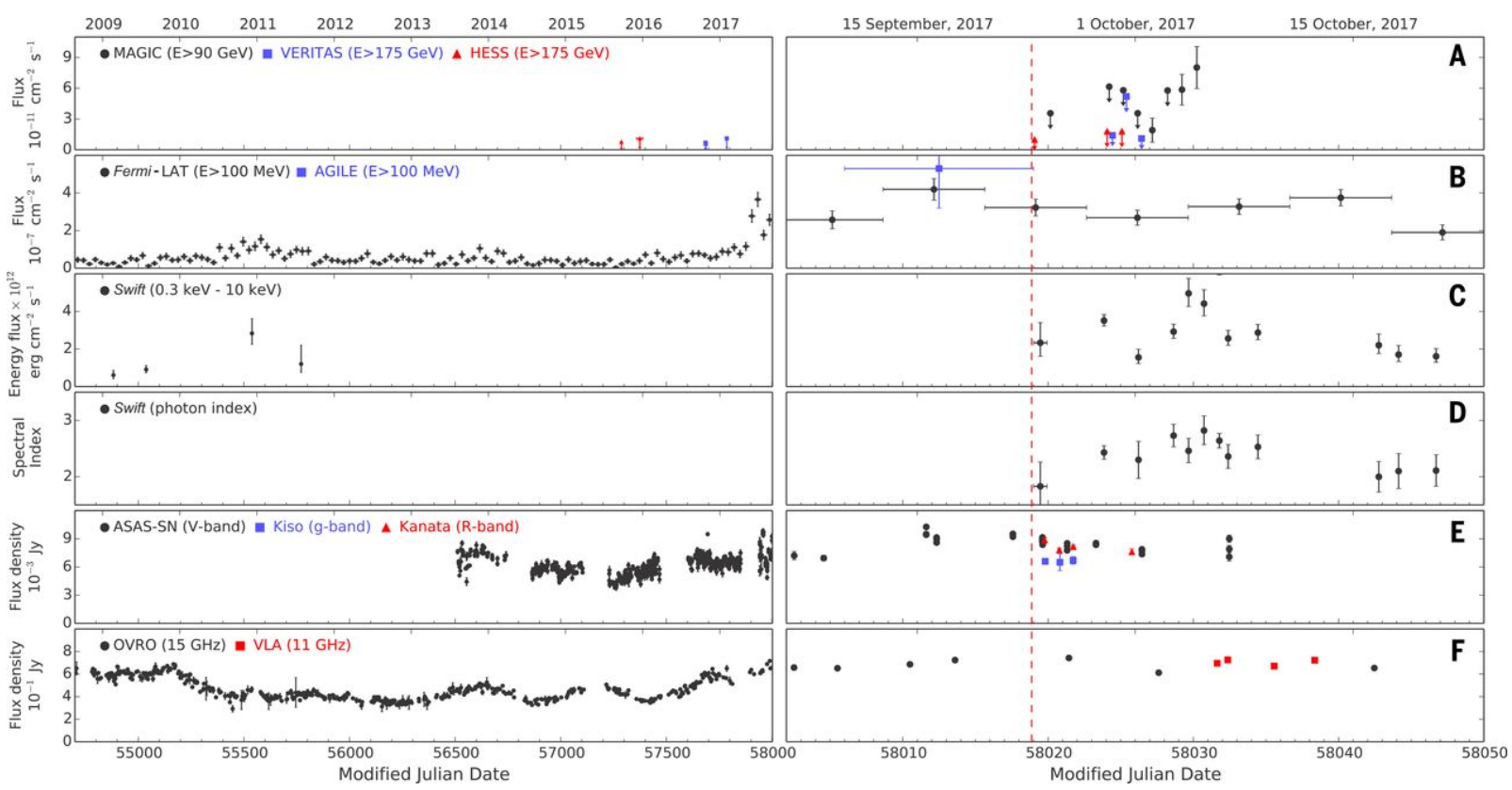

Figura 3.1: Curvas de luz em diversas faixas do espectro eletromagnético. Os dados estão divididos em: (A) Very High Energy em raios- $\gamma$ realizados por MAGIC, H.E.S.S e VERITAS; (B) altas energias em raios- $\gamma$ realizados pelo Fermi-LAT; (C e D) observações em raios-X por Swift XRT; (E) óptico por ASAS-SN, Kiso/KWFC e Kanata/HONIR; e por fim, (F) curva de luz em rádio obtida pelo OVRO e VLA. Os dados dos painéis à esquerda correspondem a todo período disponível pelo Fermi, enquanto que à direita são apresentadas medidas próximas ao evento IceCube-170922A, por fim, a linha vertical em vermelho representa o dia exato do evento de neutrinos. Fonte: IceCube Collaboration, et al. (2018).

o blazar PKS 0502+049 estava em estado de flare, contudo, no momento do evento, TXS 0506+056 domina essa região do céu tanto na faixa de rádio quanto em altas energias. No entanto, apesar da separação angular entre os dois blazares ser de $1.2^{\circ}$ (Johnston et al., 1995), a resolução angular do IceCube em energias superiores a $30 \mathrm{TeV}$ é de $0.5^{\circ}$ Aartsen et al., 2017). Com isso, elimina-se a hipótese do PKS 0502+049 ser a fonte responsável pelo evento de neutrinos de 2017.

A detecção de neutrinos entre 2014-2015 foi estudada em Murase et al. (2018); Wang et al. (2018); Reimer et al. (2018); Rodrigues et al. (2019), porém, em nenhum dos trabalhos os autores conseguiram construir um cenário para o blazar de forma contundente e que pudesse explicar o excesso de neutrinos $(13 \pm 5)$ e a não existência de flares em raios- $\gamma$.

\subsubsection{Estudos da cinemática do jato em escalas de parsecs}

Nesta seção discutiremos os cenários cinemáticos construídos a partir de ajustes das componentes superluminais do jato de TXS 0506+056 disponíveis na literatura. 


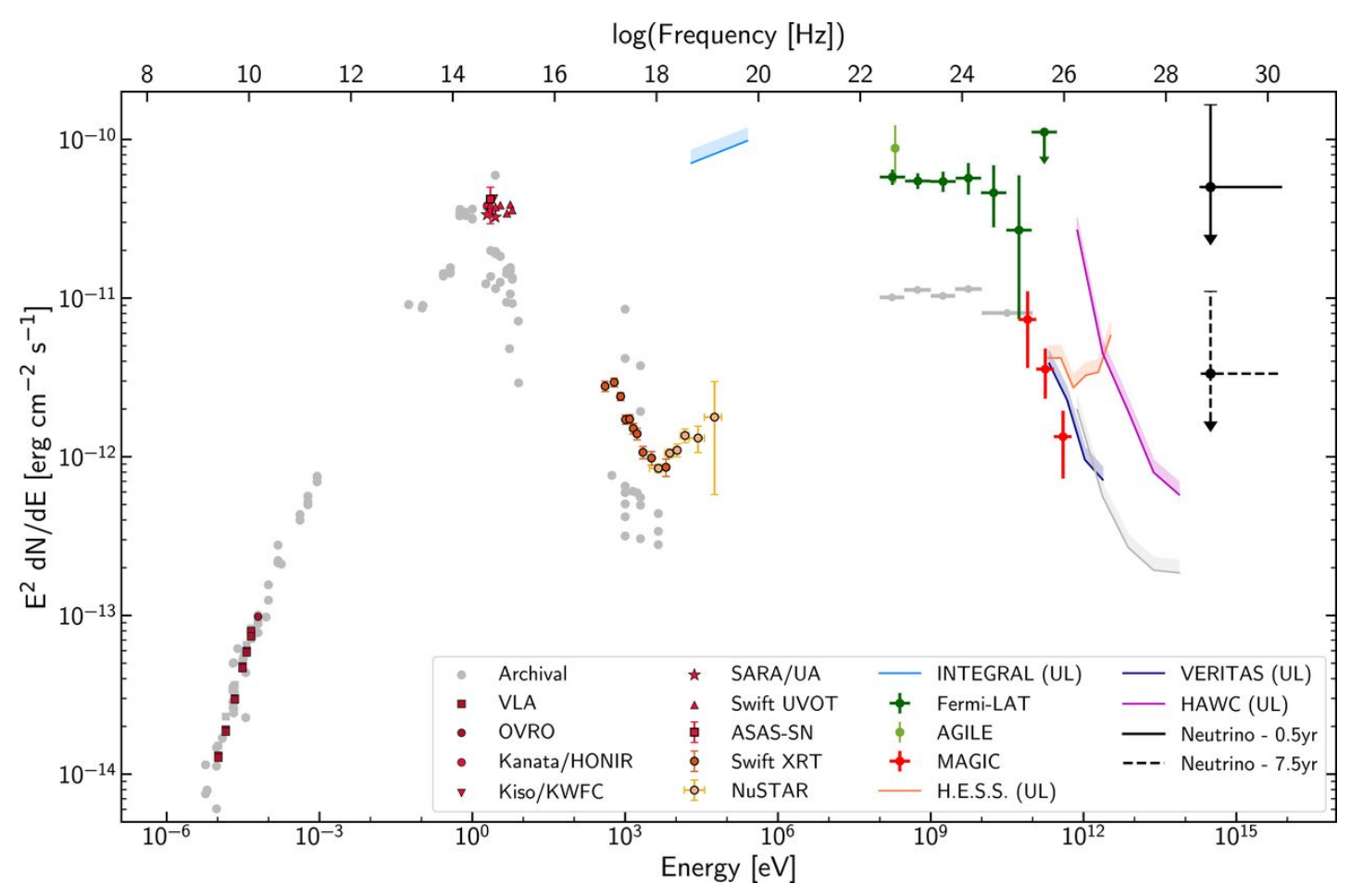

Figura 3.2: SED do blazar TXS 0506+056 obtida utilizando toda a base de dados (dados coloridos) disponível na literatura dentro de 14 dias após o evento IceCube-170922A, já os dados em cinza foram obtidos através de uma base histórica. As distribuições espectrais, obtidas em energias maiores que raios- $\gamma$, foram calculadas em períodos de 0.5 e 7.5 anos, e representam o evento mais energético conhecido para essa fonte, correspondendo a cerca de $290 \mathrm{TeV}$. Fonte: IceCube Collaboration, et al. (2018).

Através dos mapas interferométricos obtidos pelo programa MOJAVE (conforme citado no capítulo anterior) Lister et al. (2019) ajustaram gaussianas bidimensionais para as componentes do jato do blazar, e os resultados da separação das componentes com relação ao núcleo ao longo de 13 épocas distintas é apresentado na figura 3.3. Os triângulos no gráfico são componentes identificadas através método tradicional e têm suas velocidades calculadas através da inclinação das retas. No entanto, conforme citado anteriormente, o método tradicional de identificação de componentes pode apresentar componentes não robustas, estando estas apresentadas em círculos brancos e não sendo utilizadas na análise cinemática.

Os resultados cinemáticos de Lister et al. (2019) são apresentados na tabela 3.1. As retas ajustadas por Lister têm uma inclinação pequena, com isso, as velocidades aparentes das componentes são baixas, fazendo com que as componentes 1 e 3 não tenham sequer velocidades aparentemente superluminais, logo não foi possível inferir corretamente a data 
de ejeção das mesmas. Como sabe-se, blazares têm, em geral, o jato emitido em um ângulo pequeno com relação a linha de visada e devido a isso, as componentes do jato em escala de parsec apresentam velocidades aparentes acima da luz. Contudo, apesar de Lister et al. (2019) terem proposto o primeiro cenário cinemático para o jato de TXS 0506+056, os mesmos não analisaram toda a base de dados disponíveis no MOJAVE e sequer discutiram os resultados dos ajutes das retas neste artigo.

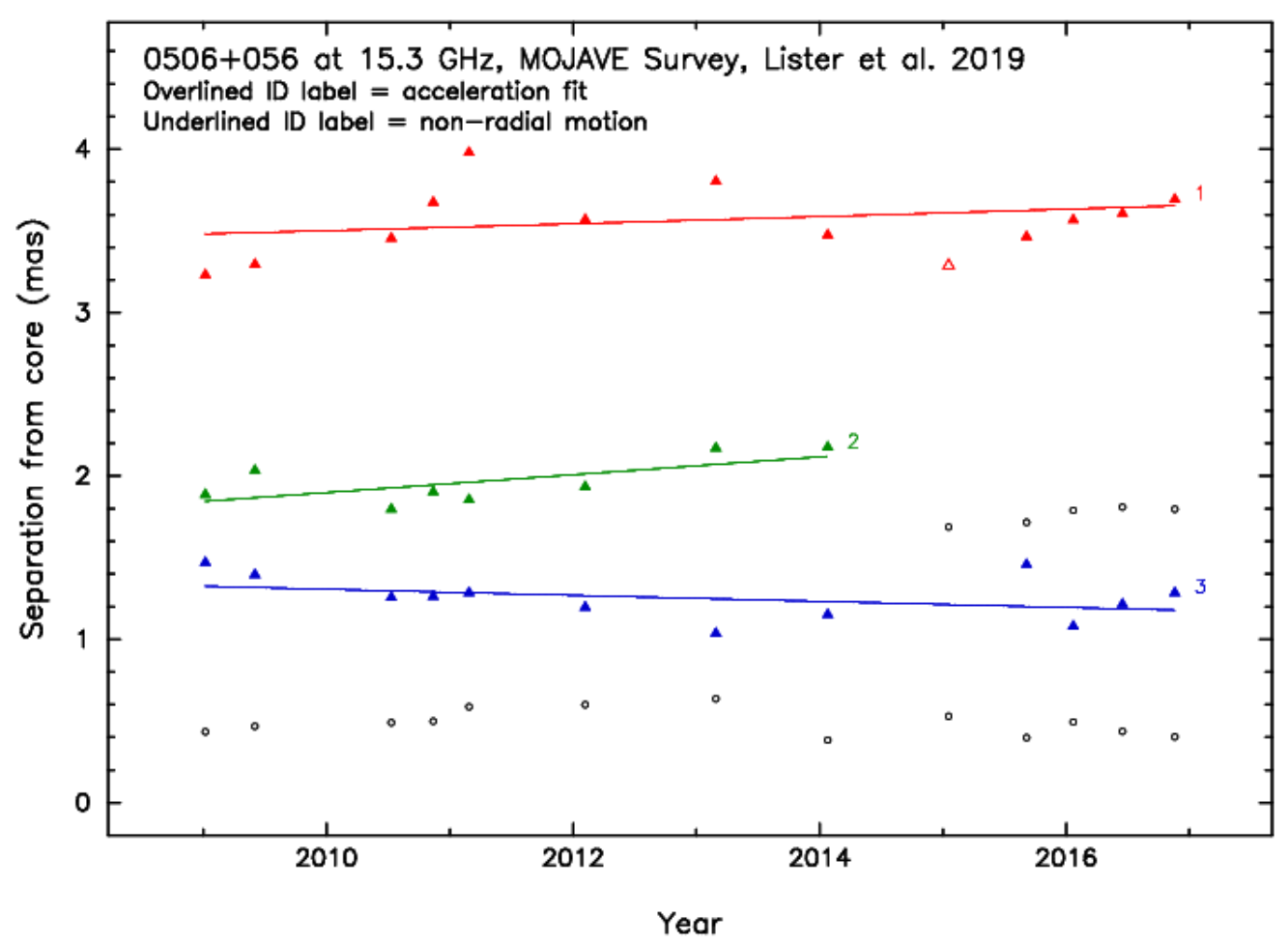

Figura 3.3: Separação das componentes dos jato de TXS 0506+056 ao longo de 13 épocas distintas obtidas entre 2009-2017, os triângulos correspondem a componentes identificadas pelo método tradicional e os círculos são componentes consideradas não robustas (vide seção do método tradicional no capítulo de Base de Dados). Fonte: Lister et al. (2019)

Tabela 3.1 - Propriedades da análise cinemática das componentes do jato do objeto TXS 0506+056. As colunas correspondem a Identificação da componente, época de observação, Densidade de fluxo em $15 \mathrm{Ghz}$, distância ao núcleo, ângulo de posição no plano do céu e a velocidade aparente da componente respectivamente.

\begin{tabular}{cccccc}
\hline \hline ID & Épocas & $I_{15 G H z}(\mathrm{mJy})$ & $\mathrm{r}(\mathrm{mas})$ & P.A. (graus) & Velocidade (c) \\
\hline $\begin{array}{l}\text { Componente } 1 \\
\text { Continua na próxima página... }\end{array}$ & 12 & 21 & 3.56 & 171.7 & $0.98 \pm 0.31$
\end{tabular}


Tabela 3.1 - Continuação

\begin{tabular}{lccccc}
\hline \hline ID da componente & Épocas & $I_{15 G H z}(\mathrm{mJy})$ & $\mathrm{r}$ (mas) & P.A. (graus) & Velocidade (c) \\
\hline \multirow{2}{*}{ Componente 2} & 8 & 49 & 1.97 & 187.8 & $1.19 \pm 0.57$ \\
Componente 3 & 12 & 14 & 1.25 & 216.0 & $0.40 \pm 0.29$ \\
\hline
\end{tabular}

A principal análise cinemática de TXS 0506+056 disponível na literatura foi realizada por Kun et al. (2019), os autores partiram dos dados de ajuste do Lister et al. (2019) e essencialmente reformularam o cenário de componentes para o jato, como é possível verificar na imagem 3.4. O gráfico também apresenta a configuração de separação do núcleo versus tempo, e acrescenta duas épocas posteriores disponibilizadas pelo MOJAVE. Contudo, as componentes anteriormente consideradas não-robustas são inseridas na análise das velocidades, como é o caso da componente C1. Além disso, a C3 teve componentes não-robustas inseridas em sua reta fazendo com que o ajuste apresentasse uma inclinação negativa. Diferentemente de Lister et al. (2019), os autores partindo da sugestão de Lister et al. (2009) (que assumiam uma incerteza na posição de $10 \%$ do tamanho da componente convoluído com o feixe), apresentam barras de erro para os ajustes da posição das componentes estimados através das equações (Kun et al., 2014):

$$
\begin{gathered}
\sigma_{x}=0.1 \cdot \sqrt{\theta_{x}^{2}+d^{2}} \\
\sigma_{x}=0.1 \cdot \sqrt{\theta_{x}^{2}+d^{2}},
\end{gathered}
$$

onde $\theta_{x}$ e $\theta_{y}$ representam a projeção de $x$ e $y$ do feixe e $d$ a largura a meia altura da componente gaussiana.

Na figura 3.4 é também possível verificar as velocidades de cada uma das componentes consideradas. As componentes $\mathrm{C} 1$ e $\mathrm{C} 2$ têm velocidades praticamente nulas, indicando um possível estado quase estacionário. Todavia, a componente C3 apresenta uma velocidade negativa o que sugere que a componente está indo em direção ao núcleo, isto é, regredindo. Por fim, a componente mais distante do núcleo, a $\mathrm{C} 4$, apresenta uma velocidade aparentemente positiva assinalando que está se movendo na direção contrária ao núcleo, como é esperado para todas as componentes em um jato de AGN em escalas de parsecs. Kun et al. (2019) sugere que a possível explicação para este cenário seria um movimento oscilatório para as componentes, similar ao que foi sugerido para o objeto S5 1803+784 (Britzen et al. 2010; Kun et al. 2018). 


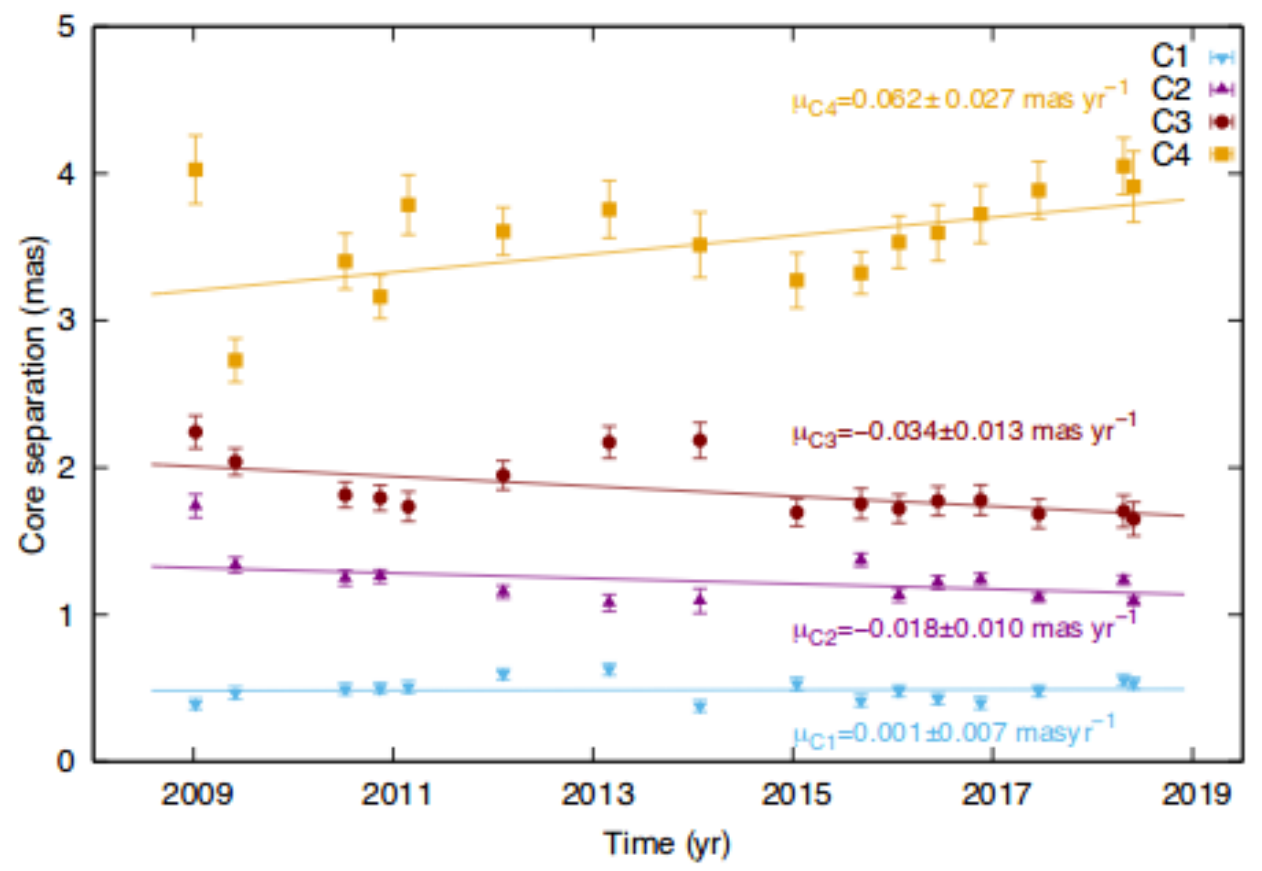

Figura 3.4: Separação das componentes C1, C2, C3 e C4 do jato de TXS 0506+056 ao longo de 15 épocas distintas obtidas entre 2009-2018. As linhas sólidas correspondem ao ajuste cinemático e suas inclinações correspondem ao movimento próprio aparente das componentes. Fonte: Kun et al. (2019).

Com os dados disponibilizados pelo MOJAVE, os ajustes das componentes de Lister et al. (2019) e dados de densidade de fluxo obtidos pela antena OVRO-40m em 15 GHz, Kun et al. (2019) calcularam a curva de luz do TXS 0506+056, conforme apresentado na figura 3.5. Os gráficos apresentados nesta figura indicam a variação da densidade de fluxo (Jy) ao longo do tempo. No painel superior são apresentados os dados interferométricos em $15 \mathrm{GHz}$ com os ajustes das componentes, enquanto no inferior estão os dados da antena de OVRO40m com demarcações de oito flares decompostos em gaussianas arbitrarias. As linhas verticais simbolizam as datas dos eventos de neutrinos, as duas primeiras correspondendo ao excesso entre 2014-2015 (IceCube Collaboration, et al., 2018), ao passo que a linha à direita refere-se ao evento IceCube-170922A (IceCube Collaboration, et al., 2018). A linha tracejada demarca o início da operação do IceCube Observatory. De acordo com os autores, o flare F7 coincide com o evento de neutrinos IC-170922A e ocorreu próximo ao núcleo do Blazar, sendo possível notar um aumento significativo da densidade do fluxo do núcleo com relação as demais componentes em épocas futuras. Pelo fato de ter havido um flare em raios- $\gamma$ neste mesmo período, possivelmente uma nova componente do jato está 
ainda dentro do núcleo e será observada no futuro, porém, esse resultado não condiz com o que foi apresentado e discutido em Kun et al. (2019) pois suas componentes, em maioria, ou estão retrocesso com relação ao núcleo ou não se movem ao longo das épocas.

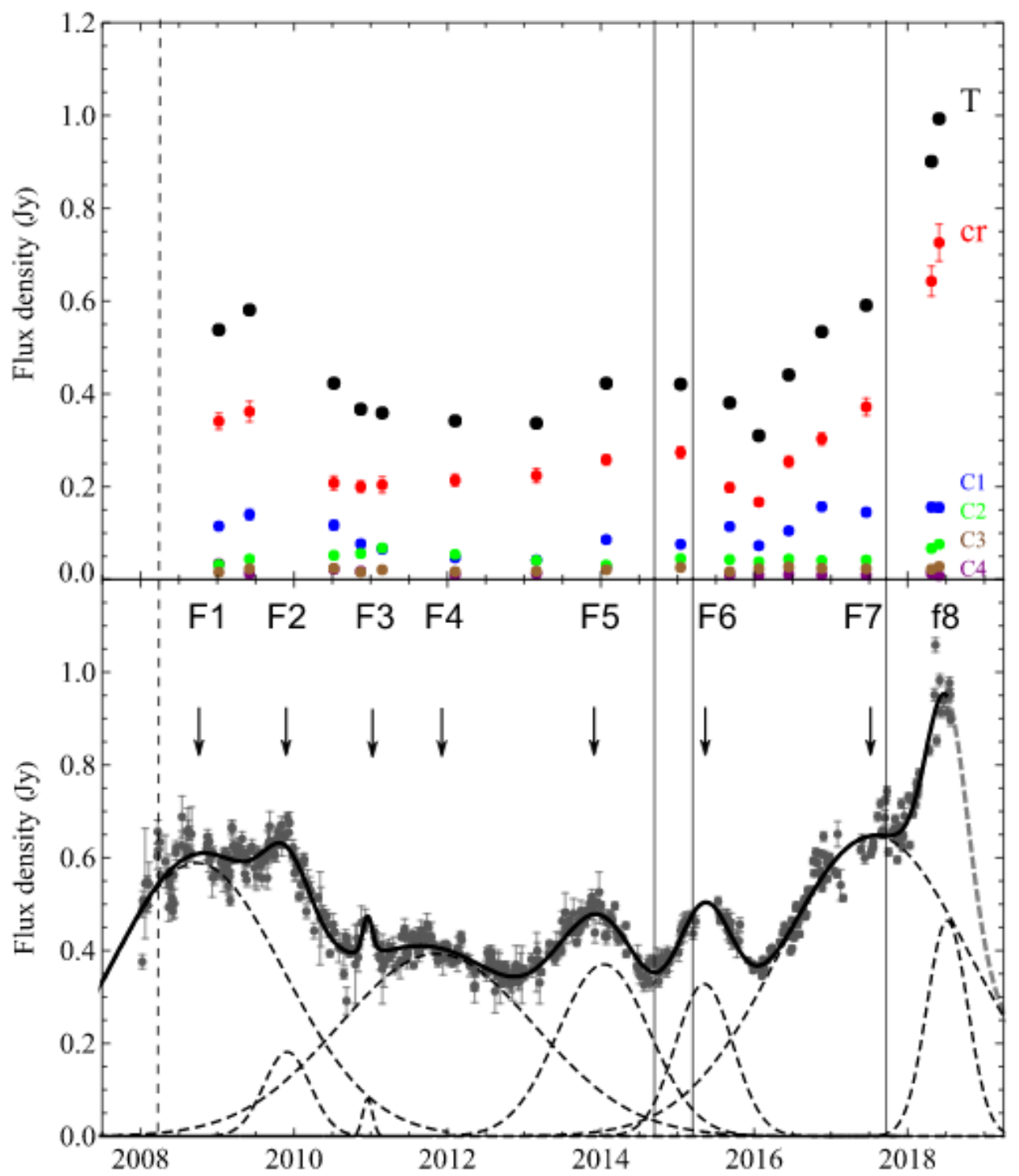

Figura 3.5: Densidade de fluxo em Jansky versus o tempo em anos. Painel superior: Dados de observações interferométricas (obtidos pelo VLBA/MOJAVE) e densidade de fluxo das componentes ajustadas bem como o núcleo. Painel inferior: densidade de fluxo observada com a antena OVRO-40m, os flares estão indicados com a letra 'F'. As linhas verticais indicam o excesso de neutrinos entre 2014-2015 e o evento de neutrinos IC-170922A. A linha tracejada especifica a data de início da operação do IceCube. Fonte: Kun et al. (2019). 
Capítulo 4

\section{Resultados e Discussão}

Neste capítulo será apresentado o processo de identificação de componentes do jato de TXS 0506+056 calculadas utilizando o algoritmo Cross-Entropy (seção 2.2.2) a partir de mapas interferométricos obtidos pelo VLBA em $15 \mathrm{GHz}$. Baseado nos parâmetros ajustados para as componentes, discutiremos os resultados de um novo cenário cinemático desenvolvido para o jato de TXS 0506+056. Em seguida, serão apresentados os resultados acerca da redução e análise dos dados em raios- $\gamma$ de TXS 0506+056 disponibilizados pelo Data Archive do Fermi-LAT com o objetivo de investigar a existência de uma correlação entre a variabilidade em raios- $\gamma$ e a ejeção de componentes do jato.

\subsection{Identificação de componentes do jato em escala de parsec}

Neste trabalho utilizamos 17 imagens de domínio público do blazar TXS 0506+056 para ajustar gaussianas elípticas bidimensionais às componentes do jato em escala de parsecs. Os mapas interferométricos foram disponibilizados pelo projeto MOJAVE e obtidas em $15 \mathrm{GHz}$ pelo VLBA, conforme citado no capítulo 2. Para modelar as componentes do jato utilizamos o método $\mathrm{CE}$, descrito na seção 2.2.2, no qual um número pré-definido de gaussianas elípticas é caracterizado pelos seguintes parâmetros: coordenadas centrais $x$ e $y$, respectivamente, em ascensão reta e declinação; semi-eixo maior (a) da elipse não convoluída; excentricidade da elipse $(\epsilon)$; inclinação da componente, e finalmente, a intensidade central $\left(I_{0}\right)$ da gaussiana.

Os mapas disponibilizados pelo MOJAVE apresentam tamanhos de $1024 \times 1024$ ou $512 \times 512$ pixeis $(1$ pixel $=0.1$ mas $)$, mas apenas uma fração da região apresenta sinal da fonte, por esse motivo, selecionamos uma porção em todas as imagens de tamanho 
$80 \times 110$ para diminuir o tempo de processamento. Inicialmente, no algoritmo do CE foram ajustadas imagens com um número de componentes entre $3 \leq N_{s} \leq 6$, seus parâmetros foram calculados dentro dos limites superior e inferior sugeridos pelo usuário, apresentados a seguir. Em todas às épocas, os intervalos de valores para os parâmetros das gaussianas foram: $0.00001 \leq a \leq 18$ em pixeis, com o limite inferior correspondendo a uma fonte pontual; $0.0001 \leq \epsilon \leq 0.1 ; 2 \times r m s \leq S_{\text {componente }} \leq S_{\text {max }}$, rms e $S_{\text {max }}$ são dados da imagem dados em $J y \cdot$ beam $^{-1}$, que podem ser verificados na tabela 2.1 ; e $-89.9 \leq$ P.A. $\leq 89.9$.

Ao modelar as imagens de uma época variando o número de componentes $N_{s}$, obtém-se valores de $S_{\text {prod }}$ (equação 2.10) e os respectivos mapas de resíduos. A priori, o ajuste com o menor valor da função de mérito $S_{\text {prod }}$ corresponderia ao melhor ajuste, entretanto, conforme aumenta-se o número de componentes, o valor de $S_{\text {prod }}$ mantém-se da mesma ordem e, com isso, é possível determinar o número mínimo de gaussianas necessárias para descrever as componentes do jato. Ao selecionar os melhores ajustes, neste trabalho, utilizamos como principais critérios a análise dos mapas de resíduos e a função de mérito. A análise dos mapas de resíduos foi realizada variando o número de componentes e averiguando qual dos ajustes apresentava regiões com resíduos melhor comportados. Contudo, como a disposição das antenas não é a mesma em todas as épocas de observação, a cobertura do plano $(\mathrm{u}, \mathrm{v})$ acaba sendo variável, em cada mapa os resíduos são diferentes. Outra forma de certificar-se da qualidade do ajuste é através do acompanhamento de componentes ao longo do tempo.

Após diversos testes, notamos que a quantidade mínima de componentes para que os ajustes apresentassem resultados satisfatórios era 5 (core +4 componentes), enquanto que $N_{s}>6$ corresponde a uma quantidade além da necessária para descrever o jato, isto é, ao ajustar um número de componentes acima do necessário, o CE insere uma gaussiana, com baixa densidade de fluxo, sobreposta as demais (Caproni et al., 2014). Na tabela 4.1 apresentamos o melhor número de componentes para cada época modelada, bem como seus respectivos $S_{\text {prod }}$. 
Tabela 4.1 - Número de gaussianas elípticas que melhor descreviam os dados em cada época, bem como os valores de suas funções de performance. A tabela está organizada seguindo: data, número de fontes, e a função de mérito do ajuste.

\begin{tabular}{|c|c|c|}
\hline Época & $N_{s}$ & $S_{\text {prod }} \cdot 10^{-5}\left(\right.$ Jy $^{6}$ beam $\left.^{-6}\right)$ \\
\hline $22 / 07 / 2019$ & 6 & $(3.73574 \pm 0.00034)$ \\
\hline 03/06/2009 & 6 & $(3.60940 \pm 0.00012)$ \\
\hline $12 / 07 / 2010$ & 6 & $(50.2 \pm 2.4)$ \\
\hline $13 / 11 / 2010$ & 5 & $(3.75271 \pm 0.00084)$ \\
\hline $27 / 02 / 2011$ & 6 & $(3.904 \pm 0.013)$ \\
\hline $06 / 02 / 2012$ & 6 & $(3.89115 \pm 0.00081)$ \\
\hline $28 / 02 / 2013$ & 6 & $(2.9881 \pm 0.00093)$ \\
\hline $25 / 01 / 2014$ & 6 & $(3.8552 \pm 0.00034)$ \\
\hline $18 / 01 / 2015$ & 6 & $(5.4210 \pm 0.0016)$ \\
\hline $06 / 09 / 2015$ & 5 & $(4.850 \pm 0.039)$ \\
\hline $22 / 01 / 2016$ & 5 & $(3.4806 \pm 0.0018)$ \\
\hline $16 / 06 / 2016$ & 5 & $(4.2048 \pm 0.0031)$ \\
\hline $18 / 11 / 2016$ & 6 & $(3.8385 \pm 0.0031)$ \\
\hline $17 / 06 / 2017$ & 6 & $(3.11682 \pm 0.00012)$ \\
\hline $22 / 04 / 2018$ & 6 & $(5.60638 \pm 0.00013)$ \\
\hline $31 / 05 / 2018$ & 5 & $(9.4516 \pm 0.0020)$ \\
\hline $16 / 12 / 2018$ & 5 & $(7.8992 \pm 0.0051)$ \\
\hline
\end{tabular}

Na figura A.5, apresentamos um exemplo das imagens observadas com as gaussianas elípticas ajustadas em vermelho na coluna da esquerda e os resíduos à direita. Tanto os resíduos negativos quanto os positivos são apresentados em contornos brancos com valores mínimo e máximo iguais em valor absoluto, os contornos representam, portanto, divisões iguais entre os limites máximo e mínimo dos resíduos. As demais imagens são apresentadas no apêndice A. Como citado anteriormente, um dos critérios de identificação de componentes é a detecção continuada das mesmas, no entanto, há dois fatores que podem influenciar na continuidade de detecção: épocas de observação muito espaçadas, e a densidade de fluxo da componente atingir valores próximos ao limite de detecção dos receptores. Para o caso de TXS 0506+056, no projeto MOJAVE, a maioria das datas de observação apresentam pelo menos 1 ano entre uma época e outra, por esse motivo, ao ajustar as componentes do jato, as mesmas aparentam não se mover ao longo do tempo com relação ao núcleo, conforme reportado por Lister et al. (2019) e Kun et al. (2019), porém esse fator pode não se dever ao fato de as componentes serem estacionários e sim 
ao fato de o tempo de ejeção ser comparável ao tempo entre as observações.
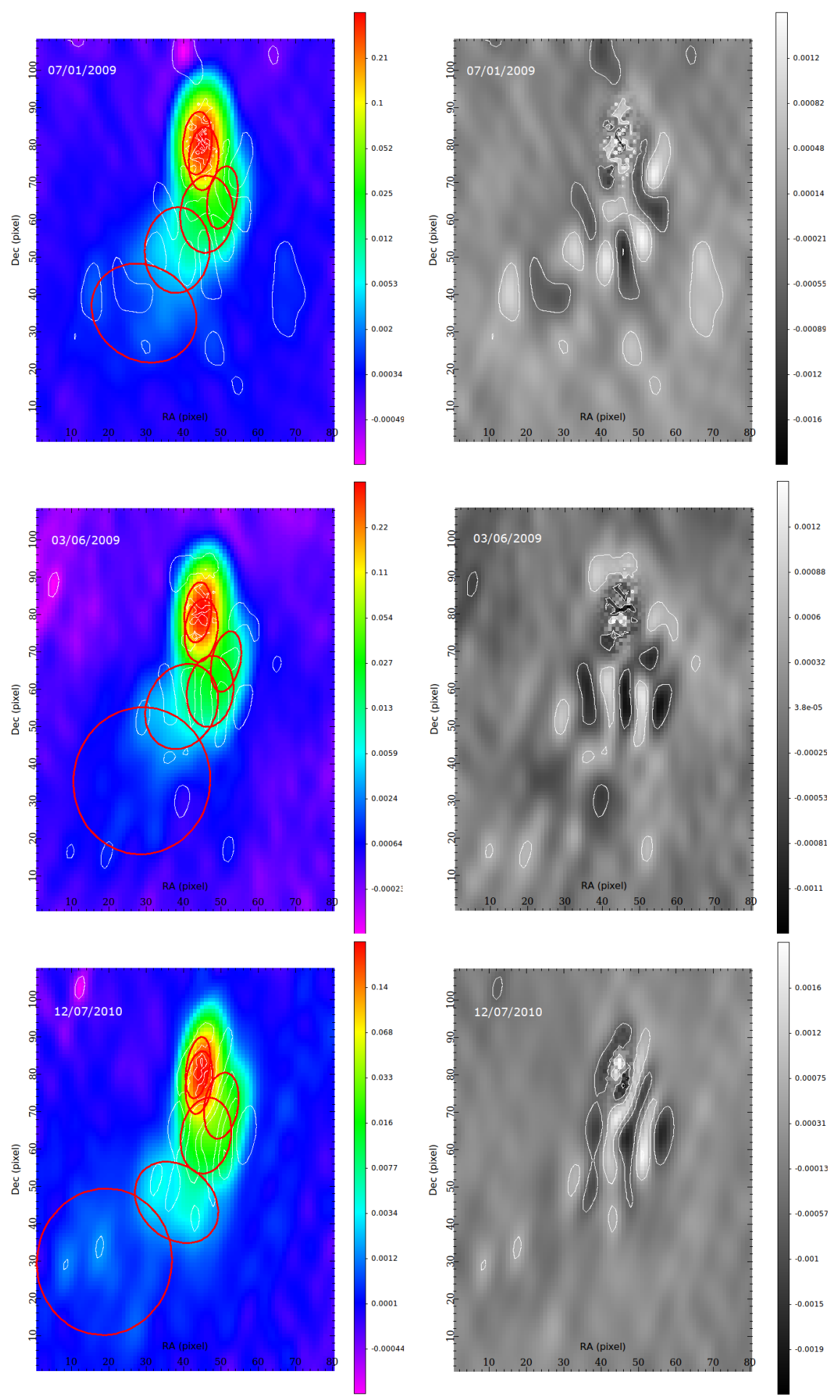

Figura 4.1: Painéis à esquerda: ajustes do CE nos mapas em $15 \mathrm{GHz}$ obtidos em 3 épocas (28/02/2013, 25/01/2014 e 18/01/2015), as elipses em vermelho representam as gaussianas ajustadas, os contornos em branco são relativos aos resíduos positivos e negativos do ajuste, a escala de cores representa a densidade de fluxo em Jy/beam em escala logarítmica. Painéis à direita: imagem de resíduos provenientes do ajuste do $\mathrm{CE}$, são apresentados dois contornos positivos e negativos, de mesmo módulo, para cada data, com as escalas de cores lineares. 


\subsubsection{Cálculo da distância ao núcleo, densidade de fluxo e ângulo de posição no céu}

A partir dos dados obtidos através do CE, pode-se calcular a distância de cada componente com relação ao núcleo para cada época, bem como suas densidade de fluxo e seus ângulos de posição no plano do céu. Os cálculos foram realizados através das equações (Caproni et al., 2011):

$$
\begin{gathered}
r(\text { mas })=\sqrt{\left(x_{c}-x_{\text {nucleo }}\right)^{2}+\left(y_{c}-y_{\text {nucleo }}\right)^{2}}, \\
F(J y)=8 \cdot \ln (2)\left(\frac{a^{2} \sqrt{1-\epsilon^{2}}}{a_{M A J} \cdot a_{M I N}}\right) I_{0}, \\
\eta(\text { graus })=\arctan \left(\frac{y_{c}-y_{\text {nucleo }}}{x_{c}-x_{\text {nucleo }}}\right) .
\end{gathered}
$$

Onde $x_{c}$ e $y_{c}$ são as coordenadas centrais de cada componente em ascensão reta e declinação, enquanto que $x_{n u c l e o}$ e $y_{\text {nucleo }}$ são as coordenadas relativas à gaussiana correspondente ao núcleo do blazar. As variáveis $a, \epsilon$ e $I_{0}$ correspondem respectivamente ao semi-eixo maior não convoluído, excentricidade e intensidade central das componentes (Jy/beam), todos calculados pelo algoritmo do CE. Todavia, os valores de $a_{M A J}$ e $a_{M I N}$ são as dimensões do feixe da observação em cada data e foram reportados na tabela 2.1.

Ao longo do período disponível, foram identificadas cerca de 12 componentes para descrever o jato do blazar TXS 0506+056, a identificação ocorreu através do comportamento de suas densidade de fluxo ao longo das épocas e a constância em seus ângulos de posição medidos considerando apenas ajustes a uma distância máxima (com relação ao núcleo) de 1.8 mas. As componentes foram nomeadas como C1, C2, C3, C4, C5, C6, C7, C8, C9, C10, C11 e C12, em ordem de ejeção. Seus parâmetros ao longo das épocas foram calculados e são apresentados na tabela do apêndice B. Nesta tabela, apresentamos a época da observação, a identificação das componentes, semi-eixo maior, (mas), a distância ao núcleo (mas), sua densidade de fluxo (Jy), e por fim, seus respectivos ângulos de posição.

As incertezas nos parâmetros estruturais podem ser calculadas de diversas maneiras, Lister et al. (2009) por exemplo, sugerem que as incertezas em $x_{c}$ e $y_{c}$ sejam, respectivamente da ordem de $10 \%$ e $30 \%$ do tamanho da componente convoluída com o feixe, conforme citado na seção 3.1.2. A dificuldade na estimativa das incertezas é oriunda principalmente do ruído, proximidade entre as componentes e de dependências não-lineares causadas pela cobertura do plano $(\mathrm{u}, \mathrm{v})$. Neste trabalho, as incertezas em cada parâmetro 
foram calculadas realizando 4 ajustes extras distintos, com o mesmo número $N_{s}$ em cada época, e truncados da mesma forma que o original. Com isso, obtivemos o desvio padrão dos parâmetros de cada componente identificada, e portanto, os valores das incertezas não foram subestimados. Os demais parâmetros que não provinham diretamente do ajuste tiveram seus erros calculados a partir de propagação de incerteza.

A curva de luz em 15 GHz obtida entre Julho de 2009 e Dezembro de 2018 calculada a partir dos ajustes do CE é mostrada na figura 4.2. A densidade de fluxo total, soma do núcleo às demais componentes identificadas é apresentada em triângulos cinzas, enquanto que a densidade apenas do núcleo é tratada pelos círculos. É possível verificar um aumento tanto do núcleo como do total na densidade de fluxo a partir de $J D \sim 7500$ (Abril de 2016), esse comportamento pode ser notado também na curva de luz em raios- $\gamma$ (figura 4.14, indicando um período de alta atividade do blazar conforme reportado por Padovani et al. (2018) e IceCube Collaboration, et al. (2018). O comportamento da densidade de fluxo total e do núcleo obtidos em $15 \mathrm{GHz}$ por Kun et al. (2019) é semelhante ao obtido neste trabalho. Em ambos os casos, o evento de neutrinos (IC-170922A) não representa um pico na densidade de fluxo em $15 \mathrm{GHz}$, isto é, se a emissão de neutrinos ocorreu no núcleo concomitantemente à formação de uma componente do jato, possivelmente essa componente poderia ser detectada em épocas posteriores. Ainda assim, o aumento da densidade de fluxo do núcleo ao longo do tempo pode indiciar que uma ou mais componentes ainda estão próximas o suficiente dele a ponto de não ser possível identificá-las.

\subsubsection{Cinemática do jato de TXS 0506+056}

A análise da cinemática das componentes em escalas de parsecs primeiro necessita que essas sejam identificadas ao longo de sucessivas épocas de observação. O processo de identificação de componentes foi realizado estudando-se a evolução temporal da densidade de fluxo e do ângulo de posição, bem como suas distâncias relativas ao núcleo. Com isso, desenvolvemos o cenário cinemático deste trabalho, apresentado na figura 4.3. As 12 componentes identificadas são apresentadas em cores e símbolos diferentes, enquanto que os círculos brancos são componentes não identificadas (geralmente pouco intensas). As linhas verticais em amarelo foram demarcadas a partir da presença de flares na curva de luz em raios- $\gamma$ apresentada na figura 4.14, enquanto que as vermelhas tracejadas correspondem, respectivamente, ao excesso de neutrinos (IceCube Collaboration, et al., 2018) e ao evento 


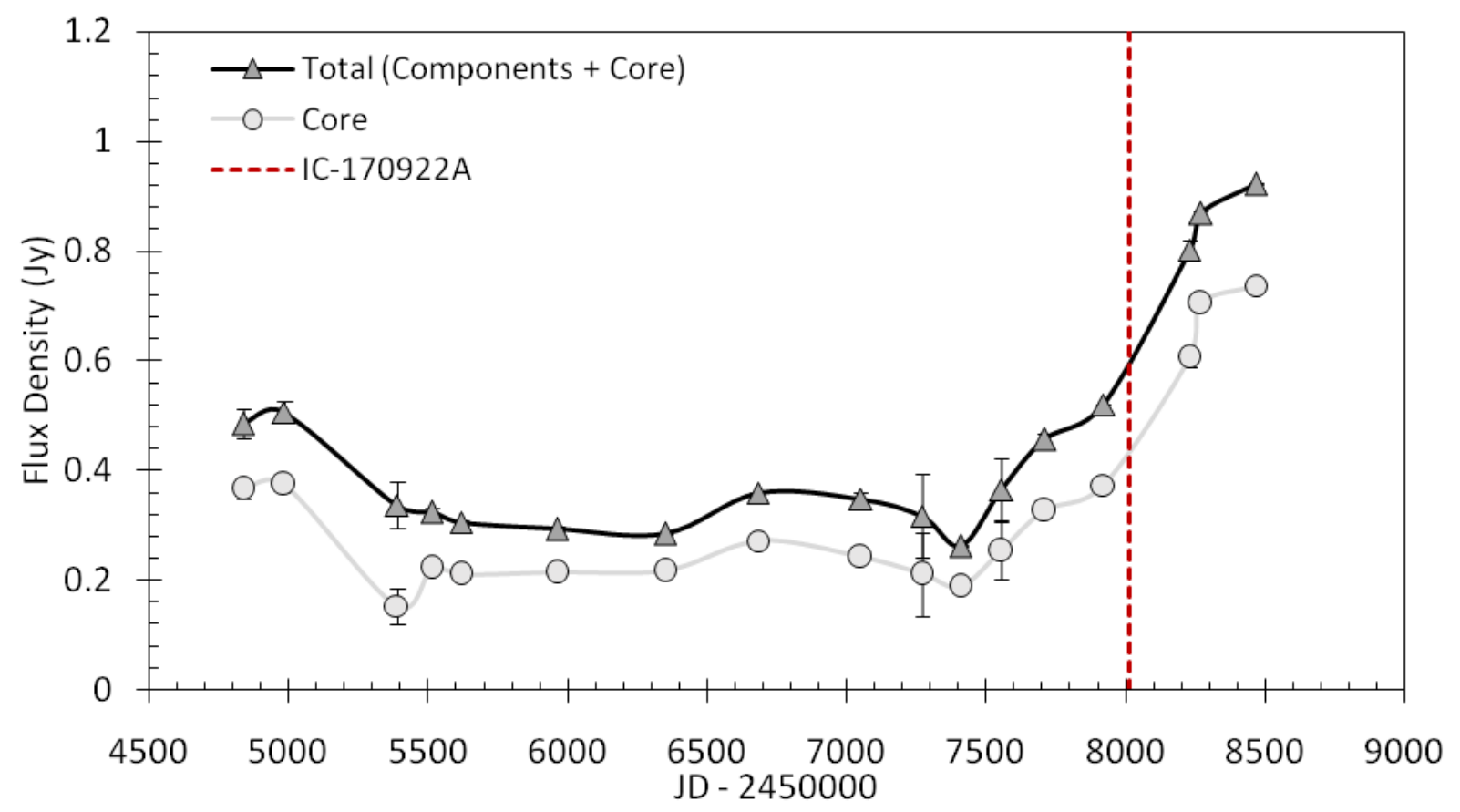

Figura 4.2: Curva de luz em $15 \mathrm{GHz}$ do blazar TXS 0506+056 obtida através de ajustes de componentes pelo CE. Os triângulos em cinza escuro representam a densidade de fluxo total (núcleo mais componentes distintas), enquanto que os círculos em cinza claro correspondem a densidade de fluxo do núcleo apenas. As barras de erro foram calculadas a partir do desvio padrão de múltiplos ajustes distintos.

IC-170922A (IceCube Collaboration, et al., 2018). As retas pretas sólidas foram calculadas assumindo que as componentes seguem trajetórias balísticas, e a partir de um ajuste linear pode-se estimar a velocidade aparente $\beta_{a p}$ (em unidades de velocidade da luz) e a data de ejeção de cada componente.

Observa-se na figura 4.3, que nenhuma componente foi considerada em $r>2.2$ mas, isso deve-se ao fato de as componentes apresentarem um desvio de uma trajetória balística a partir dessa distância, possivelmente por conta da interação com o meio interestelar. Os valores de $\beta_{a p}$, ângulo de posição médio e data de ejeção são apresentados na tabela 4.2 . As velocidades superluminais apresentam uma variação de $10.1 c \leq \beta_{a p} \leq 19.6 c$, sendo C9 a componente com a maior velocidade aparente, e $\mathrm{C} 4$ a menor. 


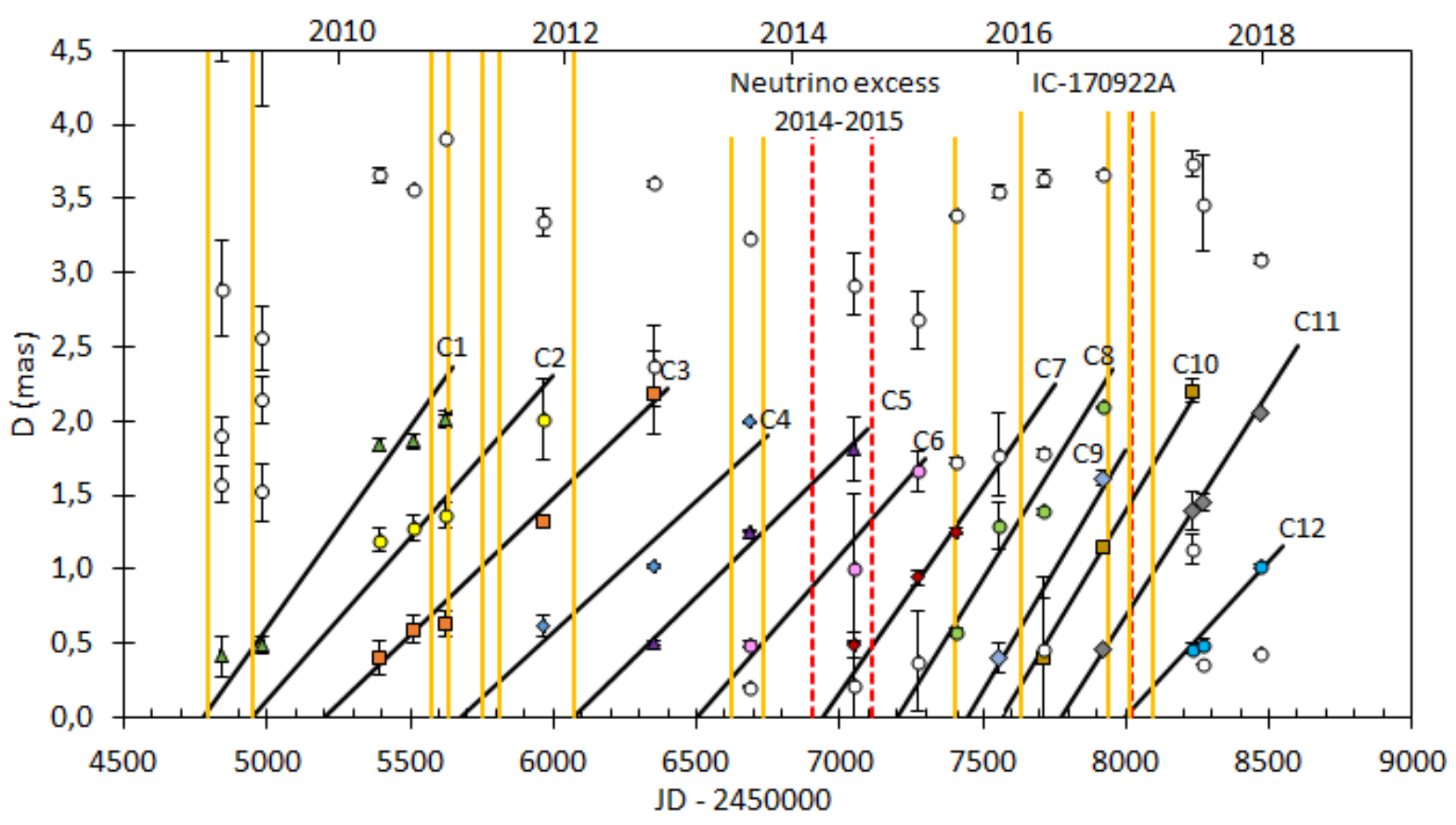

Figura 4.3: Nesta imagem apresentamos a distância das componentes com relação ao núcleo como função das épocas de observação. Ao todo são 12 componentes identificadas em cores e símbolos distintos. As linhas sólidas pretas tratam do ajuste para o movimento de cada componente, enquanto que as linhas em amarelo escuro correspondem aos flares em raios- $\gamma$ obtidos através da curva de luz da figura 4.14. As linhas tracejadas verticais demarcam os eventos de neutrinos citados pela colaboração do IceCube.

Tabela 4.2 - Propriedades da análise cinemática das componentes do jato de TXS 0506+056. As colunas correspondem a identificação da componente, época de ejeção, ângulo de posição médio no plano do céu e a velocidade aparente da componente respectivamente.

\begin{tabular}{lccc}
\hline \hline & & & \\
ID & Ejeção (JD - 2450000) & P.A. (graus) & $\beta_{a p}(\mathrm{c})$ \\
\hline $\mathrm{C} 1$ & 4775 & $-81.7 \pm 4.3$ & $14.3 \pm 0.54$ \\
$\mathrm{C} 2$ & 4950 & $-57.7 \pm 2.17$ & $12.5 \pm 2.1$ \\
$\mathrm{C} 3$ & 5200 & $-61 \pm 11$ & $10.5 \pm 0.72$ \\
$\mathrm{C} 4$ & 5680 & $-68.1 \pm 1.7$ & $10.1 \pm 0.23$ \\
$\mathrm{C} 5$ & 6070 & $-79 \pm 14$ & $10.8 \pm 0.35$ \\
$\mathrm{C} 6$ & 6500 & $-78 \pm 21$ & $12.4 \pm 1.4$ \\
$\mathrm{C} 7$ & 6940 & $-80.3 \pm 1.9$ & $15.8 \pm 1.3$ \\
$\mathrm{C} 8$ & 7200 & $-77.5 \pm 9.9$ & $17.8 \pm 0.33$ \\
$\mathrm{C} 9$ & 7450 & $-93.0 \pm 2.6$ & $18.6 \pm 1.7$ \\
$\mathrm{C} 10$ & 7570 & $-73.2 \pm 4.8$ & $18.4 \pm 1.4$ \\
$\mathrm{C} 11$ & 7772 & $-81.6 \pm 5.9$ & $17.2 \pm 0.11$ \\
$\mathrm{C} 12$ & 8000 & $-94.4 \pm 1.02$ & $11.9 \pm 0.69$ \\
& & & \\
\hline
\end{tabular}


Para verificar a relação entre os valores de velocidade aparente e as datas de ejeção das componentes, produzimos o gráfico da figura 4.4. As velocidades aparentes apresentam comportamento senoidal com relação as suas datas de ejeção, no entanto, apenas um período pode ser observado com os dados utilizados, e para verificar que de fato as componentes do jato seguem um movimento periódico seria necessário uma maior quantidade de componentes a serem detectadas no futuro. As incertezas na velocidade foram calculadas a partir de simples propagação de incerteza a partir do erro da inclinação da reta.

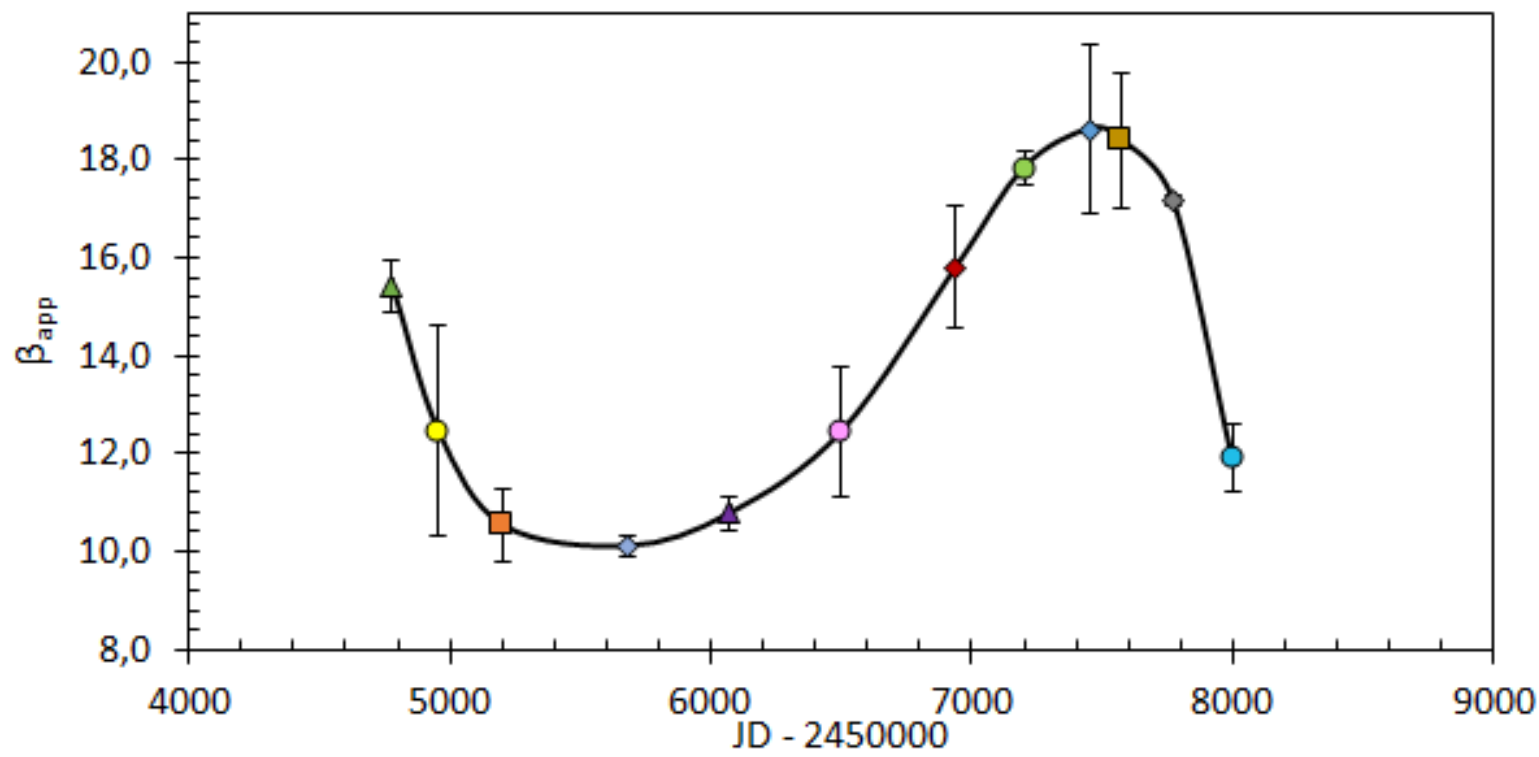

Figura 4.4: Neste gráfico são apresentas as velocidades aparentes em velocidades da luz como função da data de ejeção das componentes detectadas pelo CE em dias julianos.

As componentes superluminais nas imagens de VLBI, em geral, são interpretadas como ondas de choque que se propagam ao longo do jato do blazar (Marscher e Gear, 1985). Conforme a região vai se expandindo adiabaticamente, ela torna-se transparente, isto é, opticamente fina atingindo a densidade de fluxo máxima, após este momento a densidade de fluxo decresce até não ser mais detectada. Enquanto a componente é opticamente espessa em ondas de rádio, e próxima ao núcleo, ela pode apresentar uma intensa emissão em altas energias devido principalmente ao efeito Compton Inverso, portanto, seria esperada uma correlação entre as datas de ejeção das componentes detectadas em rádio e os flares em raios- $\gamma$, esse resultado é apresentado na figura 4.5. Como é possível verificar no ajuste, encontramos essa correlação em sete das doze componentes com um atraso médio de aproximadamente 28 dias entre a ejeção da componente e o flare em raios- $\gamma$. 


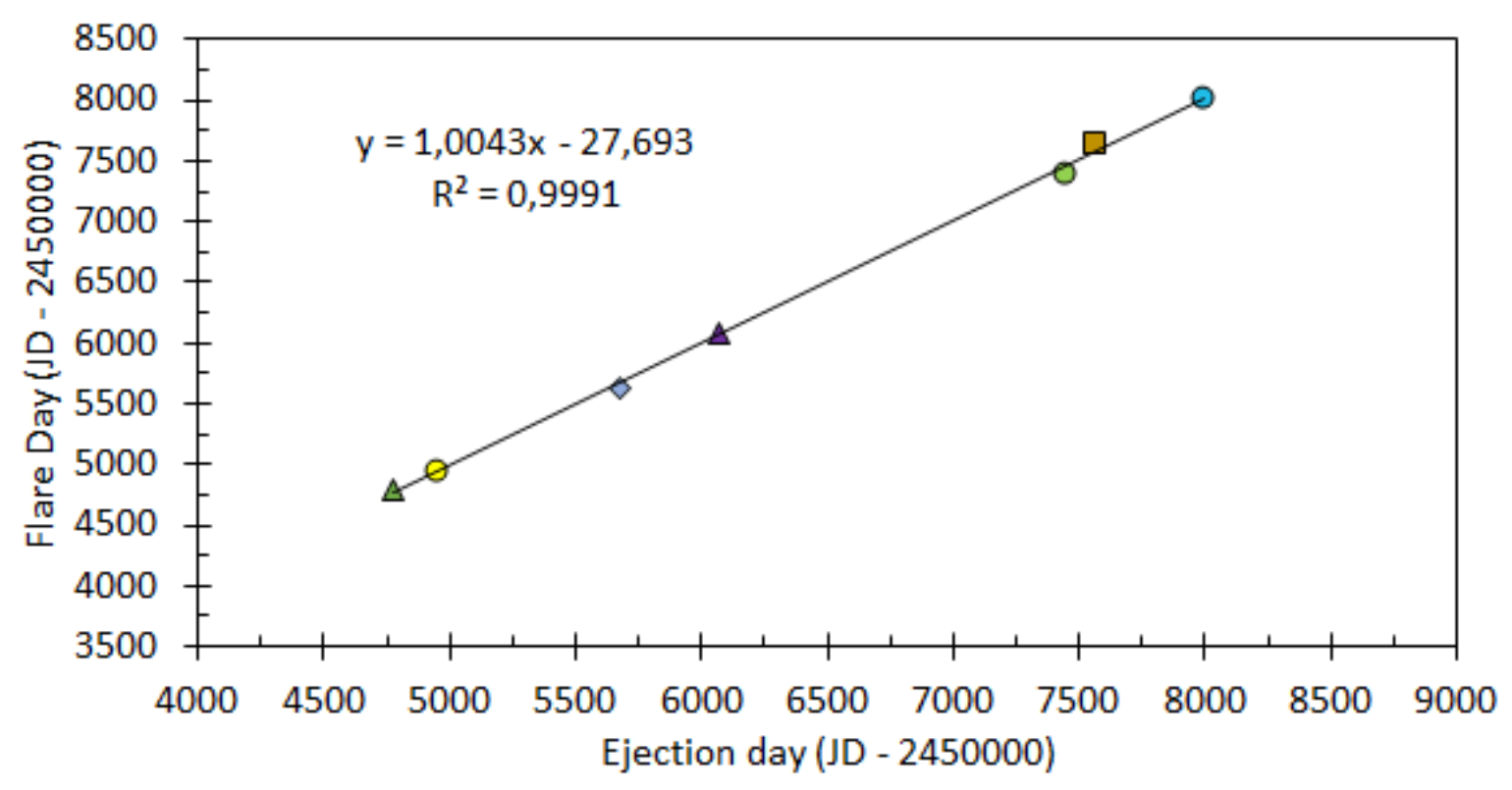

Figura 4.5: Neste gráfico são apresentas as datas de ejeção (em dias) de componentes como função da datas de flares (dias) em raios- $\gamma$. É possível verificar essa correlação em 7 das 12 componentes detectadas.

A densidade de fluxo de cada componente ao longo das épocas é reportada na figura 4.6. Apenas a componente $\mathrm{C} 1$ apresenta o comportamento citado acima, onde a densidade de fluxo inicialmente aumenta, atinge o máximo e após diminui. Como é possível verificar, as demais componentes são detectadas com uma densidade de fluxo apenas decrescente ao longo das épocas, essa característica foi reportada também por Savolainen et al. (2002) em 27 distintos AGNs. Segundo os autores, considerando que as componentes são ondas de choque, é possível que elas se desenvolvam de forma rápida enquanto estão próximas ao núcleo, e ao passarem a ser detectadas em $15 \mathrm{GHz}$ são encontradas em estados mais evoluídos, e portanto, apresentam apenas um decréscimo na densidade de fluxo. Esse comportamento pode também justificar o aumento da densidade de fluxo tanto do núcleo quanto no total (núcleo + componentes) que reportamos na figura 4.2 .

Na figura 4.6 é também possível observar que a partir da data $J D \sim 7500$, houve um aumento na densidade de fluxo inicial das componentes subsequentes, pode-se observar inclusive na figura $4.2 \mathrm{um}$ aumento na diferença entre a densidade de fluxo do núcleo para a total nessas épocas. Além do mais, nesse mesmo período as duas componentes com maior velocidade aparente detectas (C9 e C10) surgem nos mapas.

Estudamos a posição, tanto em RA quanto em Dec, com relação ao núcleo de cada 


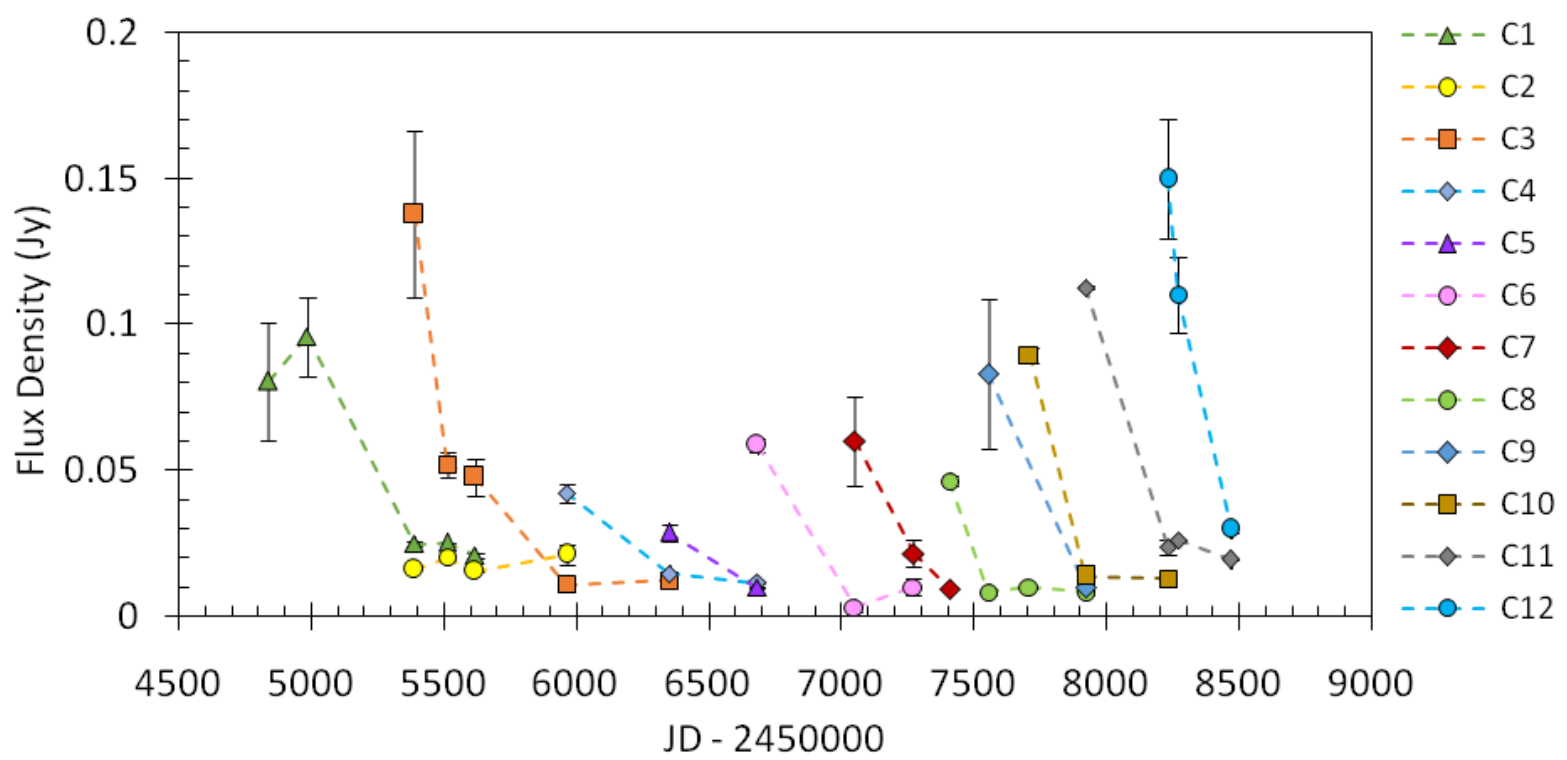

Figura 4.6: Neste gráfico são apresentas a densidade de fluxo (Jy) de cada componente ajustada pelo CE ao longo do tempo (em dias). As barras de erro foram calculadas através do desvio padrão de diversos ajustes distintos.

componente ao longo de cada época onde ela foi detectada, e apresentamos o resultado na figura 4.7. O ponto $(0,0)$ corresponde exatamente a posição da gaussiana ajustada para o núcleo, e por esse motivo as retas ajustadas foram forçadas a passar pelo $(0,0)$. Em geral, quando uma componente estava suficientemente distante do núcleo, elas passavam a apresentar tamanhos maiores, por conta de sua própria expansão, e por este motivo tornase mais difícil para o CE determinar com precisão as coordenadas centrais da gaussiana. Portanto, as componentes que apresentavam um semi-eixo maior grande, ou que estavam muito distantes do núcleo foram ignoradas nesta análise.

A partir da inclinação das retas apresentadas na figura 4.7, foi possível computar o ângulo de posição de cada componente no plano do céu. Com o intuito de prosseguir na busca por um movimento periódico nas componentes do jato, de forma similar ao período encontrado na velocidade aparente (figura 4.4), plotamos o ângulo de posição de cada componente versus data de ejeção da mesma na figura 4.8. É possível notar uma diminuição nos ângulos de posição das componentes ao longo do tempo, entretanto, não parece haver uma relação com a velocidade aparente como era de se esperar, com base no modelo de precessão proposto por Abraham e Carrara (1998). A dificuldade na obtenção de ângulos de posição, tanto quanto no acompanhamento de componentes, tornou-se grande pois as épocas de observação foram bastante espaçadas, chegando a mais de um ano em 


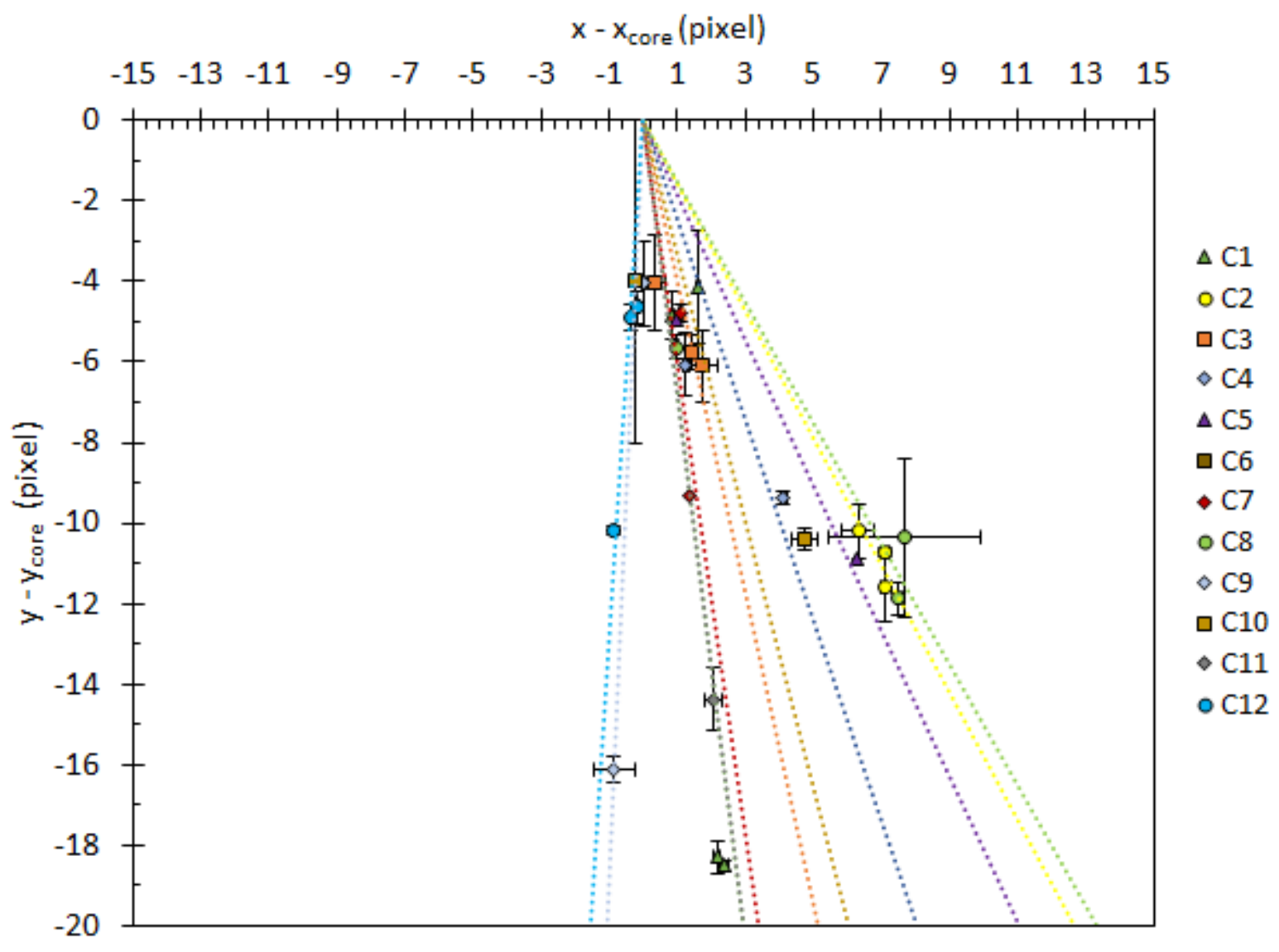

Figura 4.7: Neste gráfico são demonstradas as posições $y-y_{\text {core }}$ (pixel) como função das posições $x-x_{\text {core }}$ (pixel) de cada componente ao longo das épocas, com $y_{\text {core }}$ e $x_{\text {core }}$ sendo a posição $y$ e $x$ da elipse ajustada núcleo, respectivamente.

alguns casos, e algumas imagens apresentaram pouca cobertura do plano $(\mathrm{u}, \mathrm{v})$ de forma que o acompanhamento das componentes que vinham sendo ajustadas foi prejudicado. Devido ao alto interesse em se estudar os fenômenos físicos do blazar TXS 0506+056, possivelmente esse panorama será mudado pela equipe do MOJAVE.

Por fim, o principal objetivo deste trabalho era buscar indícios de um movimento de precessão no jato de TXS 0506+056, alguns dos indicativos costumam ser o movimento periódico das velocidades aparentes, bem como nos ângulos de posição das componentes. Como citado anteriormente, apesar dos $\beta_{a p}$ serem um indicador de precessão, em geral, eles devem ser associados a uma variação também nos ângulos de posição, o que não ocorreu. 


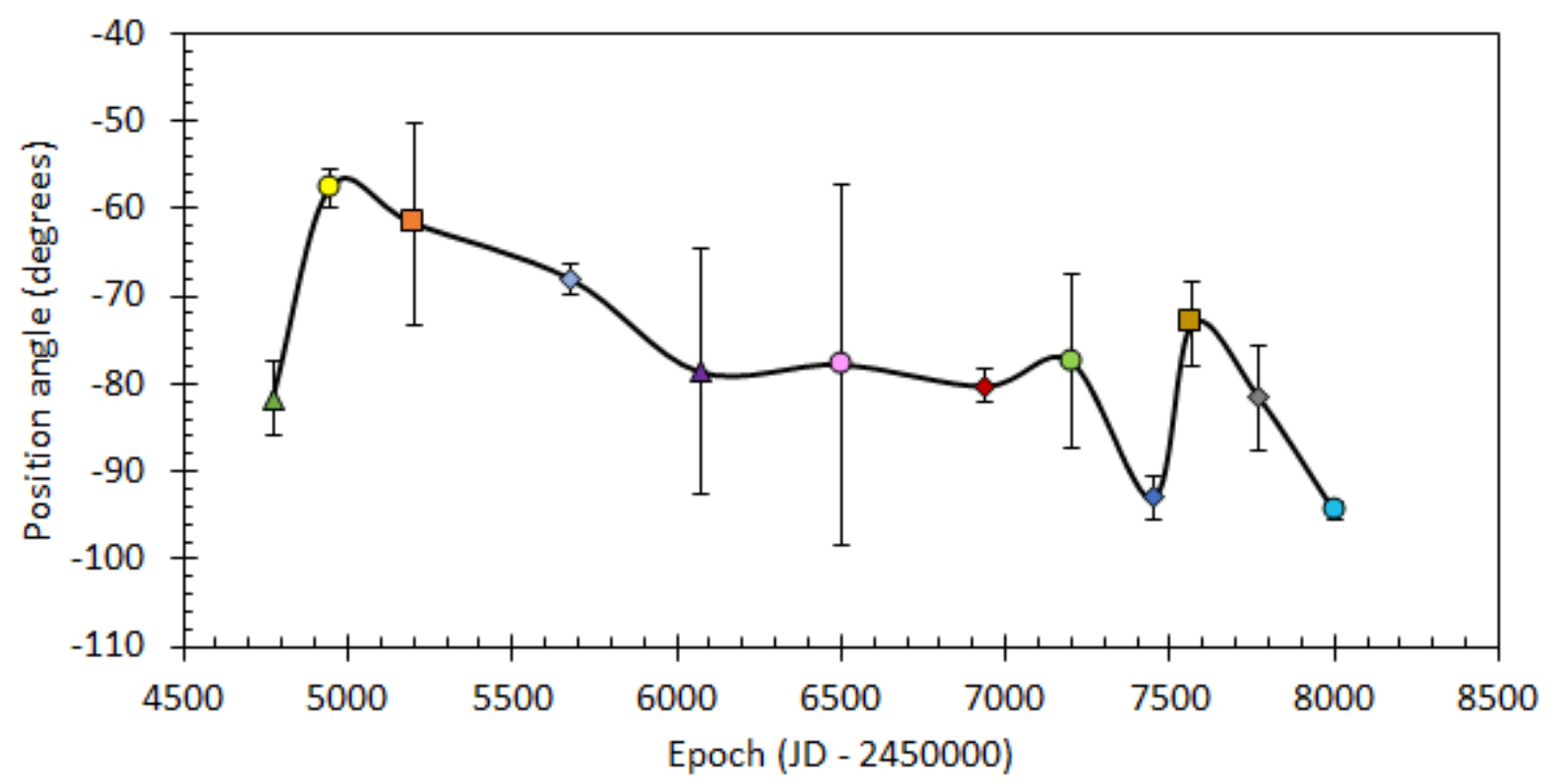

Figura 4.8: O ângulo de posição (em graus) calculado é apresentado no eixo das ordenadas enquanto que as datas de ejeção estão no eixo das abscissas.

\subsection{Redução e análise dos dados em raios- $\gamma$}

Inicialmente, foram extraídos os dados em raios- $\gamma$ a partir da base de dados do FermiLAT Pass 8, sendo estes obtidos no período de 04 de Agosto de 2008 a 05 de Junho de 2019. O procedimento padrão de redução e tratamento de dados não-binados foi seguido, conforme recomenda a equipe do Fermi-LAT em seu websit£. Como o Fermi observa o céu todo em questão de três horas foi necessário selecionar a região de interesse (ROI, em inglês) ao redor do blazar TXS 0506+056 (ou 4FGL J0509.4+0542). A ROI foi definida como uma área de $12^{\circ} \times 12^{\circ}$, centrada em TXS $0506+056$ com $R A=77.3593$ e $D e c=5.7014$, foram utilizados dados de energias entre $300 \mathrm{MeV}-300 \mathrm{GeV}$, conforme discutido na seção 2.1 .2 .

A etapa posterior à definição da ROI foi a seleção de eventos com alta probabilidade de serem fótons, foram inclusos eventos que tiveram alta qualidade na reconstrução de sua trajetória bem como energia medida pelo calorímetro. Para evitar a contaminação terrestre utilizaram-se dados obtidos com ângulo zenital, medido com relação à superfície da Terra, $z<90^{\circ}$, e como fator adicional à seleção de eventos foi utilizada a configuração a qual o telescópio estava em situação normal de aquisição de dados. Foi realizada uma correlação entre os eventos energéticos e as posições da espaçonave, para que fossem computados a

\footnotetext{
${ }^{1}$ https://fermi.gsfc.nasa.gov/ssc/data/analysis/scitools/likelihood_tutorial.html
} 
posição do céu de onde estes provinham ao longo do tempo. Ademais, durante o processo de tratamento e modelagem dos dados foram empregues os modelos padrões de emissões da galáxia e os isotrópicos que descrevem as contribuições difusas do fundo. Os parâmetros utilizados durante essa etapa estão listado na tabela 4.3 .

Tabela 4.3 - Parâmetros utilizados ao longo da etapa de redução e análise dos dados obtidos através do Fermi-LAT.

\begin{tabular}{lc}
\hline \hline \multicolumn{1}{c}{ Parâmetros } & Valores e arquivos \\
\hline evclass & 128 \\
evtype & 3 \\
DATAQUAL & $>0$ \\
LAT CONFIG & 1 \\
Modelo de emissão galáctico & $g l l_{-} i e m_{-} v 07$ \\
Modelo de emissão isotrópico & $i s o \_P 8 R 3_{-} S O U R C E_{-} V 2_{-} v 1$ \\
Resposta do instrumento & $P 8 R 3_{-} S O U R C E \_V 2$ \\
\hline
\end{tabular}

Os procedimentos descritos a seguir buscavam associar a quais fontes os eventos (posteriormente chamado de fótons) energéticos eram provenientes. Inicialmente, representamos na figura 4.9 as contagens de eventos dessa região a partir dos dados diários integrados durante todo o período de observação. Utilizando os modelos espectrais das fontes contidas na ROI, obtidos pelo catálogo 4FGL (The Fermi-LAT Collaboration, 2019) em 8 anos de observação, produzimos uma imagem modelo (figura 4.10) com o número esperado de contagens dentro do período destacado. As fontes que encontravam-se em um raio $r>4^{\circ}$ centrado em TXS 0506+056, tiveram os seus valores de índice e normalização extraídos do catálogo 4FGL. Por outro lado, as fontes com raio $r<4^{\circ}$ tiveram apenas o índice extraído do 4FGL, enquanto que as normalizações foram deixadas variáveis durante a modelagem. Esse procedimento foi realizado para efeitos de convergência do modelo. Segundo The Fermi-LAT Collaboration (2019), o modelo espectral do blazar TXS 0506+056, nessa faixa de energias, é do tipo LogParabola (Massaro et al., 2004) descrito pela equação:

$$
\frac{d N}{d E}=N_{0}\left(\frac{E}{E_{b}}\right)^{-\left(\alpha+\beta \cdot \log \left(E / E_{b}\right)\right)}
$$

sendo $\alpha, \beta$ índices espectrais, $N_{0}$ o parâmetro de normalização e $E_{b}$ um parâmetro de escala. Enquanto o valor de $E_{b}$ foi obtido por The Fermi-LAT Collaboration (2019) e mantido 


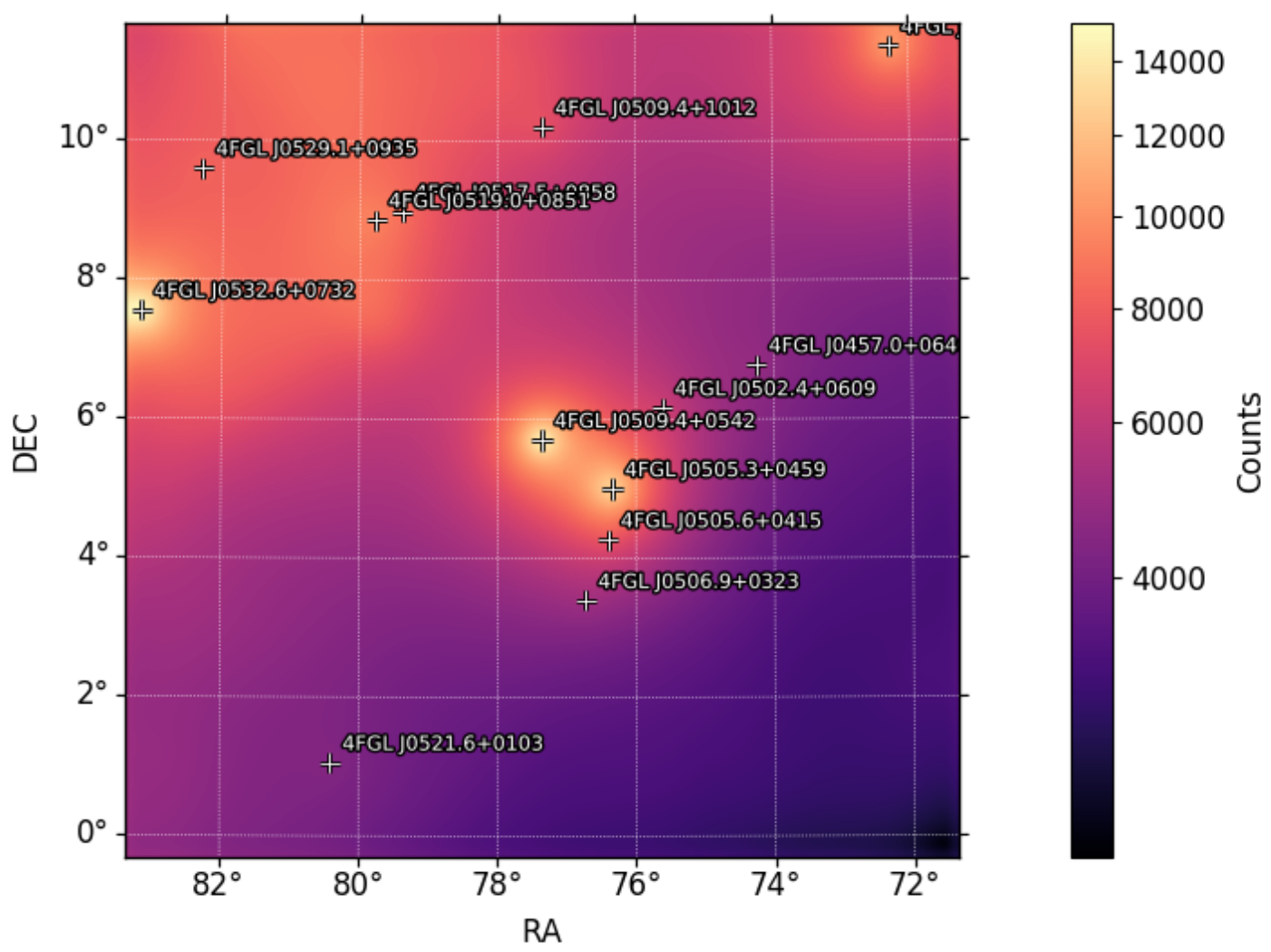

Figura 4.9: Mapa de contagens de eventos energéticos gerado a partir dos dados observados pelo Fermi-LAT da ROI de $12^{\circ}$ x $12^{\circ}$ centrada em TXS $0506+056$ ao longo do período determinado entre 04/08/2008 e 05/06/2019.

fixo, os demais valores foram calculados por nosso modelo e são: $\alpha=(2.022 \pm 0.024)$, $\beta=(0.043 \pm 0.010)$ e $N_{0}=(77.53 \pm 0.22) \cdot 10^{-13}$.

Como verificação da qualidade do modelo proposto na figura 4.10, foi realizada uma análise dos resíduos. Subtraindo-se os números de contagens da imagem (figura 4.9) das do modelo (figura 4.10), obtém-se um mapa residual com a significância dos ajustes, conforme figura 4.11. Nela pode-se observar que grande parte das regiões apresentam uma significância $\sim 3 \sigma$, implicando que o modelo aproxima-se então dos dados observados com uma significância considerável (The Fermi-LAT Collaboration, 2019). No mapa de resíduos, há uma faixa de tamanho considerável ao redor de $R A, D e c \sim\left(80^{\circ}, 3^{\circ}\right)$, e uma plausível justificativa pode vir do modelo de emissão galáctico utilizado, isto é, possivelmente o modelo não considerou algum fenômeno que houve nessa região durante o período de obtenção dos dados. Ainda assim, a região tem até $3 \sigma$ de significância, não comprometendo o ajuste, 


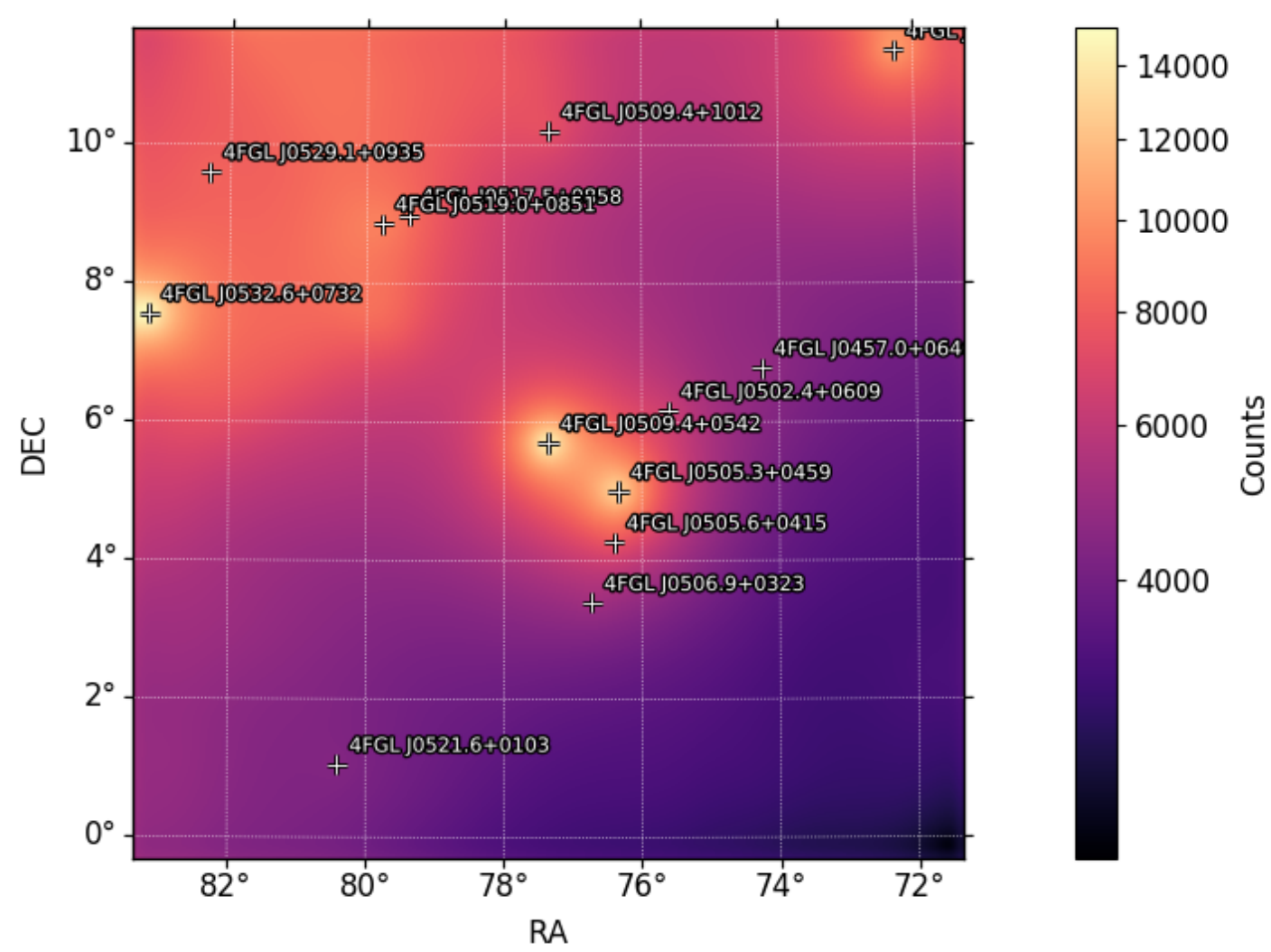

Figura 4.10: Imagem modelo que busca descrever a contagem de eventos dos objetos na ROI de $12^{\circ} \times 12^{\circ}$ centrada em TXS $0506+056$ ao longo do período determinado entre $04 / 08 / 2008$ e $05 / 06 / 2019$.

principalmente por ela estar a mais de $3^{\circ}$ da fonte principal. No canto inferior direito da figura, é possível verificar uma região com contornos de $5 \sigma$ de significância, porém, a região também está bem afastada de TXS 0506+056 e não poderia contribuir com a sua emissão.

Na figura 4.12 são computados os valores de significância do mapa residual (em verde), a linha sólida preta é uma gaussiana que modelaria os dados fazendo com que os resíduos apresentassem um distribuição normal centrada em zero, esse seria o comportamento esperado caso o número de contagens do modelo subtraído pelas contagens reais fosse apenas ruído. A linha tracejada em vermelho representa a gaussiana calculada a partir dos dados do modelo. A média da gaussiana ajustada a partir dos resíduos é -0.07 e seu desvio padrão 1.65, por conta disso pode-se concluir que os resíduos têm o comportamento de típico de ruído.

Os modelos espectrais foram utilizados para separar os fótons de cada fonte presente na 


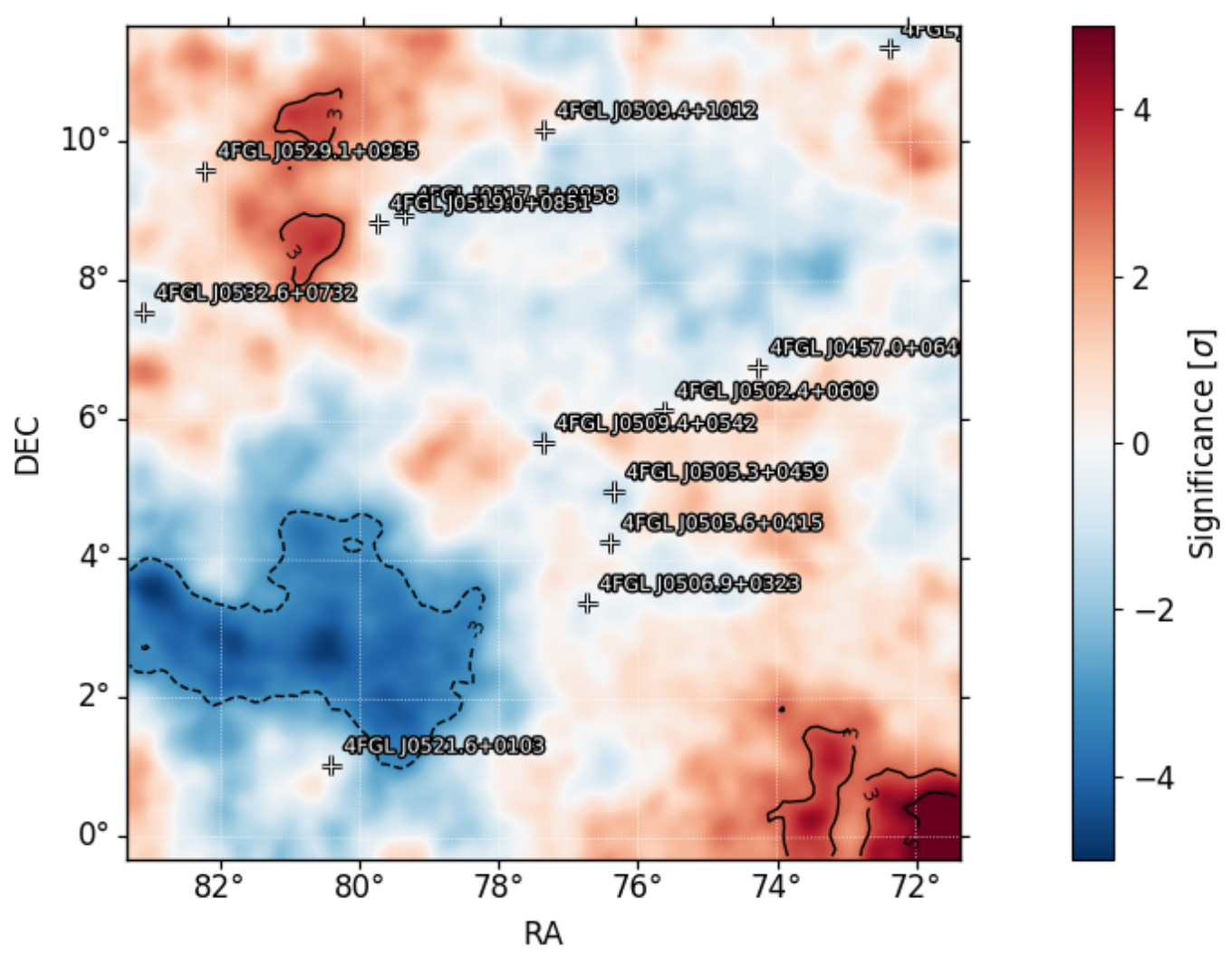

Figura 4.11: Mapa de resíduos das contagens observadas e modeladas de fótons. As cores representam os níveis de significância entre o ajuste do modelo e os dados observados.

ROI e os do fundo, com isso, foi obtido o modelo de emissão de fótons para TXS 0506+056. Para a validação foram utilizadas diversas ferramentas de verificação, conforme sugerido pela equipe do Fermi-LAT como: o mapa de resíduos, o histograma de significância, e o mapa de TS. Essas foram as etapas descritas anteriormente, no entanto, o objetivo principal do processo de redução e tratamento dos dados era calcular a SED Sprectral Energy Distribution e a curva de luz do blazar TXS 0506+056.

Conforme citado no capítulo 3, diversos trabalhos calcularam a SED com os dados obtidos em épocas próximas ao evento de neutrinos IC-170922A (Padovani et al. 2018; Gao et al., 2019; Murase et al., 2018; Keivani et al., 2018; Oikonomou et al., 2019; Cerruti et al. 2019; Liu et al., 2019), enquanto que Murase et al. (2018); Reimer et al. (2018); Wang et al. (2018); Rodrigues et al. (2019) modelaram a SED a partir dos dados da época 2014-2015, mesmo período da detecção do excesso de neutrinos IceCube Collaboration, et al., 2018). Na figura 4.13 apresentamos a SED em raios- $\gamma$ (entre $300 \mathrm{MeV}$ e $300 \mathrm{GeV}$ ) de 


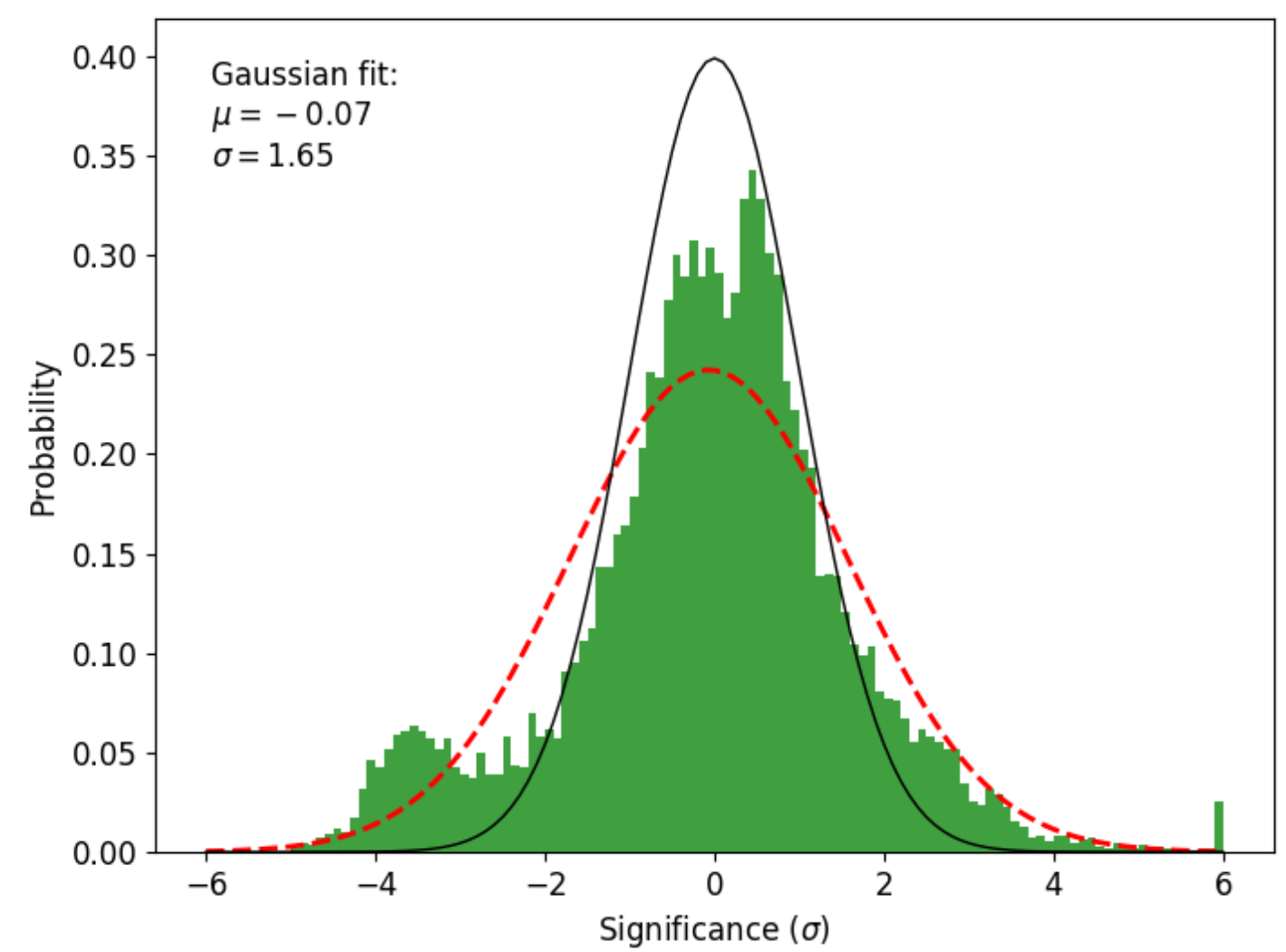

Figura 4.12: Histograma de resíduos calculados a partir do número de contagens calculados pelo modelo menos as contagens reais. A linha sólida representa uma gaussiana unitária centrada em zero, enquanto a linha tracejada vermelha representa o ajuste realizado para os resíduos calculados.

TXS 0506+056 correspondente a todo o período de dados disponibilizados pela colaboração Fermi-LAT. As barras de erro horizontais representam os tamanhos de bin, enquanto que as verticais são consequências do ajuste. A linha sólida preta corresponde ao esperado pelo modelo espectral e as tracejadas são os limites superior e inferior calculados. Os pontos mais energéticos foram plotados em seus limites superiores de incerteza, pois suas significâncias eram da ordem de $5 \sigma$, por conta da baixa quantidade de fótons nessa faixa de energia.

Anteriormente à geração da curva de luz final, reproduzimos a curva de luz calculada por IceCube Collaboration, et al. (2018), isto é, foi realizado o cálculo de fotons $\cdot \mathrm{cm}^{-2} \mathrm{~s}^{-1} \mathrm{em}$ bins de 28 dias. Esse procedimento foi realizado como uma forma adicional de confirmação do método. No entanto, bins de 28 dias ou mais podem excluir variações rápidas na curva 


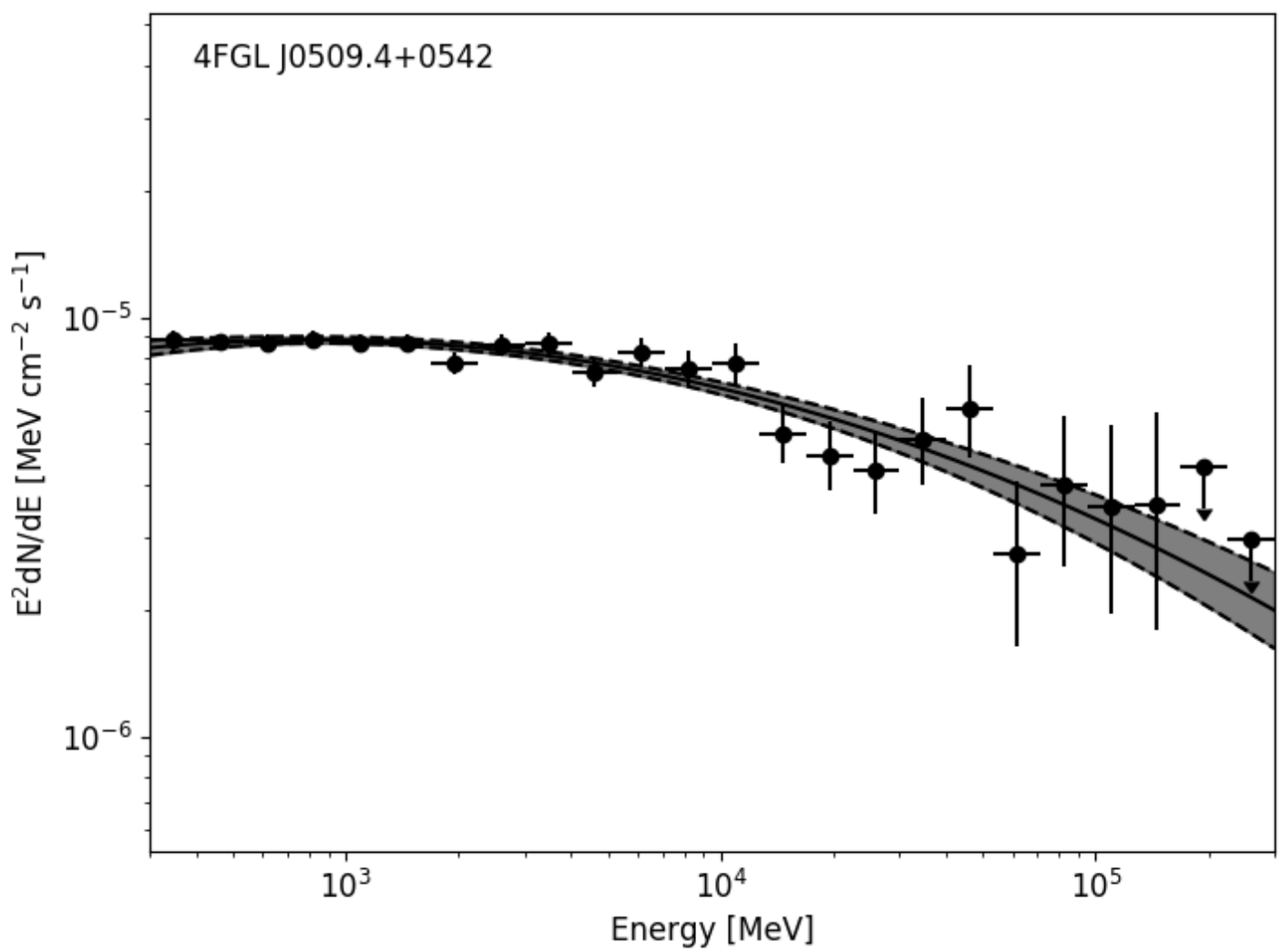

Figura 4.13: Spectral Energy Distribution do blazar TXS 0506+056 a partir dos dados obtidos entre 2008 e 2019. Foram feitos bins de energia de tamanho $25 \mathrm{MeV}$. A linha sólida preta foi calculada através do modelo, tal como as pontilhadas que representam os limites superior e inferior.

de luz em raios- $\gamma$, por esse motivo, reproduzimos a curva de luz do blazar TXS 0506+056 em bins 5 dias. Como o ruído era grande, optamos por utilizar a curva de luz para todo o período disponível (entre 2008 e 2019) com bins de 10 dias calculados a partir dos dados obtidos em 5 dias.

Os resultados são apresentados na figura 4.14 onde é plotado o número de fotons . $\mathrm{cm}^{-2} \mathrm{~s}^{-1}$ como função do tempo (Julian Days - 2450000). Os pontos foram computados a partir dos bins de 5 dias e pesados por suas respectivas barras de erro. O evento IC170922A é representado pela linha tracejada em vermelho a direita, enquanto que o período de excessos de neutrino citados por IceCube Collaboration, et al. (2018) esta delimitado pelas linhas tracejadas a esquerda. Além do mais, as demais curvas sólidas representam as datas de ejeção de cada componente do jato obtida dos mapas interferométricos obtidos 
em $15 \mathrm{GHz}$ pelo VLBA.

Com o intuito de aplicar o modelo de precessão (Abraham e Carrara, 1998) no jato de TXS 0506+056 realizamos uma busca por uma periodicidade na curva de luz da figura 4.14 . Foram utilizados dois diferentes testes estatísticos para detectar um período: o Stellingwerf (Stellingwerf, 1978) e a função em estrutural (SF em inglês). O método Stellingwerf não é adequado para detectar periodicidades maiores do que um quinto do tempo total disponível na curva de luz, com isso, não é possível encontrar um período maior que 2 anos com esse teste. A função estrutural é um teste simples para verificar a variação de intensidade após um dado tempo. Em ambos os testes, nenhum período foi detectado, isso pode ser devido a simples não existência de um período em raios- $\gamma$ ou o período da fonte ser maior que a quantidade de dados disponíveis (da ordem de 10 anos). 


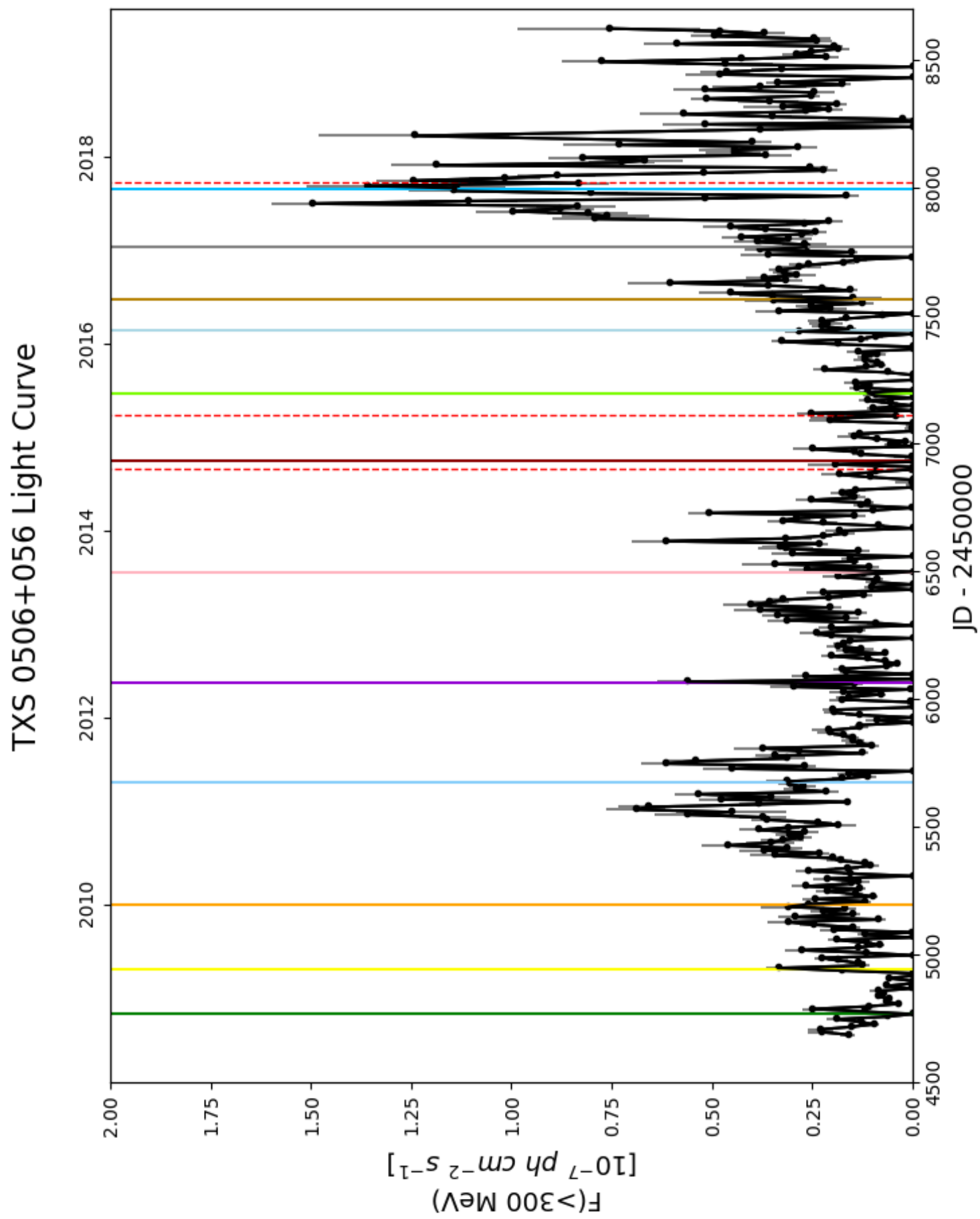

Figura 4.14: Curva de luz (fotons $\cdot \mathrm{cm}^{-2} \mathrm{~s}^{-1}$ como função do tempo, em dias julianos) do blazar TXS 0506+056 a partir dos dados obtidos entre 2008 e 2019 com bins de 10 dias. As linhas vermelhas tracejadas retratam os dados de neutrinos (IceCube Collaboration, et al. 2018 ?), com tracejada à direita representando a data do evento IC-170922A. As demais linhas sólidas correspondem as datas de ejeção das componentes detectadas em $15 \mathrm{Ghz}$, que serão apresentadas na seção 4.1 . 
Capítulo 5

\section{Conclusões}

Até o momento, apenas dois trabalhos construíram o cenário cinemático para as componentes superluminais do jato de TXS 0506+056 utilizando mapas interferométricos em $15 \mathrm{GHz}$ foram eles Lister et al. (2019) e Kun et al. (2019). Apesar de Lister et al. (2019) terem ajustado e obtido os parâmetros das componentes, os mesmos não exploraram a evolução e velocidades aparentes calculadas. Por outro lado, Kun et al. (2019) apresentam um cenário cinemático baseado nos ajustes de Lister et al. (2019) com acréscimos da curva de luz obtida tanto a partir dos dados interferométricos quanto da antena OVRO-40m em $15 \mathrm{GHz}$. Contudo, no cenário cinemático proposto pelos autores, as componentes estão em movimento quasi-estacionário, e em alguns casos chegam a retroceder com relação ao núcleo. A explicação dos autores para esse cenário é que as componentes encontram-se em regiões do jato conhecidas por "lanternas" devido a seu alto fator Doppler, isto é, os autores buscam explicar as variações na densidade de fluxo de uma determinada componente através da variação do movimento helicoidal, conforme modelo de Steffen et al. (1995).

Em nosso trabalho, a identificação de componentes superluminais do jato em mapas de $15 \mathrm{GHz}$ foi realizada através do Cross-Entropy, metodologia adaptada por Caproni et al. (2009, 2011). A técnica do CE foi comparada à identificação das componentes pelo método tradicional por Caproni et al. (2014), sendo considerada tão ou mais eficaz que esta. A partir dos parâmetros do ajuste, e assumindo uma trajetória balística, construímos o cenário cinemático com 12 componentes para o jato de TXS 0506+056, apresentado na figura 4.3. Suas velocidades aparentes apresentam uma variação quase senoidal (de aproximadamente 10 anos) ao serem confrontadas com suas épocas de ejeção, enquanto que as datas de ejeção de sete componentes identificadas neste trabalho apresentam um atraso médio de cerca de 28 dias com relação as datas de flares em raios- $\gamma$ (figura 4.5). 
Como o principal objetivo era buscar indícios de um movimento de precessão no jato para então aplicar ao modelo desenvolvido por Abraham e Carrara (1998), calculamos os ângulos de posição das componentes identificadas. Estes deveriam apresentar um comportamento variável de mesmo período que o da velocidades aparentes, entretanto, até o momento essa variação não foi encontrada, principalmente pela dificuldade, citada anteriormente, no calculo exato dos ângulos de posição das componentes. Mais dados poderão ser adicionados nesta análise ao longo do tempo, pois o programa MOJAVE continua a monitorar a fonte. Com os resultados obtidos neste trabalho não foi possível concluir se o jato de TXS 0506+056 precessiona e se há alguma correlação com o evento de neutrinos reportado.

As principais curvas de luz disponíveis em raios- $\gamma$ na literatura para TXS 0506+056 apresentam bins de 28 (IceCube Collaboration, et al., 2018) e 55 dias (Padovani et al. 2018). Entretanto, esse tamanho de bin pode eventualmente excluir quaisquer variações no fluxo menores que um mês, comuns em AGNs. Por esse motivo, decidimos, em contrapartida, reproduzir essas curva de luz utilizando os dados diários para todo o período de disponibilidade do Fermi-LAT. Entretanto, com bins reduzidos acabam surgindo flutuações de baixa relevância estatística na curva de luz, principalmente pela falta de fótons detectáveis em altíssimas energias. Para contornar esse problema, produzimos a curva de luz com bins de 10 dias, e cada bin foi ponderado por seu erro para que as flutuações fossem minimizadas e os valores de fluxo fossem computados considerando suas respectivas incertezas.

Padovani et al. (2018) construíram a curva de luz em raios- $\gamma$ com bins ainda maiores, utilizando fótons entre $2 G e V \leq E \leq 100 G e V$, ou seja, fótons mais energéticos, que contam com uma PSF melhor para o instrumento. A explicação dos autores para tal seleção de fótons é que nessas energias seria possível distinguir qualquer emissão de outras fontes. Entretanto, se a seleção de fótons realizada através dos modelos espectrais for robusta, como demonstramos ao longo da seção 4.2, acaba não sendo necessário selecionar uma faixa tão estreita de energia, e com isso conta-se com uma quantidade maior de fótons (100 vezes mais) a serem computados na curva de luz. Por esses motivos, reproduzimos a curva de luz com bins de 10 dias, na faixa de energia entre $300 \mathrm{MeV}-300 \mathrm{GeV}$, apresentada na figura 4.14. Com o intuito de verificar se o período de variação nas velocidades aparentes seria compatível com uma possível periodicidade na curva de luz em raios- $\gamma$ conforme o 
modelo de precessão desenvolvido por Abraham e Carrara (1998), realizamos dois testes de periodicidade: o Stellingwerf (Stellingwerf, 1978) e a função estrutural. No entanto, em ambos os testes, não foi encontrada nenhuma periodicidade, e uma possível explicação para esse fato é que, se existe periodicidade, o período de variação nessas energias é maior que o tempo de observação disponível até o momento.

É possível notar uma correlação entre a curva de luz em $15 \mathrm{GHz}$ (figura 4.2 e a de raios- $\gamma$ (figura 4.14). O mesmo processo que produz neutrinos, acaba também produzindo raios- $\gamma$ (conforme modelo hadrônico), por exemplo, quando prótons acelerados interagem com fótons menos energéticos acabam produzindo píons neutros - que decaem em raios- $\gamma$ - e píons carregados, que decaem em neutrinos e léptons. A componente C12, apresentada no cenário cinemático, teve sua data ejeção coincidente com um dos flares próximos ao evento de neutrinos, podendo ser coincidente ao evento de geração de neutrinos no núcleo. Entretanto, existe a possibilidade da emissão de neutrinos não ter ocorrido no núcleo, e sim no próprio jato do blazar.

Por fim, como perspectiva futura para este trabalho, pretendemos em conjunto com colaboradores, propor um cenário cinemático para o jato de PKS 0502+049. Este objeto também é um blazar, sendo também acompanhado pelo programa de monitoramento do MOJAVE, e próximo no plano do céu de TXS 0506+056. Por esse motivo, pode ser um objeto interessante a ser analisado de forma conjunta ao blazar estudado neste trabalho. 


\section{Referências Bibliográficas}

Aartsen M. G., Abraham K., Ackermann M., Adams J., Aguilar J. A., Ahlers M., Ahrens M., Altmann D., et al. All-sky Search for Time-integrated Neutrino Emission from Astrophysical Sources with 7 yr of IceCube Data, ApJ, 2017, vol. 835, p. 151

Abraham Z., Precession, beaming and the periodic light curve of OJ287, A\&A, 2000, vol. 355 , p. 915

Abraham Z., Jet precession in binary black holes, Nature Astronomy, 2018, vol. 2, p. 443

Abraham Z., Carrara E. A., The Precessing Jet in 3C 279, ApJ, 1998, vol. 496, p. 172

Abraham Z., Carrara E. A., Zensus J. A., Unwin S. C., Velocities and life-times in the VLBI jet of 3C 273., A\&AS, 1996, vol. 115, p. 543

Ackermann M., Ajello M., Atwood W. B., Baldini L., Ballet J., Barbiellini G., Bastieri D., et al. VizieR Online Data Catalog: Third catalog of LAT-detected AGNs (3LAC) (Ackermann+, 2015), VizieR Online Data Catalog, 2015, p. J/ApJ/810/14

Atwood W. B., Abdo A. A., Ackermann M., Althouse W., Anderson B., Axelsson M., Baldini L., Ballet J., et al., ApJ, 2009, vol. 697, p. 1071

Bañados E., Venemans B. P., Mazzucchelli C., Farina E. P., Walter F., et al. An 800million-solar-mass black hole in a significantly neutral Universe at a redshift of 7.5 , Nature, 2018, vol. 553, p. 473

Bardeen J. M., Petterson J. A., The Lense-Thirring Effect and Accretion Disks around Kerr Black Holes, ApJ, 1975, vol. 195, p. L65 
Beaklini P. P. B., Abraham Z., 3C 273 variability at $7 \mathrm{~mm}$ : evidence of shocks and precession in the jet, MNRAS, 2014, vol. 437, p. 489

Beaklini P. P. B., Dominici T. P., Abraham Z., Motter J. C., Multiwavelength analysis of brightness variations of $3 \mathrm{C} 279$ : probing the relativistic jet structure and its evolution, A\&A, 2019, vol. 626, p. A78

Beckmann V., Shrader C. R., Active Galactic Nuclei, 2012

Blandford R. D., Königl A., Relativistic jets as compact radio sources., ApJ, 1979, vol. 232, p. 34

Bloom S. D., Marscher A. P., An Analysis of the Synchrotron Self-Compton Model for the Multi-Wave Band Spectra of Blazars, ApJ, 1996, vol. 461, p. 657

Boer M., Ricker G., Atteia J. L., Kawai N., Lamb D., Woosley S., Arimoto M., Donaghy T., Fenimore E., et al., GRB Coordinates Network, 2005, vol. 3653, p. 1

Böttcher M., Reimer A., Zhang H., Leptonic and Hadronic Modeling of Fermi-Detected Blazars. Spectral Energy Distribution Modeling and High-Energy Polarization Predictions. In European Physical Journal Web of Conferences, vol. 61, 2013, p. 05003

Bruel P., Burnett T. H., Digel S. W., Johannesson G., Omodei N., Wood M., , arXiv e-prints, 2018, p. arXiv:1810.11394

Caproni A., Abraham Z., Jet precession and its observational evidence: The cases of 3C 345 and 3C 120. In The Interplay Among Black Holes, Stars and ISM in Galactic Nuclei , vol. 222 of IAU Symposium, 2004, p. 83

Caproni A., Abraham Z., Monteiro H., Parsec-scale jet precession in BL Lacertae (2200+420), MNRAS, 2013, vol. 428, p. 280

Caproni A., Abraham Z., Motter J. C., Monteiro H., Jet Precession Driven by a Supermassive Black Hole Binary System in the BL Lac Object PG 1553+113, ApJ, 2017, vol. 851, p. L39

Caproni A., Melo I. T. e., Abraham Z., Monteiro H., Roland J., , MNRAS, 2014, vol. 441, p. 187 
Caproni A., Monteiro H., Abraham Z., , MNRAS, 2009, vol. 399, p. 1415

Caproni A., Monteiro H., Abraham Z., Teixeira D. M., Toffoli R. T., , ApJ, 2011, vol. 736, p. 68

Cerruti M., Zech A., Boisson C., Emery G., Inoue S., Lenain J. P., , MNRAS, 2019, vol. 483 , p. L12

Condon J. J., Cotton W. D., Greisen E. W., Yin Q. F., Perley R. A., Taylor G. B., Broderick J. J., The NRAO VLA Sky Survey, AJ, 1998, vol. 115, p. 1693

Condon J. J., Ransom S. M., Essential Radio Astronomy, 2016

Fanaroff B. L., Riley J. M., The morphology of extragalactic radio sources of high and low luminosity, MNRAS, 1974, vol. 167, p. 31P

Fossati G., Maraschi L., Celotti A., Comastri A., Ghisellini G., A unifying view of the spectral energy distributions of blazars, MNRAS, 1998, vol. 299, p. 433

Gao S., Fedynitch A., Winter W., Pohl M., , Nature Astronomy, 2019, vol. 3, p. 88

Ghisellini G., The Blazar Sequence 2.0, Galaxies, 2016, vol. 4, p. 36

Gregory P. C., Condon J. J., The 87GB Catalog of Radio Sources Covering 0 degrees \&lt; delta \&lt; +75 degrees at $4.85 \mathrm{GHz}$, ApJS, 1991, vol. 75, p. 1011

Högbom J. A., Aperture Synthesis with a Non-Regular Distribution of Interferometer Baselines, A\&AS, 1974, vol. 15, p. 417

Hough D. H., Zensus J. A., Porcas R. W., Evidence for Acceleration and Nonradial Motion of Parsec-Scale Jet Components in the Lobe-dominated Superluminal Quasar 3C 263, ApJ, 1996, vol. 464, p. 715

IceCube Collaboration, Aartsen M. G., Ackermann M., Adams J., Aguilar J. A., Ahlers M., et al. Multimessenger observations of a flaring blazar coincident with high-energy neutrino IceCube-170922A, Science, 2018, vol. 361, p. eaat1378

IceCube Collaboration, Aartsen M. G., Ackermann M., Adams J., Aguilar J. A., Ahlers M., et al. Neutrino emission from the direction of the blazar TXS 0506+056 prior to the IceCube-170922A alert, Science, 2018, vol. 361, p. 147 
Johnston K. J., Fey A. L., Zacharias N., Russell J. L., Ma C., de Vegt C., Reynolds J. E., Jauncey D. L., Archinal B. A., Carter M. S., et al., AJ, 1995, vol. 110, p. 880

Jorstad S. G., Marscher A. P., Lister M. L., Stirling A. M., Cawthorne T. V., Gómez J.-L., Gear W. K., Change in Speed and Direction of the Jet near the Core in the Quasar 3C 279, AJ, 2004, vol. 127, p. 3115

Katz J. I., A Precessing Disk in OJ 287?, ApJ, 1997, vol. 478, p. 527

Keivani A., Murase K., Petropoulou M., Fox D. B., Cenko S. B., Chaty S., Coleiro A., DeLaunay J. J., Dimitrakoudis S., Evans P. A., et al., ApJ, 2018, vol. 864, p. 84

Kellermann K. I., Lister M. L., Homan D. C., Vermeulen R. C., Cohen M. H., Ros E., Kadler M., Zensus J. A., Kovalev Y. Y., , ApJ, 2004, vol. 609, p. 539

Kellermann K. I., Vermeulen R. C., Zensus J. A., Cohen M. H., Sub-Milliarcsecond Imaging of Quasars and Active Galactic Nuclei, AJ, 1998, vol. 115, p. 1295

Kovalev Y. Y., Kellermann K. I., Lister M. L., Homan D. C., Vermeulen R. C., Cohen M. H., Ros E., Kadler M., Lobanov A. P., Zensus J. A., Kardashev N. S., Gurvits L. I., Aller M. F., Aller H. D., , AJ, 2005, vol. 130, p. 2473

Kroese D. P., Porotsky S., Y. R. R., , Methodol. Comp. Appl., 2006, vol. 8, p. 383

Kun E., Biermann P. L., Gergely L. A., , MNRAS, 2019, vol. 483, p. L42

Kun E., Gabanyi K. E., Karouzos M., Britzen S., Gergely L. A., , MNRAS, 2014, vol. 445, p. 1370

Lister M. L., Aller M. F., Aller H. D., Homan D. C., Kellermann K. I., Kovalev Y. Y., Pushkarev A. B., Richards J. L., Ros E., Savolainen T., , AJ, 2013, vol. 146, p. 120

Lister M. L., Cohen M. H., Homan D. C., Kadler M., Kellermann K. I., Kovalev Y. Y., Ros E., Savolainen T., Zensus J. A., , AJ, 2009, vol. 138, p. 1874

Lister M. L., Cohen M. H., Homan D. C., Kadler M., Kellermann K. I., Kovalev Y. Y., Ros E., Savolainen T., Zensus J. A., , VizieR Online Data Catalog, 2011, p. 138 
Lister M. L., Homan D. C., Hovatta T., Kellermann K. I., Kiehlmann S., Kovalev Y. Y., Max-Moerbeck W., Pushkarev A. B., Readhead A. C. S., Ros E., Savolainen T., , ApJ, 2019, vol. 874 , p. 43

Liu R.-Y., Wang K., Rui X., Taylor A. M., Wang X.-Y., Li Z., Yan H., , Phys. Rev. D, 2019, vol. 99, p. 063008

Marscher A., Variability of Blazars and Blazar Models over 38 Years, Galaxies, 2016, vol. 4, p. 37

Marscher A. P., Gear W. K., Models for high-frequency radio outbursts in extragalactic sources, with application to the early 1983 millimeter-to-infrared flare of 3C 273., ApJ, 1985, vol. 298, p. 114

Massaro E., Perri M., Giommi P., Nesci R., , Astronomy and Astrophysics, 2004, vol. 413, p. 489

Monteiro H., Dias W. S., Caetano T. C., , A\&A, 2010, vol. 516, p. A2

Mortlock D., Warren S., Patel M., Venemans B., McMahon R., Hewett P., Simpson C., Theuns T., Rottgering H., Kuiper R., Bolton J., Harhnelt M., The discovery of a luminous redshift 7.1 quasar. In Galaxy Formation, 2011, p. 88

Murase K., Oikonomou F., Petropoulou M., , ApJ, 2018, vol. 865, p. 124

Oikonomou F., Murase K., Petropoulou M., . In European Physical Journal Web of Conferences , vol. 210 of European Physical Journal Web of Conferences, 2019, p. 03006

Padovani P., Alexander D. M., Assef R. J., De Marco B., Giommi P., Hickox R. C., Richards G. T., Smolčić V., Hatziminaoglou E., Mainieri V., Salvato M., Active galactic nuclei: what's in a name?, A\&A Rev., 2017, vol. 25, p. 2

Padovani P., Giommi P., Resconi E., Glauch T., Arsioli B., Sahakyan N., Huber M., Dissecting the region around IceCube-170922A: the blazar TXS 0506+056 as the first cosmic neutrino source, MNRAS, 2018, vol. 480, p. 192

Padovani P., Oikonomou F., Petropoulou M., Giommi P., Resconi E., TXS 0506+056, the first cosmic neutrino source, is not a BL Lac, MNRAS, 2019, vol. 484, p. L104 
Paiano S., Falomo R., Treves A., Scarpa R., The Redshift of the BL Lac Object TXS 0506+056, ApJ, 2018, vol. 854, p. L32

Peterson B. M., An introduction to Active Galactic Nuclei, 1997

Readhead A. C. S., Pearson T. J., Cohen M. H., Ewing M. S., Moffet A. T., Hybrid maps of the milli-arcsecond structures of 3C 120, 3C 273, and 3C 345., ApJ, 1979, vol. 231, p. 299

Rees M. J., Appearance of Relativistically Expanding Radio Sources, Nature, 1966, vol. 211 , p. 468

Reimer A., Boettcher M., Buson S., , arXiv e-prints, 2018, p. arXiv:1812.05654

Rodrigues X., Gao S., Fedynitch A., Palladino A., Winter W., , ApJ, 2019, vol. 874, p. L29

Rubinstein R., , European Journal of Operations Research, 1997, vol. 99, p. 89

Rubinstein R., , Methodology and Computing in Applied Probability, 1999, vol. 2, p. 127

Rybicki G. B., Lightman A. P., Radiative Processes in Astrophysics, 1986

Salpeter E. E., Accretion of Interstellar Matter by Massive Objects., ApJ, 1964, vol. 140, p. 796

Savolainen T., Wiik K., Valtaoja E., Jorstad S. G., Marscher A. P., Connections between millimetre continuum variations and VLBI structure in 27 AGN, A\&A, 2002, vol. 394, p. 851

Schneider P., Extragalactic Astronomy and Cosmology, 2006

Seyfert C. K., Nuclear Emission in Spiral Nebulae., ApJ, 1943, vol. 97, p. 28

Shepherd M. C., . In Astronomical Data Analysis Software and Systems VI , vol. 125 of Astronomical Society of the Pacific Conference Series, 1997, p. 77

Sikora M., Begelman M. C., Rees M. J., Comptonization of Diffuse Ambient Radiation by a Relativistic Jet: The Source of Gamma Rays from Blazars?, ApJ, 1994, vol. 421, p. 153 
Steffen W., Zensus J. A., Krichbaum T. P., Witzel A., Qian S. J., A helical model for the compact jet in 3C345., A\&A, 1995, vol. 302, p. 335

Stellingwerf R. F., Period determination using phase dispersion minimization., ApJ, 1978, vol. 224 , p. 953

The Fermi-LAT Collaboration, arXiv e-prints, 2019, p. arXiv:1902.10045

Thompson A. R., Moran S., Swenson G. W., The Interferometer in Practice. In Synthesis Imaging in Radio Astronomy, Astronomical Society of the Pacific Conference Series, 1989, vol. 6, p. 11

Wang K., Liu R.-Y., Li Z., Wang X.-Y., Dai Z.-G., , arXiv e-prints, 2018, p. arXiv:1809.00601

Wild J. P., De-convolution of barely resolved radio sources mapped with aerial beams of elliptical cross section, Australian Journal of Physics, 1970, vol. 23, p. 113

Wood M., Caputo R., Charles E., Di Mauro M., Magill J., Perkins J. S., Fermi-LAT Collaboration, 2017, vol. 35 , p. 824

Zensus J. A., Ros E., Kellermann K. I., Cohen M. H., Vermeulen R. C., Kadler M., , AJ, 2002, vol. 124, p. 662 
Apêndice 



\title{
Apêndice A
}

\section{Resultados complementares}

\author{
A.1 Ajuste de gaussianas bidimensionais e os respectivos resíduos em \\ imagens de TXS 0506+056
}

Neste apêndice são encontradas as imagens com os ajustes das gaussianas bidimensionais ajustadas pelo CE para todas as datas disponibilizadas pelo MOJAVE. 


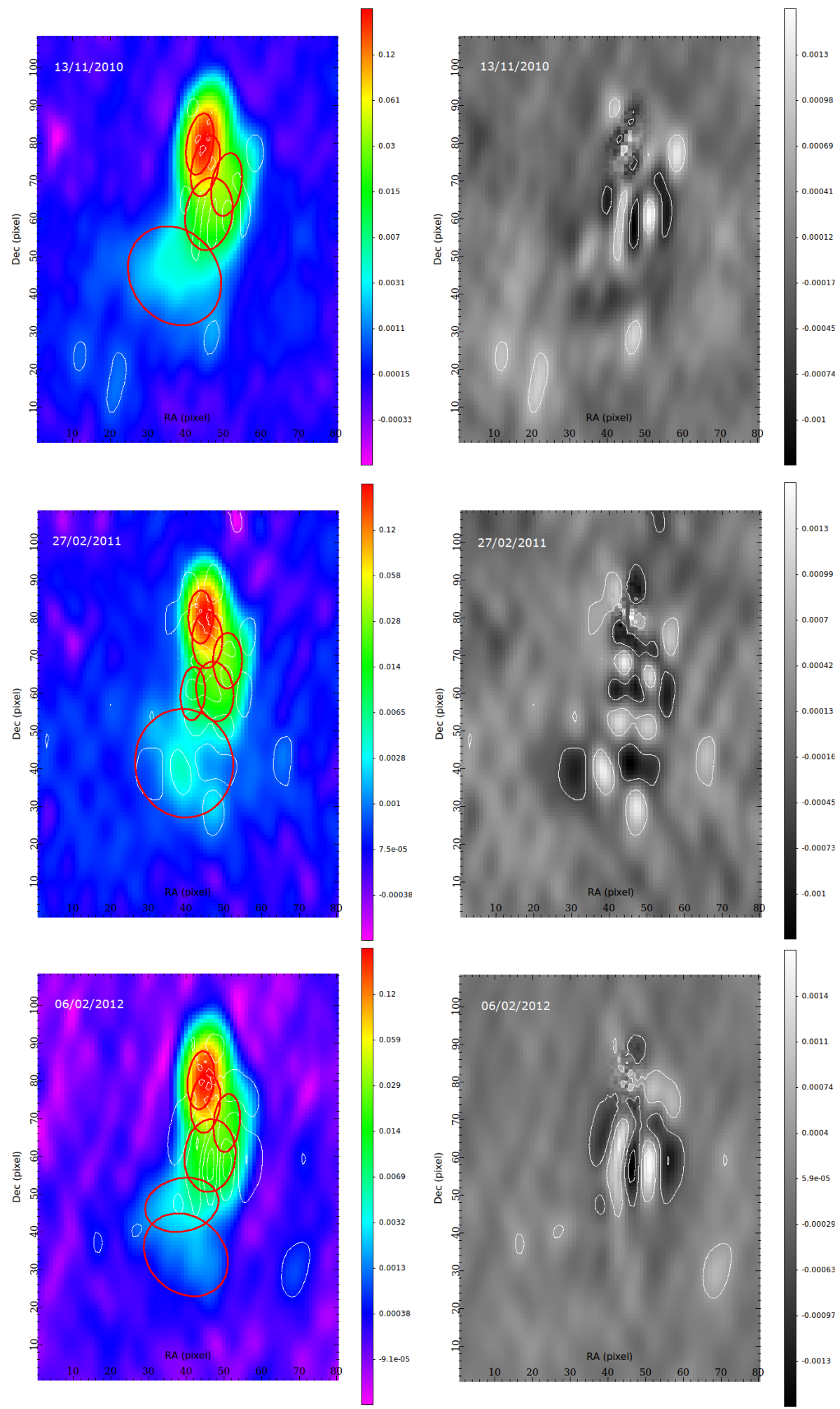

Figura A.1: Painéis à esquerda: ajustes do CE nos mapas em $15 \mathrm{GHz}$ obtidos em 3 épocas (13/11/2010, 27/02/2011 e 06/02/2012), as elipses em vermelho representam as gaussianas ajustadas, os contornos em branco são relativos aos resíduos positivos e negativos do ajuste, a escala de cores representa a densidade de fluxo em Jy/beam em escala logarítmica. Painéis à direita: imagem de resíduos provenientes do ajuste do $\mathrm{CE}$, são apresentados dois contornos positivos e negativos, de mesmo módulo, para cada data, com as escalas de cores lineares. 


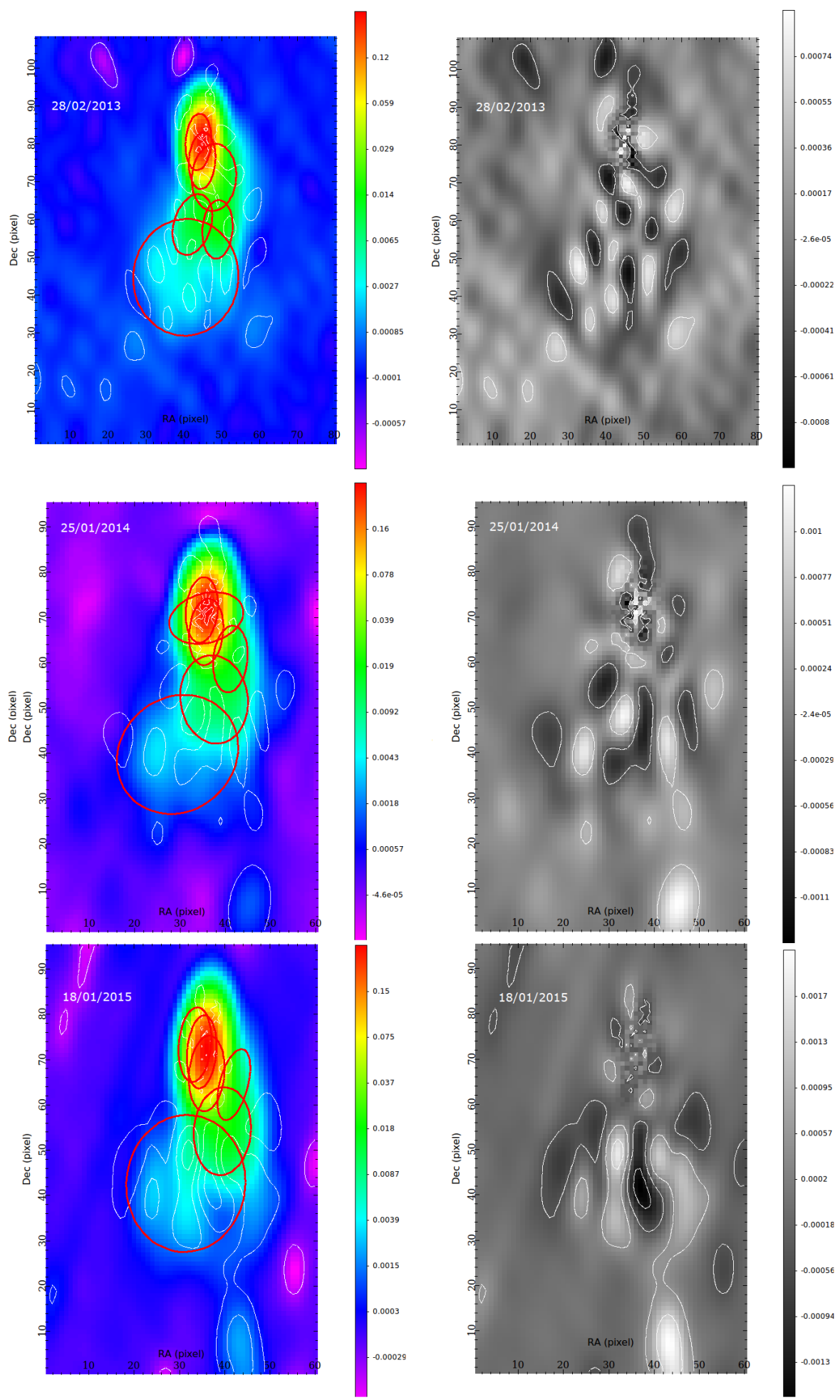

Figura A.2: Painéis à esquerda: ajustes do CE nos mapas em $15 \mathrm{GHz}$ obtidos em 3 épocas (28/02/2013, 25/01/2014 e 18/01/2015), as elipses em vermelho representam as gaussianas ajustadas, os contornos em branco são relativos aos resíduos positivos e negativos do ajuste, a escala de cores representa a densidade de fluxo em Jy/beam em escala logarítmica. Painéis à direita: imagem de resíduos provenientes do ajuste do $\mathrm{CE}$, são apresentados dois contornos positivos e negativos, de mesmo módulo, para cada data, com as escalas de cores lineares. 

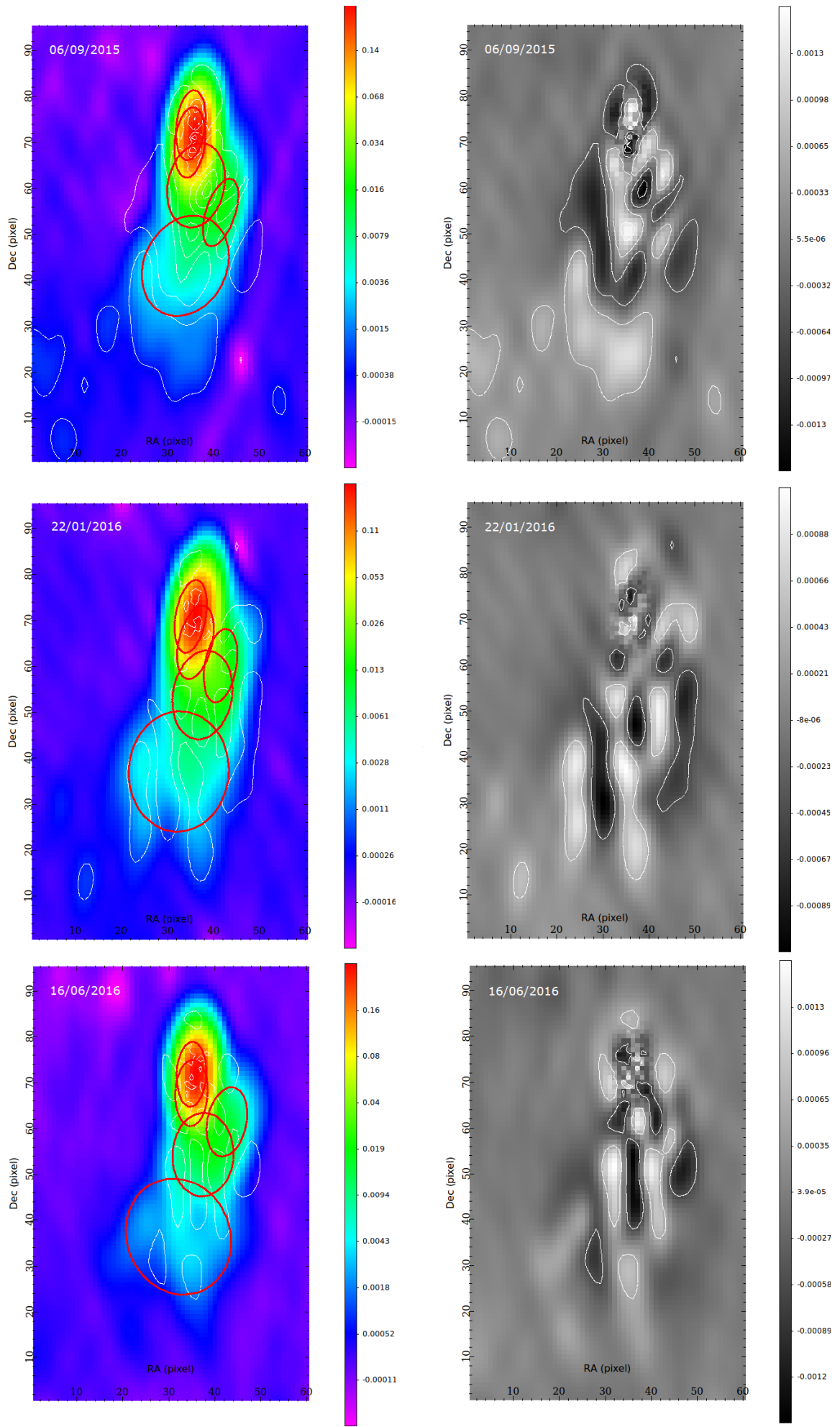

Figura A.3: Painéis à esquerda: ajustes do CE nos mapas em $15 \mathrm{GHz}$ obtidos em 3 épocas $(06 / 09 / 2015,22 / 01 / 2016$ e 16/06/2016), as elipses em vermelho representam as gaussianas ajustadas, os contornos em branco são relativos aos resíduos positivos e negativos do ajuste, a escala de cores representa a densidade de fluxo em Jy/beam em escala logarítmica. Painéis à direita: imagem de resíduos provenientes do ajuste do $\mathrm{CE}$, são apresentados dois contornos positivos e negativos, de mesmo módulo, para cada data, com as escalas de cores lineares. 


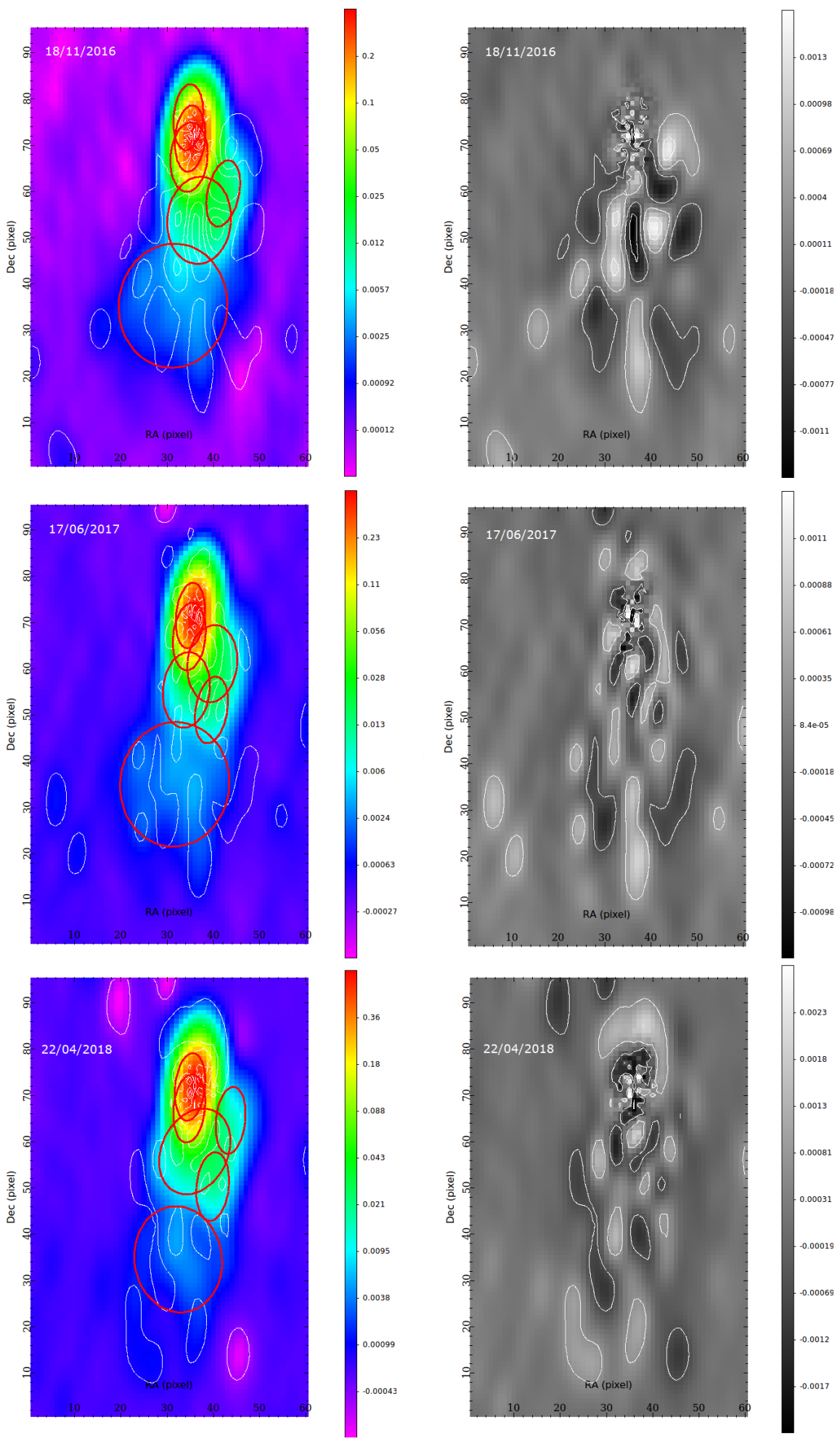

Figura A.4: Painéis à esquerda: ajustes do $\mathrm{CE}$ nos mapas em $15 \mathrm{GHz}$ obtidos em 3 épocas (18/11/2016, 17/06/2017 e 22/04/2018), as elipses em vermelho representam as gaussianas ajustadas, os contornos em branco são relativos aos resíduos positivos e negativos do ajuste, a escala de cores representa a densidade de fluxo em Jy/beam em escala logarítmica. Painéis à direita: imagem de resíduos provenientes do ajuste do $\mathrm{CE}$, são apresentados dois contornos positivos e negativos, de mesmo módulo, para cada data, com as escalas de cores lineares. 


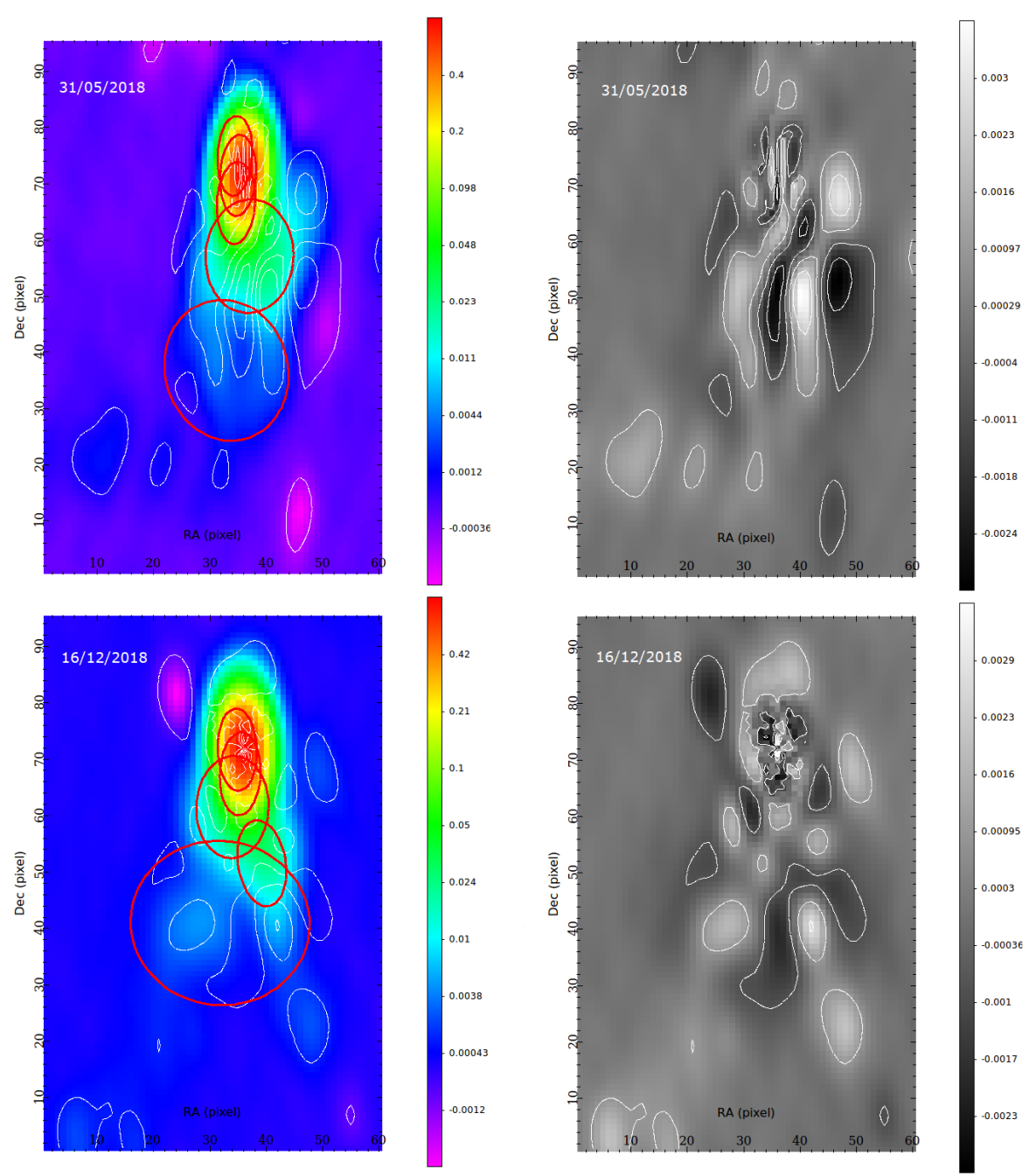

Figura A.5: Painéis à esquerda: ajustes do CE nos mapas em $15 \mathrm{GHz}$ obtidos em 2 épocas (31/05/2018 e 16/12/2018), as elipses em vermelho representam as gaussianas ajustadas, os contornos em branco são relativos aos resíduos positivos e negativos do ajuste, a escala de cores representa a densidade de fluxo em Jy/beam em escala logarítmica. Painéis à direita: imagem de resíduos provenientes do ajuste do CE, são apresentados dois contornos positivos e negativos, de mesmo módulo, para cada data, com as escalas de cores lineares. 


\section{Apêndice B}

\section{Tabela com os parâmetros das gaussianas ajustadas através do $\mathrm{CE}$}

Tabela B.1 - Valores dos parâmetros das componentes ajustadas ao longo das épocas e suas respectivas incertezas. A tabela está organizada seguindo: data, identificação da componente, semi-eixo maior $(a)$, excentricidade $(\epsilon)$, distância ao núcleo $(r)$, densidade de fluxo $\left(S_{\nu}\right)$ e ângulo de posição $(\eta)$.

\begin{tabular}{|c|c|c|c|c|c|c|}
\hline Época & ID & $a$ (mas) & $\epsilon$ & $r$ (mas) & $S_{\mu}(\mathrm{Jy})$ & $\eta\left({ }^{\circ}\right)$ \\
\hline \multirow[t]{6}{*}{ 07/01/2009 } & Core & $0,8444 \pm 0,0016$ & $0,8897 \pm 0,0017$ & 0 & $0,367 \pm 0,017$ & - \\
\hline & $\mathrm{C} 1$ & $0,849 \pm 0,013$ & $0,884 \pm 0,014$ & $0,41 \pm 0,14$ & $0,081 \pm 0,020$ & $-68,4 \pm 4,3$ \\
\hline & no-ID & $0,85 \pm 0,0095$ & $0,886 \pm 0,010$ & $1,57 \pm 0,12$ & $0,0121 \pm 0,0026$ & $-65,5 \pm 6,4$ \\
\hline & no-ID & $1,03 \pm 0,10$ & $0,729 \pm 0,085$ & $1,89 \pm 0,13$ & $0,0190 \pm 0,0028$ & $-82,8 \pm 4,2$ \\
\hline & no-ID & $1,151 \pm 0,060$ & $0,655 \pm 0,037$ & $2,89 \pm 0,33$ & $0,0055 \pm 0,0041$ & $-100,7 \pm 4,9$ \\
\hline & no-ID & $1,4653 \pm 0,00030$ & $0,51264 \pm 0,00011$ & $4,75 \pm 0,32$ & $0,00165 \pm 0,00055$ & $-107,5 \pm 1,4$ \\
\hline \multirow[t]{6}{*}{ 03/06/2009 } & Core & $0,8089 \pm 0,00044$ & $0,89736 \pm 0,00049$ & 0 & $0,375 \pm 0,014$ & - \\
\hline & $\mathrm{C} 1$ & $0,848 \pm 0,013$ & $0,857 \pm 0,013$ & $0,491 \pm 0,058$ & $0,096 \pm 0,014$ & $-79,7 \pm 1,6$ \\
\hline & no-ID & $0,821 \pm 0,091$ & $0,884 \pm 0,081$ & $1,52 \pm 0,20$ & $0,0116 \pm 0,0025$ & $-60,3 \pm 5,5$ \\
\hline & no-ID & $0,955 \pm 0,086$ & $0,761 \pm 0,079$ & $2,14 \pm 0,15$ & $0,0172 \pm 0,0040$ & $-81,2 \pm 3,9$ \\
\hline & no-ID & $1,18 \pm 0,11$ & $0,614 \pm 0,065$ & $2,56 \pm 0,22$ & $0,0061 \pm 0,0033$ & $-99,8 \pm 6,3$ \\
\hline & no-ID & $1,971 \pm 0,095$ & $0,369 \pm 0,019$ & $4,76 \pm 0,64$ & $0,00137 \pm 0,00066$ & $-108,4 \pm 2,3$ \\
\hline \multirow[t]{6}{*}{$12 / 07 / 2010$} & Core & $0,8460 \pm 0,0014$ & $0,9107 \pm 0,0016$ & 0 & $0,155 \pm 0,032$ & - \\
\hline & C3 & $0,8290 \pm 0,0051$ & $0,9294 \pm 0,0054$ & $0,40 \pm 0,12$ & $0,138 \pm 0,028$ & $-85,3 \pm 3,0$ \\
\hline & $\mathrm{C} 2$ & $0,893 \pm 0,024$ & $0,863 \pm 0,024$ & $0,858 \pm 0,073$ & $0,01595 \pm 0,00034$ & $-45,8 \pm 1,6$ \\
\hline & $\mathrm{C} 1$ & $1,0203 \pm 0,0081$ & $0,7552 \pm 0,0061$ & $1,437 \pm 0,039$ & $0,02472 \pm 0,00065$ & $-82,64 \pm 0,45$ \\
\hline & no-ID & $1,230 \pm 0,063$ & $0,624 \pm 0,029$ & $3,267 \pm 0,052$ & $0,003730 \pm 0,000038$ & $79,36 \pm 0,55$ \\
\hline & no-ID & $1,966 \pm 0,074$ & $0,392 \pm 0,018$ & $5,43 \pm 0,18$ & $0,000890 \pm 0,000024$ & $62,2 \pm 1,8$ \\
\hline \multirow[t]{5}{*}{$13 / 11 / 2010$} & Core & $0,82347 \pm 0,00018$ & $0,90569 \pm 0,00020$ & 0 & $0,2238 \pm 0,0060$ & - \\
\hline & C3 & $0,8242 \pm 0,0054$ & $0,9049 \pm 0,0057$ & $0,60 \pm 0,043$ & $0,0520 \pm 0,0044$ & $-75,93 \pm 0,40$ \\
\hline & $\mathrm{C} 2$ & $0,8433 \pm 0,0051$ & $0,8846 \pm 0,0053$ & $1,2847 \pm 0,0095$ & $0,02010 \pm 0,00065$ & $-56,49 \pm 0,47$ \\
\hline & $\mathrm{C} 1$ & $0,9683 \pm 0,0011$ & $0,77023 \pm 0,00092$ & $1,866 \pm 0,011$ & $0,02506 \pm 0,00020$ & $-82,66 \pm 0,40$ \\
\hline & no-ID & $1,382 \pm 0,035$ & $0,539 \pm 0,013$ & $3,560 \pm 0,028$ & $0,003460 \pm 0,000038$ & $-100,86 \pm 0,38$ \\
\hline $27 / 02 / 2011$ & Core & $0,7090 \pm 0,0007$ & $0,88943 \pm 0,00083$ & 0 & $0,2113 \pm 0,0032$ & - \\
\hline
\end{tabular}

Continua na próxima página... 
Tabela B.1 - Continuação

\begin{tabular}{|c|c|c|c|c|c|c|}
\hline Época & ID & $a$ (mas) & $\epsilon$ & $r$ (mas) & $S_{\nu}(\mathrm{Jy})$ & $\eta\left({ }^{\circ}\right)$ \\
\hline & C3 & $0,747 \pm 0,053$ & $0,844 \pm 0,054$ & $0,634 \pm 0,091$ & $0,0476 \pm 0,0062$ & $-74,0 \pm 1,7$ \\
\hline & $\mathrm{C} 2$ & $0,7387 \pm 0,0083$ & $0,854 \pm 0,010$ & $1,361 \pm 0,087$ & $0,01535 \pm 0,00032$ & $-58,3 \pm 2,2$ \\
\hline & $\mathrm{C} 1$ & $0,798 \pm 0,056$ & $0,790 \pm 0,050$ & $2,011 \pm 0,052$ & $0,02079 \pm 0,00069$ & $-79,2 \pm 1,8$ \\
\hline & no-ID & $0,71 \pm 0,30$ & $0,89 \pm 0,30$ & $2,04 \pm 0,50$ & $0,0083 \pm 0,0042$ & $84 \pm 25$ \\
\hline & no-ID & $1,44 \pm 0,35$ & $0,437 \pm 0,191$ & $3,91 \pm 0,15$ & $0,00306 \pm 0,00032$ & $83,6 \pm 2,0$ \\
\hline \multirow[t]{6}{*}{$06 / 02 / 2012$} & Core & $0,77400 \pm 0,00066$ & $0,89322 \pm 0,00076$ & 0 & $0,2153 \pm 0,0040$ & - \\
\hline & $\mathrm{C} 4$ & $0,793 \pm 0,016$ & $0,872 \pm 0,017$ & $0,619 \pm 0,078$ & $0,0421 \pm 0,0033$ & $-78,4 \pm 1,7$ \\
\hline & $\mathrm{C} 3$ & $0,774 \pm 0,011$ & $0,893 \pm 0,012$ & $1,320 \pm 0,046$ & $0,0109 \pm 0,0013$ & $-58,6 \pm 2,0$ \\
\hline & $\mathrm{C} 2$ & $0,967 \pm 0,061$ & $0,715 \pm 0,051$ & $2,01 \pm 0,27$ & $0,0212 \pm 0,0035$ & $-83,1 \pm 2,4$ \\
\hline & no-ID & $0,99 \pm 0,15$ & $0,700 \pm 0,081$ & $3,345 \pm 0,095$ & $0,0032 \pm 0,0025$ & $81,4 \pm 1,0$ \\
\hline & no-ID & $1,21 \pm 0,60$ & $0,57 \pm 0,25$ & $4,65 \pm 0,50$ & $0,00165 \pm 0,00083$ & $85 \pm 26$ \\
\hline \multirow[t]{6}{*}{$28 / 02 / 2013$} & Core & $0,74948 \pm 0,00039$ & $0,89119 \pm 0,00046$ & 0,0000 & $0,2181 \pm 0,0024$ & - \\
\hline & $\mathrm{C} 5$ & $0,7532 \pm 0,0041$ & $0,8868 \pm 0,0049$ & $0,506 \pm 0,018$ & $0,0285 \pm 0,0027$ & $-78,0 \pm 1,9$ \\
\hline & $\mathrm{C} 4$ & $0,8899 \pm 0,0015$ & $0,7517 \pm 0,0013$ & $1,024 \pm 0,011$ & $0,01462 \pm 0,00034$ & $-65,5 \pm 1,0$ \\
\hline & $\mathrm{C} 3$ & $0,828 \pm 0,022$ & $0,8068 \pm 0,023$ & $2,19 \pm 0,28$ & $0,0097 \pm 0,0020$ & $-94,3 \pm 9,4$ \\
\hline & no-ID & $0,779 \pm 0,019$ & $0,8578 \pm 0,020$ & $2,37 \pm 0,28$ & $0,0121 \pm 0,0018$ & $-78 \pm 11$ \\
\hline & no-ID & $1,546 \pm 0,019$ & $0,4338 \pm 0,0060$ & $3,600 \pm 0,022$ & $0,002880 \pm 0,000040$ & $-95,4 \pm 0,4$ \\
\hline \multirow[t]{6}{*}{$25 / 01 / 2014$} & Core & $0,72528 \pm 0,00034$ & $0,87515 \pm 0,00040$ & 0 & $0,27273 \pm 0,00043$ & - \\
\hline & C6 & $0,836 \pm 0,00033$ & $0,75871 \pm 0,00027$ & $0,205 \pm 0,011$ & $0,004680 \pm 0,000045$ & $-62 \pm 15$ \\
\hline & $\mathrm{C} 5$ & $0,7365 \pm 0,0091$ & $0,862 \pm 0,010$ & $0,495 \pm 0,017$ & $0,0585 \pm 0,0024$ & $-78,8 \pm 8,7$ \\
\hline & $\mathrm{C} 4$ & $0,738 \pm 0,015$ & $0,860 \pm 0,017$ & $1,2551 \pm 0,0037$ & $0,00973 \pm 0,00038$ & $-60 \pm 14$ \\
\hline & no-ID & $0,9768 \pm 0,0058$ & $0,6493 \pm 0,0042$ & $1,9934 \pm 0,0066$ & $0,01144 \pm 0,00018$ & $-82,24 \pm 0,25$ \\
\hline & no-ID & $1,400 \pm 0,012$ & $0,4530 \pm 0,0042$ & $3,23 \pm 0,28$ & $0,00316 \pm 0,00026$ & $-99,6 \pm 5,7$ \\
\hline \multirow[t]{6}{*}{$18 / 01 / 2015$} & Core & $0,8081 \pm 0,0022$ & $0,9183 \pm 0,0024$ & 0 & $0,243 \pm 0,011$ & - \\
\hline & no-ID & $0,823 \pm 0,010$ & $0,902 \pm 0,012$ & $0,22 \pm 0,29$ & $0,023 \pm 0,025$ & $-47 \pm 14$ \\
\hline & $\mathrm{C} 7$ & $0,837 \pm 0,028$ & $0,886 \pm 0,028$ & $0,490 \pm 0,088$ & $0,060 \pm 0,015$ & $-76,8 \pm 1,9$ \\
\hline & C6 & $0,805 \pm 0,082$ & $0,922 \pm 0,081$ & $1,01 \pm 0,50$ & $0,0031 \pm 0,0060$ & $-46 \pm 21$ \\
\hline & C5 & $0,972 \pm 0,017$ & $0,763 \pm 0,014$ & $1,81 \pm 0,22$ & $0,0167 \pm 0,0033$ & $-75 \pm 12$ \\
\hline & no-ID & $1,51 \pm 0,12$ & $0,496 \pm 0,042$ & $2,92 \pm 0,21$ & $0,003280 \pm 0,000073$ & $-96,9 \pm 7,7$ \\
\hline \multirow[t]{5}{*}{ 06/09/2015 } & Core & $0,7691 \pm 0,0035$ & $0,9053 \pm 0,0041$ & 0 & $0,212 \pm 0,075$ & - \\
\hline & no-ID & $0,763 \pm 0,018$ & $0,913 \pm 0,021$ & $0,38 \pm 0,34$ & $0,068 \pm 0,021$ & $-92,9 \pm 2,0$ \\
\hline & $\mathrm{C} 7$ & $0,9267 \pm 0,0057$ & $0,7513 \pm 0,0046$ & $0,942 \pm 0,053$ & $0,0215 \pm 0,0046$ & $-81,76 \pm 0,36$ \\
\hline & $\mathrm{C} 6$ & $0,7648 \pm 0,0070$ & $0,9104 \pm 0,0081$ & $1,66 \pm 0,14$ & $0,0099 \pm 0,0030$ & $-66,3 \pm 2,5$ \\
\hline & no-ID & $1,133 \pm 0,071$ & $0,614 \pm 0,035$ & $2,68 \pm 0,19$ & $0,0067 \pm 0,0024$ & $-92,1 \pm 2,5$ \\
\hline \multirow[t]{5}{*}{$22 / 01 / 2016$} & Core & $0,8006 \pm 0,00025$ & $0,91233 \pm 0,00029$ & 0 & $0,1894 \pm 0,0023$ & - \\
\hline & $\mathrm{C} 8$ & $0,8147 \pm 0,0010$ & $0,8965 \pm 0,0011$ & $0,574 \pm 0,029$ & $0,0463 \pm 0,0018$ & $-79,922 \pm 0,030$ \\
\hline & $\mathrm{C} 7$ & $0,8068 \pm 0,0027$ & $0,9053 \pm 0,0031$ & $1,255 \pm 0,022$ & $0,009360 \pm 0,000093$ & $-58,93 \pm 0,11$ \\
\hline & no-ID & $0,97188 \pm 0,00086$ & $0,75149 \pm 0,00077$ & $1,730 \pm 0,016$ & $0,01397 \pm 0,00012$ & $-81,549 \pm 0,024$ \\
\hline & no-ID & $1,3101 \pm 0,0021$ & $0,5572 \pm 0,0010$ & $3,3846 \pm 0,0050$ & $0,0040 \pm 0,0020$ & $-94,45 \pm 0,10$ \\
\hline \multirow[t]{4}{*}{$16 / 06 / 2016$} & Core & $0,7061 \pm 0,0018$ & $0,8922 \pm 0,0022$ & 0 & $0,255 \pm 0,053$ & - \\
\hline & C9 & $0,7215 \pm 0,0052$ & $0,8732 \pm 0,0065$ & $0,41 \pm 0,10$ & $0,083 \pm 0,051$ & $-89,8 \pm 1,3$ \\
\hline & $\mathrm{C} 8$ & $0,76 \pm 0,11$ & $0,829 \pm 0,095$ & $1,29 \pm 0,15$ & $0,0083 \pm 0,0010$ & $-53,4 \pm 9,9$ \\
\hline & no-ID & $0,9141 \pm 0,0042$ & $0,6893 \pm 0,0035$ & $1,77 \pm 0,28$ & $0,0156 \pm 0,0017$ & $-81,8 \pm 1,3$ \\
\hline
\end{tabular}

Continua na próxima página... 
Tabela B.1 - Continuação

\begin{tabular}{|c|c|c|c|c|c|c|}
\hline Época & ID & $a(\operatorname{mas})$ & $\epsilon$ & $r$ (mas) & $S_{\nu}(\mathrm{Jy})$ & $\eta\left({ }^{\circ}\right)$ \\
\hline & no-ID & $1,287 \pm 0,011$ & $0,4893 \pm 0,0047$ & $3,550 \pm 0,042$ & $0,003570 \pm 0,000022$ & $-94,55 \pm 0,40$ \\
\hline \multirow[t]{6}{*}{$18 / 11 / 2016$} & Core & $0,71665 \pm 0,00013$ & $0,89360 \pm 0,00016$ & 0 & $0,328 \pm 0,012$ & - \\
\hline & $\mathrm{C} 10$ & $0,754 \pm 0,020$ & $0,850 \pm 0,023$ & $0,40 \pm 0,40$ & $0,0894 \pm 0,0025$ & $-93,2 \pm 4,8$ \\
\hline & no-ID & $0,715 \pm 0,029$ & $0,90 \pm 0,53$ & $0,46 \pm 0,49$ & $0,0137 \pm 0,0015$ & $-86 \pm 52$ \\
\hline & $\mathrm{C} 8$ & $0,7251 \pm 0,0067$ & $0,8832 \pm 0,0080$ & $1,387 \pm 0,026$ & $0,00976 \pm 0,00028$ & $-58,93 \pm 0,17$ \\
\hline & no-ID & $0,9417 \pm 0,0055$ & $0,6800 \pm 0,0040$ & $1,779 \pm 0,024$ & $0,01280 \pm 0,00040$ & $-83,65 \pm 0,20$ \\
\hline & no-ID & $1,34 \pm 0,21$ & $0,48 \pm 0,11$ & $3,631 \pm 0,056$ & $0,0033 \pm 0,0042$ & $-95,8 \pm 7,6$ \\
\hline \multirow[t]{6}{*}{$17 / 06 / 2017$} & Core & $0,711386 \pm 0,000027$ & $0,903040 \pm 0,000030$ & 0 & $0,3738 \pm 0,0006$ & - \\
\hline & $\mathrm{C} 11$ & $0,73123 \pm 0,00028$ & $0,87874 \pm 0,00032$ & $0,4582 \pm 0,0035$ & $0,11275 \pm 0,00032$ & $-92,44 \pm 0,18$ \\
\hline & $\mathrm{C} 10$ & $0,836 \pm 0,014$ & $0,769 \pm 0,014$ & $1,145 \pm 0,032$ & $0,0136 \pm 0,0012$ & $-65,5 \pm 2,8$ \\
\hline & C9 & $0,818 \pm 0,029$ & $0,786 \pm 0,027$ & $1,613 \pm 0,051$ & $0,0098 \pm 0,0010$ & $-93,0 \pm 2,5$ \\
\hline & $\mathrm{C} 8$ & $0,7273 \pm 0,0059$ & $0,8832 \pm 0,0072$ & $2,0919 \pm 0,0075$ & $0,00806 \pm 0,00069$ & $-77,32 \pm 0,34$ \\
\hline & no-ID & $1,3463 \pm 0,0026$ & $0,4837 \pm 0,0010$ & $3,663 \pm 0,012$ & $0,003190 \pm 0,000013$ & $-95,26 \pm 0,21$ \\
\hline \multirow[t]{6}{*}{$22 / 04 / 2018$} & Core & $0,73077 \pm 0,00026$ & $0,89859 \pm 0,00031$ & 0 & $0,606 \pm 0,016$ & - \\
\hline & $\mathrm{C} 12$ & $0,7388 \pm 0,0040$ & $0,8889 \pm 0,0049$ & $0,464 \pm 0,035$ & $0,150 \pm 0,020$ & $-92,05 \pm 0,42$ \\
\hline & no-ID & $0,728 \pm 0,082$ & $0,901 \pm 0,087$ & $1,14 \pm 0,10$ & $0,0059 \pm 0,0031$ & $-39,5 \pm 9,7$ \\
\hline & C11 & $0,969 \pm 0,055$ & $0,678 \pm 0,036$ & $1,40 \pm 0,13$ & $0,0236 \pm 0,0026$ & $-85,8 \pm 5,9$ \\
\hline & $\mathrm{C} 10$ & $0,743 \pm 0,012$ & $0,884 \pm 0,015$ & $2,205 \pm 0,073$ & $0,0127 \pm 0,0020$ & $-77,21 \pm 0,82$ \\
\hline & no-ID & $1,149 \pm 0,048$ & $0,571 \pm 0,022$ & $3,732 \pm 0,087$ & $0,00400 \pm 0,00010$ & $-93,94 \pm 0,66$ \\
\hline \multirow[t]{5}{*}{$31 / 05 / 2018$} & Core & $0,71882 \pm 0,00027$ & $0,89899 \pm 0,00037$ & 0 & $0,7046 \pm 0,0059$ & - \\
\hline & no-ID & $0,72 \pm 0,20$ & $0,90 \pm 0,45$ & $0,35 \pm 0,50$ & $0,0244 \pm 0,0073$ & $-81 \pm-24$ \\
\hline & $\mathrm{C} 12$ & $0,7290 \pm 0,0030$ & $0,8864 \pm 0,0037$ & $0,492 \pm 0,033$ & $0,110 \pm 0,013$ & $-94,0 \pm 1,0$ \\
\hline & C11 & $1,014 \pm 0,010$ & $0,6413 \pm 0,0062$ & $1,453 \pm 0,053$ & $0,02604 \pm 0,00035$ & $-81,91 \pm 0,71$ \\
\hline & no-ID & $1,265 \pm 0,010$ & $0,5107 \pm 0,0063$ & $3,47 \pm 0,32$ & $0,003090 \pm 0,000084$ & $-93,4 \pm 1,4$ \\
\hline \multirow[t]{5}{*}{$16 / 12 / 2018$} & Core & $0,729494 \pm 0,000040$ & $0,879420 \pm 0,000047$ & 0 & $0,73725 \pm 0,00066$ & - \\
\hline & no-ID & $0,73567 \pm 0,00048$ & $0,8721 \pm 0,0005$ & $0,4313 \pm 0,0050$ & $0,1333 \pm 0,0025$ & $-83,44 \pm 0,59$ \\
\hline & $\mathrm{C} 12$ & $0,907 \pm 0,012$ & $0,709 \pm 0,010$ & $1,020 \pm 0,011$ & $0,02976 \pm 0,00097$ & $-94,74 \pm 0,09$ \\
\hline & $\mathrm{C} 11$ & $0,7681 \pm 0,0019$ & $0,8352 \pm 0,0021$ & $2,060 \pm 0,013$ & $0,01930 \pm 0,00020$ & $-77,81 \pm 0,34$ \\
\hline & no-ID & $1,589 \pm 0,063$ & $0,402 \pm 0,015$ & $3,087 \pm 0,025$ & $0,003230 \pm 0,000084$ & $84,37 \pm 0,46$ \\
\hline
\end{tabular}

